\title{
VISUAL SIGNALLING IN PLANT-ANIMAL INTERACTIONS
}

By

Nik Fadzly N Rosely

\begin{abstract}
A thesis
Submitted to the Victoria University of Wellington In fulfillment of the requirements for the degree of

Doctor of Philosophy

In Ecology \& Biodiversity
\end{abstract}

Victoria University of Wellington

2010 


\begin{abstract}
The process of visual signalling between plant and animals is often a combination of exciting discoveries and more often than not; highly controversial hypotheses. Plants and animals interact mutualistically and antagonistically creating a complex network of species relations to some extent suggesting a co evolutionary network. In this study, I investigate two basic research questions: the first is how plants utilize aposematic and cryptic colours? The second is how animals are affected by the colour signals broadcasted by plants? By using the avian eye model, I discover how visual signals/colours from plants are actually perceived, and the effects of these signals on birds (not human) perception. Aposematism and crypsis are common strategies utilized by animals, yet little evidence is known of such occurrences in plants. Aposematic and cryptic colours were evaluated by studying different colouration strategy through the ontogeny of two native heteroblastic New Zealand plants: Pseudopanax crassifolius and Elaeocarpus hookerianus. To determine the potential effect of colour signals on animals, I investigated an evolutionary theory of leaf colours constraining the conspicuousness of their fruit colour counterparts. Based on the available data, I also conducted a community level analysis about the effects of fruit colours and specific avian frugivores that might be attracted to them. Finally, I examined the fruit colour selection by a frugivorous seed dispersing insect; the Wellington Tree Weta (Hemideina crassidens). My result shows that aposematic and cryptic colours are successfully applied by plants to either warn or remain inconspicuous from browsing herbivores. The evidence I presented lends support to the Moa browsing hypothesis in relation to
\end{abstract}


the cryptic plant colourations. However, the same level of selective interaction could not be inferred for frugivore fruit colour selection based on avian vision. I demonstrated that leaf reflectance does not constrain/influence the conspicuousness of fruit colours. There was also no fruit colour diversity based on geographical location. Fruit colour alone is not sufficient to influence a specific frugivore assemblage. Other environmental factors and species interaction must be taken into account. Weta proved to possess colour vision capable of colour perception even in low light conditions. Weta also consistently selected naturally blue streaked and manipulated blue coloured fruits of Coprosma acerosa in a binary test. This supports the idea of weta co- evolving with fruit colours of certain divaricating plants in New Zealand. I suggest that the fruit colours of New Zealand are shaped by the combined selection pressure from birds, lizards/geckos and weta. 


\section{ACKNOWLEDGEMENTS}

My sincere thanks to all the people who have contributed to and worked on this dissertation during the past three years.

My special thanks to my supervisor, Dr Kevin Burns for believing in me. Thank you for giving a naïve person like me, a chance in Science. I shall always and forever remain indebted to him. Thank you also to Dr Martin Schaefer, who endured my silly questions about eye models and laboriously explaining complex math integration through email conversations from Germany. Special thanks also go to my secondary supervisor, Dr Phil Lester, who provides the complete support in dealing with financial supports, grants, ideas, and the occasional "reality check" that every PhD students needs.

Thanks for the tremendous support, advice and warm friendship from all friends and staffs within the School of Biological Sciences at Victoria University of Wellington. Cameron Jack for introducing me to the world of spectroradiometer and $\mathrm{R}$ computing. Leslie Milicich for assisting in the weta experiment. Also a special shout out to my comrades in $\mathrm{PhD}$. Huge thanks goes to Elizabeth "Beaux" Berkeley, who shall forever remain the best office mate. Also Gaius Willson (yes, you're also the best office mate I've ever had) who is always off to exotic places looking for an adventure (per $\mathrm{PhD}$ requirement).

My project would not have been possible without the permission received from Rewi Elliot (Otari-Wilton's Bush) and Raewynn Anderson (Karori Wildlife Sanctuary). Thank you to both of them. 
I am also grateful for the financial support given to me by various funding bodies: the Ministry of Higher Education Malaysia, Universiti Sains Malaysia, Victoria University of Wellington, Faculty Strategic Research Grant, and $\mathrm{PhD}$ Submission Scholarship; without which this project would have not been possible.

Finally, I wish my highest gratitude to my wife, Wan Fatma Zuharah and my incredibly kiwi son, Nik Adam Farees for the unwavering support, understanding and assistance till the end of my Ph.D. journey. Thank you dear, for not making me turn into "Mike Slackerny" (refer to PhDComics, Jorge Cham).

Thank you also to my parents, sisters and little (and not so little) nieces and nephews for their encouragement and support. I'm forever grateful and thankful to all of you! 


\section{TABLE OF CONTENTS}

Page

Abstract..................................................................... i

Acknowledgements................................................... iii

Table of content.................................................. v v

List of figure..................................................... viii

List of table................................................................ $\quad x$

1 General Introduction................................................. 2

1.1 General introduction...................................... 3

1.2 The New Zealand unique ecology.......................... 4

1.3 Visual signaling between plants and animals ................................ 6

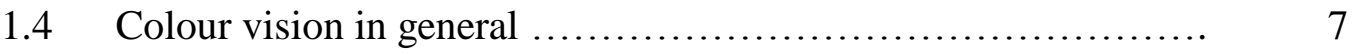

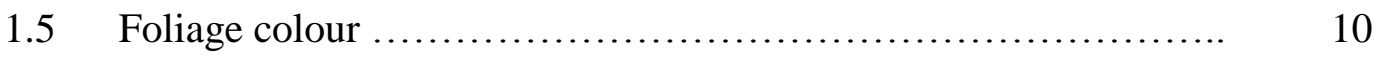

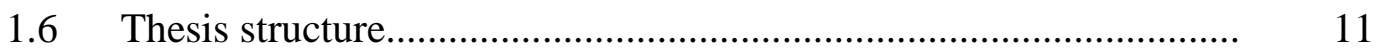

2 Ontogenetic colour changes in an insular tree species: Signalling to 15 extinct browsing birds?.................................................

$2.1 \quad$ Abstract................................................... 16

$2.2 \quad$ Introduction.................................................. 17

2.3 Materials and methods........................................ 19

$2.4 \quad$ Results................................................... 23

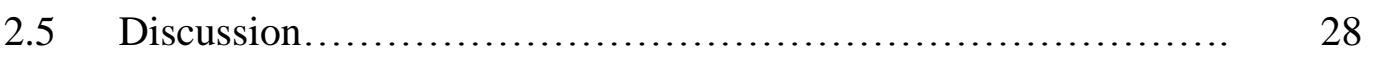


insular tree species

$3.1 \quad$ Abstract....................................................... 33

$3.2 \quad$ Introduction................................................... 34

3.3 Materials and methods.................................... 36

$3.4 \quad$ Results................................................. 40

$3.5 \quad$ Discussion.................................................. 41

4 Are fruit colours adaptively significant? A test of two hypotheses....... 48

$4.1 \quad$ Abstract..................................................... 49

$4.2 \quad$ Introduction.............................................. 50

4.3 Materials and methods..................................... 52

4.3.1 Fruit colour analyses.......................................... 52

4.3.2 Frugivore sampling $\ldots \ldots \ldots \ldots \ldots \ldots \ldots \ldots \ldots \ldots \ldots \ldots \ldots . \ldots \ldots$

4.3.3 Statistical analysis .................................. 57

$4.4 \quad$ Results..................................................... 59

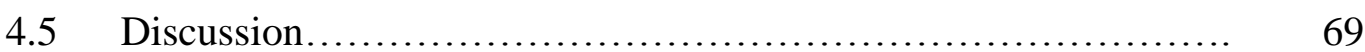

5 What weta want: Colour preferences of a frugivorous insect.......... 74

$5.1 \quad$ Abstract..................................................... 75

5.2 Introduction.

5.3 Materials and methods....................................... 79

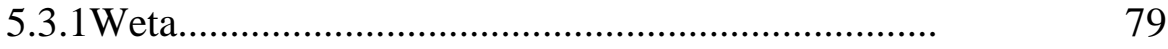

5.3.2 Coprosma acerosa ..............................................

5.3.3 Spectrographic analyses.................................... $\quad 80$

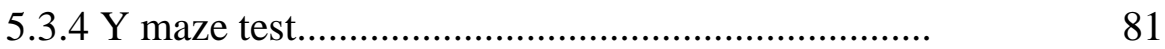


$5.4 \quad$ Results................................................. 85

5.5 Discussion.............................................. 91

6 General Discussion.............................................. 95

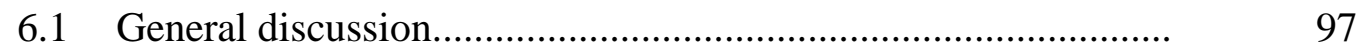

6.2 The how-and-why of plant colours function.................... 98

$6.3 \quad$ A tree stuck in a time warp .................................. 98

6.4 The illusive life of E. hookerianus.................................................. 100

6.5 Effects of colour signals to animals.......................... 100

6.6 Do different colours attract different birds?.................................. 101

6.7 Weird world of weta..................................... 102

6.8 Putting together the how-why- and- what of visual signaling 103 in plant-animal

$6.9 \quad$ Future research................................................ 104

Appendices $\quad$..................................................... 106

A Avian Eye Model..................................................... 107

B Abstract from The $25^{\text {th }}$ Annual Meeting of The Society

C Fadzly N, Jack C, Schaefer HM, Burn KC. 2010.

Ontogenetic colour changes in an insular tree species: signaling to extinct browsing birds? New Phytologist. 184: 495-501.

D Fadzly N, Burns KC. 2010. Hiding from the ghost of herbivory past: Evidence for crypsis in an insular tree species. International Journal of Plant Sciences 171 (7) DOI: $10.1086 / 654850$.

References. 


\section{LIST OF FIGURES}

Figure Abbreviated Caption Page

\section{Chapter two}

2.1 Pictures of $P$. crassifolius ................................ 24

2.2 Reflectance curves of P. crassifolius seedling leaves, $P$. 25 chathamicus seedling leaves and leaf litter.

$2.3 \quad$ Reflectance curves of $P$. crassifolius sapling leaves, $P$. 26 chathamicus sapling leaves...

$2.4 \quad$ Reflectance curves of $P$. crassifolius adult leaves, $P$. chathamicus adult leaves and leaves from other plants.

\section{Chapter Three}

3.1 Reflectance curves for the adult and juvenile E. hookerianus, and the leaf litter background

3.2 Multidimensional scaling analyses

\section{Chapter Four}

4.1 Percent reflectance curve comparison between fruits and leaves gathered from North and South Island

4.2 The observed and expected values of fruit colour contrast; (a) Chromatic contrast refers to the Euclidean distance in tetrahedral colour space, (b) Achromatic contrast refers to the JND values from the avian eye model calculation

4.3 Multidimensional scaling of plant species based on bird 66 visitation.

4.4 A tetrahedral colour space representation of the fruit colours. Each point represents how the specific colour of a fruit is processed by the bird eye receptors. 
4.5 Mantel's test correlation results for North Island and South

Island between the distances from the multidimensional scaling based on bird visits and distances in the tetrahedral colour space.

\section{Chapter Five}

$5.1 \quad$ (a) A close up of a female Wellington Tree Weta (Hemideina crassidens). (b) Coprosma acerosa fruit natural colouration......

5.2 Y- maze diagram used in binary test.......................................... 88

5.3 Spectra properties of full moonlight and fluorescent light condition. 88

5.4 Reflectance spectra of natural C. acerosa fruits and leaf, fruits dyed blue and red................................................. 89

5.5 Observed and expected probabilities of weta fruit colour $\quad 90$ choices obtained in a computer simulation.... 


\section{LIST OF TABLES}

Table Abbreviated Title Page

Chapter Four

4.1 Full list of plants, sampled location, and the chromatic and 62 achromatic contrasts along with the total number of bird visits ......

\section{Chapter Five}

5.1 Total number of fruit selection based on colour by Weta in a binary test. 86 


\section{Chapter 1}


General Introduction 


\subsection{General introduction}

Plant and animal interactions have played a key role in the development of ecological theory and could be viewed as a co-evolution process. The co-evolution concept was first defined through the study of relationship between particular plant species and the herbivorous insects that feed on them (Erlich \& Raven 1964). The concept of co-evolution is viewed as the process of reciprocal evolutionary change between interacting species driven by natural selection (Thompson 2005).

The study of plant-animal interaction has recently begun to define as a distinct sub discipline; which has managed to establish itself into realms far beyond the earliest concerns of community ecology (Smallwood 2001). For example various studies had focused on the subject of seed dispersals mutualism between fruits and their disperser counterparts. The relationship between fruits and frugivores via fruit traits might affect the behavioral pattern of the frugivores (Janzen 1980). This selective pattern would then be passed to future generations, suggesting a coevolutionary pattern of existence between the fruits and the dispersers. Similarly many insects, birds and mammals serve as important pollinators and seed dispersers of flowering plants, receiving in return food such as nectar or pollen or fruit pulp. Such mutualistic interactions between plants and animals occur in all kinds of ecosystem and their study has a long tradition (Olesen \& Valido 2003).

Plants change certain traits such as colour (fruit, flower and foliage), fruit presentation, leaf arrangement, and odour in order to suit different types of dispersers. Howe and Smallwood (1982) suggested the term of "directed dispersal" referring to plant species with special requirements; seed dispersal 
may be highly advantageous if it predictably enhances the probability of seeds reaching such favorable micro sites. There are certain examples to illustrate the idea; Sargent (1995) found that in mistletoes, seedling establishment is optimal in a narrow range of host twig diameter. Hanzawa et al. (1988) reported that ants dispersed herb Corydalis aurea directed dispersal of seeds to ant's nests effectively increases the population growth rate because of a significant increase in the survival of seeds to reproduction. Another example is the relationship between a tropical forest tree Ocotae endresiana and its major seed dispersers, the bellbirds (Procnias tricarunculata). The seeds dispersed by birds of this species predominantly land at microsites characterized by lower incidence of fungal pathogens and increased seedling survival rates (Wenny \& Levey 1998). These examples are merely diminutive cases compared to the richness of animals associated with each plant species ranging from 265000 species of described higher plants to the undescribed species with numbers of around $10-100$ million, over half of them insects (Price 2002).

\subsection{The New Zealand unique ecology}

The ecological history of New Zealand is unique and different compared to the other parts of the world. The percentage of unique organisms in New Zealand (endemism) is among the highest in the world, shared only with other Southern Hemisphere lands such as New Caledonia, Australia and South Africa (Gibbs 2006). In the context of New Zealand plants, Lord et al., (2002) described that the fruit colors on New Zealand, plants are unusual (all colors mentioned refer to the human visual spectrum). There are no green fruits at maturity; some species have white or pale blue to sky-blue fruits, simultaneous bicolored fruit in which one 
color is white or blue pale, or species polymorphic for fruit color in which one morph has white fruit, make up $21.2 \%$ of the fleshy-fruited flora. The suggested fruit dispersers in New Zealand are birds, lizards and weta (Lord \& Marshall 2001; Lord et al. 2002; Wotton 2002; Duthie et al. 2006; Burns 2006b). Each of these animal taxa has different vision capabilities and eye structure. From the seed dispersers overview, New Zealand is also unique due to the variety of seed disperser types. While birds are common, lizards, geckos and weta are also considered to share the same role (Lord et al. 2002).

Whitaker (1987) recognized the importance of lizards as seed dispersers of many native New Zealand plants. As many as 18 New Zealand lizard species were known to feed frequently on fruit (Lord \& Marshall. 2001). Wotton (2002) provided strong evidence that fruit is an important component of the diet Hopodactylus maculatus, and that common geckos provide effective seed dispersal for Coprosoma propinqua. Very little attention were given towards lizards as mutualistic agents because most of them are regarded as carnivorous and only about one percent is known to be truly herbivorous (Wotton 2002). However, lizards have a broad diet, which can include fiber-poor components (i.e. flowers, fruit, nectar and pollen) (Cooper \& Vitt 2002).

Duthie et al. (2006) documented that Wellington tree weta (Hemideina crassidens) consumes fleshy fruits and disperse seeds after ingestion. No other insect is known to perform such functions. Altogether, these three type of dispersers (birds, lizards and weta) have different sensory capabilities, habitat and movement patterns. Burns (2006b) raises the question of the co evolution between certain fruiting mechanisms of certain plants and their seed dispersers; 
such as the divaricate branching pattern of trees and shrubs that produces fleshy fruits in the inner most branches, restricting access to birds but facilitating access to small sized animals such as lizards and weta. However, the significant role of weta within New Zealand ${ }^{e e}$ s natural history still remains contentious (Burns 2008; Morgan-Richards et al. 2008).

\subsection{Visual signaling between plants and animals}

Visual signaling between plants and animals has always been a fascinating form of communication between two different kingdoms. The basic communication between senders and receivers often differ in their intentions based on the nature of the signals. Colours and shapes play an important factor in the plant-animal interactions. The animal (whether vertebrate or invertebrate) uses multiple arrays of techniques and sensory mechanisms to detect food, mate selection, navigation and other activities. Plants on the other hand, will need either to advertise and/or remain inconspicuous depending on their need for pollination, seed dispersal or to avoid seed/leaf predators. The mutualistic interaction between plant and animals creates a large network of potentially positive and negative interactions between species.

One of the key issues investigating signals system is that the transmitted signals are received by a variety of receivers whether they are mutualists or antagonists. Such complex situations can be explained by the multiple receivers' hypothesis; for example in widowbirds, males and females of the species exert different selection pressures on a signal, each one acting as an independent receiver (Andersson et al. 2002). This situation creates a possibility of wrong signals being 
transmitted to the wrong receivers. Warning signals or cryptic signals are received by multiple receivers, the complexity of how each receiver would actually react towards it has rarely been considered (Rowe \& Guilford 2000; Endler \& Mappes 2004). However, Schaefer et al., (2004a) suggested that the complexity of the problem could be investigated based on the differences in the receiver's photosensitivities. Depending on the required spectral receptor type and the associated neural mechanisms, the receivers could be categorized as either dichromatic, trichromatic or tetrachromatic. Each animal group has different spectral vision capabilities, therefore although the broadcasted signal is the same; it is perceived and processed differently by the receivers.

From the point of plant advertisement, highly contrasting fruit/foliage colors are used to attract seed disperser; however, the fruit size, shape and seed size must also conform to the seed disperser's preferences (i.e. the gape size of the mouth/beak, palatability). While trying to advertise for seed dispersal or pollination purposes, plants must also devise strategies to protect fruits from seed predators, pests and herbivores. For defence purposes, the plant kingdoms had evolved and develop an array of defensive tactics to deter herbivores and pathogens ranging from chemical (poisons, irritants, odours, taste etc. ) and physical (thorns, spines, tough barks etc. ) (Lev-Yadun 2003; Lev-Yadun \& Ne'eman 2006; Lev-Yadun 2009a,b).

\subsection{Colour vision in general}

What is color vision? Color vision is best thought of as the ability to discriminate variation in a spectrum of light changes in overall intensity of light; it 
requires comparison of responses in two or more spectral types of photoreceptors (Osorio \& Vorobyev 2005; Bennet \& Thery 2007). In comparison to color vision or chromatic vision, there is another type of vision mode, which is called achromatic vision or luminance vision. Luminance is the ability to discriminate differences in the intensity of light; this requires only one-photoreceptor or summation outputs of several photoreceptors (Bennet \& Thery 2007). This type of vision is usually used by primates for detecting form and texture (Osorio \& Vorobyev 2005). Colours are also perceived differently among animal taxa. In terms of perception, green or dull colored fruits when ripe are usually associated with dispersal by mammals, while fruits dispersed by birds tend to be brightly pigmented. Birds in both tropical and temperate regions usually favor red and black fruits (Willson et al. 1990). Color patterns of birds and their visual backgrounds consist of a mosaic of patches that differ in colour, brightness, size, shape and position (Endler 1978).

The juxtaposition between ripe and unripe fruit itself attracts the dispersers. In some cases, the contrasting colors between the fruits and the adjacent leaves or so called foliar flags, would also acts as visual attraction (Stiles 1982). Ripe fruits of certain plants also reflect ultraviolet light and certain color spectrum such as dark colors (blue, black, and brown) may absorb more radiation in the visible spectrum than pale colors (white, yellow, and orange, red). This will raise the fruit temperatures, increasing the fruit growth rate and decreasing the time of the fruit's exposure to seed predators and pathogen (Wheelwright \& Janson 1985).

Willson and Whelan (1989) stated that certain plants have evolved to enhance the visual signs of fruits, since the color vision of many birds extends to the near UV. Insects are known to lack visual receptors for red hues, which are the most 
common fruit hues and are readily detected by birds and other mammals (Willson et al. 1990). Wheelwright and Janson (1985) found that dull or dark colors are common among ripe fruits, contrary to popular conceptions about bird fruits (which are generally thought of red in color). Burns and Dalen (2002) stated that fruit colour varies temporally, with high contrasting colours to maximize conspicuousness against seasonal changes in foliage coloration. Bennet and Thery (2007) discuss recent advances in understanding avian coloration and color vision are due to recognition that birds see colors in a different way than humans. What began as a simple conspicuousness theory to explain frugivory and fruit features has evolved into a more complicated new branch of science involving chromatic contrast/ UV reflectance, and spectral sensitivity.

Humans see light from wavelengths of about 400 nanometers (violet) and to 700 nanometers (red), but cannot perceive longer (infrared) wavelengths or the shorter (ultraviolet) wavelengths. Bird's are tetrachromatic; with capabilities of detecting wavelengths in the near ultraviolet range (300-400 nm) (Withgott 2000). Some insects can see colors such as green and blue, along with mixtures of these colors. Insects such as honeybees have the ability to see in ultraviolet (UV) ranges, invisible to humans, giving them ability to distinguish contrast or details in objects such as flower structures (Osorio \& Vorobyev 2005). Many reptiles (11 species) have four-color cone types and, consequently, have four primary colors and capability to detect UV light (Honkavaara et al. 2002). Therefore, colors as defined and seen by the human eye could not necessarily be described through the eyes of other vertebrates/insects. 


\subsection{Foliage colour}

Foliage colour is a subject that had garnered a considerable amount of attention in recent years. More specifically, there is renewed interest in the age old simple question; why do leaves turn red? The red foliage colouration is caused by the anthocyanins. While usually red, there are also purple and blue pigment anthocyanins. In flowering plants, anthocyanins are mostly concentrated in the flowers and fruits, although it can also be found in the leaves, stems and roots. Despite the widespread distribution of anthocyanins among vegetative organs, and the long history of interests in anthocyanins, relatively little research has been directed towards their function in leaves (Lee and Gould 2002). There are however, many different hypotheses for anthocyanin function in leaves such as ; (1) UV-B protection and reducing photoinhibition and DNA damage in UV-irradiated material (Takahashi et al. 1991; Kakegawa et al. 1991; Klaper et al. 1996). (2) Elevating leaf temperatures (Hoch et al. 2001). (3) Providing water resistance by changing the osmotic pressure of the vacuolar sap ( Chalker-Scott 1999). (4) Photoprotection and reducing structural damage under high irradiance and low temperatures (Gould et al. 1995). (5) Preventing oxidative damage in leaves due to biotic or abiotic stress (Neill et al. 2002). (6) Defence against herbivores and pathogens (Stone 1979; Stiles 1982; Givnish 1990; Archetti 2000; LevYadun 2009a,b ).

These multiple hypotheses signifies the complexity of plant colour signals. For example, Chittka and Döring (2007) reviewed the case of aphids and autumnal leaf

colours. Red autumn leaf colours are hypothesized as warning signals to aphids (Archetti 2000). This however is confounded by the fact that the colour yellow (caused by yellow carotenoids which also exists in a senescence leaf) actually attracts aphids 
rather than deter them. The examplifies how the subject of signal itself is a complex interaction between multiple receivers and signal transmitters that could be easily misinterpretated by humans.

\subsection{Thesis structure}

This thesis incorporates theoretical applications and several experimental designs to explain the intricate relation between plants and animals based on visual signaling. In general, the first research question is how do plants utilize aposematic and cryptic colours? The second research question is how are animals affected by the colour signals broadcasted by plants? Both research questions are viewed from the plant and animal perspective. From the plant perspective, I examined how several species of New Zealand trees manipulated foliage colours as an adaptation to the natural surroundings. Most of the information and discussion is integrated within the second and third chapter. From the animals' perspective, I investigated how fruit/foliage colour affects the food selection by birds and weta. This portion is encapsulated in the fourth and fifth chapter.

In the second chapter, I examined how an unusual plant species utilizes different colouration strategies throughout ontogeny. Aposematism and crypsis are common strategy amongst animals, yet little evidence is known of such occurrences in plants. Here, I tested whether ontogenetic changes in leaf colour of lancewood (Pseudopanax crassifolius) may have been part of a defensive strategy against flightless browsing birds called moa, which were once the only large herbivores in New Zealand. The working hypothesis is does the P.crassifolius employs different type of colour defense strategy based on its life stages? During seedling stage, $P$. crassifolius utilizes colours to remain cryptic. As the tree passes into juvenile stage, 
sharp marginal teeth begins to form along the leaf blade. The trees during this phase use warning colours to highlight the teeths. As the tree matures beyond three to four meters, leaf colours change again to green colour. I tested this hypothesis by conducting spectrographic measurements on different-sized plants grown in a common garden. I also compared these results to a closely related, derived species that evolved in the absence of moa on the Chatham Islands (Pseudopanax chathamicus).

In the third chapter, I examined Elaeocarpus hookerianus Raoul, a native New Zealand tree that also undergoes striking heteroblastic changes through ontogeny. Unlike the $P$. crassifolius, E. hookerianus does not have defensive appendages (i.e. teeth/thorns ) on leaves, and the changes only occur from juvenile to adults. During the juvenile stage the plant is more susceptible to herbivory and therefore must rely heavily on cryptic colouration. I conducted a series of morphological and spectrographic analyses on E. hookerianus to test the hypothesis that it is cryptically coloured to deter avian browsers.

In the fourth chapter, I conducted a community level analysis of fruit colours and leaf colours in New Zealand. I reviewed and tested fruit-foliage contrast hypothesis to ascertain whether fruit colours are constrained by their own leaf reflectance. I also tested frugivore specificity hypothesis testing whether specific fruit colours are connected with specific frugivore assemblages.

In the fifth chapter, I examined how fruit colours are commonly selected by frugivores. However, evidence for insect frugivores selecting for particular fruit traits is equivocal. I tested whether a frugivorous, seed dispersing insect selects fruits based on their colours, and whether different lighting conditions affect fruit colour selection. 
I tested the fruit colour preferences using Wellington tree weta (Hemideina crassidens) with a Y-maze choice test by using Coprosma acerosa .The C. acerosa fruit were dyed in red and blue colour along with unmanipulated natural colouration to test for colour preferences under two separate lighting conditions.

In the sixth chapter, I summarized my findings and present suggestions for future research to be undertaken. Each chapter is written as stand-alone manuscript. There are repetitions in the information that might appear in certain portion of each chapter. 


\section{Chapter 2}




\section{Ontogenetic colour changes in an insular tree}

\section{species: Signalling to extinct browsing birds?}

(published as Fadzly N, Cameron J, Schaefer HM, Burns KC. 2009. Ontogenetic colour changes in an insular tree species: signalling to extinct browsing birds? New Phytologist. 184: 495-501) 


\section{Chapter 2: Cryptic and Aposematic Colours}

\subsection{Abstract}

Animals often use colours to hide from predators (crypsis) or advertise defences (aposematism), but there is little evidence for colour-based defence in plants. Here, I test whether ontogenetic changes in leaf colour of lancewood (Pseudopanax crassifolius) may have been part of a defensive strategy against flightless browsing birds called moa, which were once the only large herbivores in New Zealand. I tested this hypothesis by conducting spectrographic measurements on different-sized plants grown in a common garden. I also compared these results to a closely related, derived species that evolved in the absence of moa on the Chatham Islands. Spectrographic analyses showed that birds would have difficulty distinguishing seedling leaves against a background of leaf litter. Conversely, brightly coloured marginal teeth on sapling leaves are highly conspicuous to birds. Once above the reach of the tallest known moa, adults produce leaves that are typical apparent adult leaves. The Chathams island species lacks ontogenetic colour changes entirely. Overall results indicate that $P$. crassifolius goes through a remarkable series of colour changes during development, from cryptically coloured seedlings to aposematically coloured saplings, which may have formed a defensive strategy to protect against giant browsing birds. 


\subsection{Introduction}

Plants are attacked by a bewildering array of herbivores. In response, plants have evolved a variety of defences to deter herbivores. In addition to defences such as thorns and noxious chemicals, there is growing speculation that plants might also use colours to defend themselves (Stone 1979; Lev-Yadun \& Inbar 2002). For example, aposematic or warning colours could be used to signal defensive structures (Lev-Yadun 2001, 2009a). Alternatively, plants could be cryptically coloured in ways that make them difficult for herbivores to locate (Barlow \& Wiens 1977; Wiens 1978; Givnish et al. 1994; Watson 2004; Lee 2007). Although aposematic and cryptic colour patterns are common in animals, there is little evidence for their existence in plants.

I investigated ontogenetic shifts in leaf colours of Pseudopanax crassifolius (A.Cunn) C.Koch Araliaceae, a heteroblastic tree that is endemic to New Zealand. To the human eye, $P$. crassifolius goes through a strange series of morphological transitions from germination to maturity (Figure 2.1$)$. Seedlings $(<10 \mathrm{~cm}$ tall) produce small, narrow leaves that are mottled in appearance to the human eye. Saplings (10-300 $\mathrm{cm}$ tall) produce larger, more elongate leaves that have marginal teeth, each coinciding with a distinctive patch of different coloured tissue. Adult plants (> $300 \mathrm{~cm}$ tall) produce oblong leaves that are more ordinary in appearance.

These morphological changes could be adaptations to changing environmental conditions as plants grow vertically (Gould 1993). Alternatively, they might also deter herbivory (Greenwood \& Atkinson 1977, see also Boege \& Marquis 2005). Prior to human arrival, New Zealand lacked native land mammals (except for two species of bat) and instead was home to massive, flightless birds 
called moa (Worthy \& Holdaway 2002; Wood et al. 2008). If the mottled colours of seedling leaves make them difficult to distinguish against a background of leaf litter, their colours may have provided some defence against moa herbivory. Moa lacked teeth and swallowed leaves by placing them in their bill and snapping their head forward to orient them down the oesophagus (Bond et al. 2004). Several distinctive features of plant species inhabiting other isolated islands, such as divaricate branching and heteroblastic leaf morphology, may have complicated their ingestion by toothless browsers (Greenwood \& Atkinson 1977; Diamond 1990; Givnish et al. 1994; Bond et al. 2004; Eskildsen et al. 2004; Burns \& Dawson 2006; Bond \& Silander 2007). Unusual attributes of plants inhabiting other locales, such as excessively large fruits, have previously linked to extinct “megafauna” (Janzen 1986; Janzen \& Martin 1982; White 1988; Barlow 2000; Hansen \& Galetti 2009). Similarly, the unusually long, rigid leaves produced by P. crassifolius saplings, coupled with the marginal teeth, may have made them difficult for moa to swallow, and the distinctive colour patches associated with spines could have served as a reliable warning signal of structural defence. The maximum browsing height of the largest moa was approximately $300 \mathrm{~cm}$ (Worthy \& Holdaway 2002). Therefore, colour-based defence would not have been advantageous as plant grew above the reach of moa, perhaps leading to more typical leaf characteristics.

The Chatham Islands are a small group of islands of recent geological origin located $800 \mathrm{~km}$ east of New Zealand. The Chatham Island flora appears to be derived from overseas dispersal from New Zealand (see Trewick 2000; Trewick et al. 2007). A notable example is Pseudopanax chathamicus Kirk. Araliaceae. Recent molecular analyses indicate that $P$. chathamicus is derived from a $P$. 
crassifolius ancestor in New Zealand (Mitchell \& Wagstaff 1997; Leon Perrie pers. comm.). Unlike New Zealand, the Chathams lacked large browsers, including moa. Dawson (1991) and Greenwood (1992) commented that plant taxa that are heteroblastic in New Zealand appear to have reduced morphological differentiation between adult and juvenile plants in the Chathams (see also Burns \& Dawson 2009). If ontogenetic changes in the colour of $P$. crassifolius evolved in response to moa herbivory in New Zealand, than ontogenetic colour changes may be reduced in P. chathamicus, which evolved in the absence of moa.

I conducted spectrometric analyses to quantify ontogenetic colour changes in P. crassifolius from the perspective of birds to test four predictions arising from the moa browsing hypothesis: (1) P. crassifolius seedlings resemble the reflectance properties of leaf litter, making them difficult to distinguish against their natural background (i.e. crypsis). (2) As plants grow taller, saplings advertise the marginal teeth with conspicuous colour patches (i.e. aposematism). (3) Once plants grow above the reach of the tallest known moa, they produce leaves that are ordinary in size, shape and colour. (4) P. chathamicus, a closely related species that evolved in the absence of moa, has lost the ontogenetic changes in leaf colour displayed by $P$. crassifolius.

\subsection{Materials and Methods}

All plants used in analyses were grown in a common garden located in OtariWilton's Bush, Wellington, New Zealand $\left(41^{\circ} 15^{\text {ee }} \mathrm{S}, 174^{\circ} 45^{\mathrm{ee}} \mathrm{E}\right)$. One randomly selected leaf was collected from 10 plants within three height classes. Seedlings were small enough to be consistently associated with a background of leaf litter. Saplings were too large to be associated consistently with leaf litter, but were within 
reach of browsing moa. Adults stood above the reach of the largest known moa. Sample sizes of adult plants of $P$. chathamicus were smaller $(\mathrm{n}=2)$, due to their limited availability in the garden. Spectral readings were replicated five times for all leaves, which were then averaged prior to analyses. Leaf litter (i.e. dead leaves, earth and fallen branches) reflectance measurements were collected in 10 random locations within old-growth forest following (Uy \& Endler 2004), which were averaged prior to analyses.

Spectral analyses were made using a USB Ocean Optics 2000 spectroradiometer and Xenon Pulse X2 lamp (Ocean Optics) light source. An object's reflectance properties were measured as the proportion of a diffuse, Teflonbased, white reflectance standard. The fiber optics probe was mounted inside a matte black plastic tube to exclude ambient light. The distance between each object and the probe was fixed at $1 \mathrm{~cm}$. The angle of illumination and reflection was fixed at $45^{\circ}$ to minimize glare. Spectra were calculated at $5 \mathrm{~nm}$ intervals from 300 to 700 $\mathrm{nm}$ with SpectraSuite software. I chose to restrict my analyses to wavelengths below $700 \mathrm{~nm}$ because the far-red spectrum cannot be discriminated by birds (Stiles 1981; Varela et al. 1993). Irradiance was measured with a cosine corrected sensor and a D65 (normal daylight) light bulb as a reference.

I quantified the appearance of leaves using the contrast comparison method, which follows simple colour pattern measures related to photon capture (Endler \& Mielke 2005; Vorobyev et al. 1998b; Schaefer et al. 2004a; Schaefer et al. 2007). A detailed explanation of the mathematical model is given elsewhere (Osorio \& Vorobyev 1996; Vorobyev et al. 1998b; Vorobyev \& Osorio 1998). This method quantifies the discriminability of any two spectra, provided only that receptor spectral sensitivities and noise can be estimated. 
The receptor spectral sensitivity values were obtained from Endler and Mielke (2005) for both the $U$ and $V$ avian cones. Since exact spectral discrimination data are not available for Moa, I used the $V$ model based on its closest living relative, Struthio camelus (Ostrich) (Turvey et al. 2005). I choose to use the ostrich receptor because of their close phylogenetic relatedness to moa and widespread evolutionary conservatism in avian colour vision (see Ödeen 2003).

Colour is defined as a point in a perceptual space whose co-ordinate axes represent quantum catches of receptors (Poirson \& Wandell 1990). Discriminability of any two colours is described by the "distance", $\Delta S$, between them in JND units ("just noticeable differences"). A colour patch with a JND value of more than 1 is at the threshold of discrimination from the background. Increasing JND values indicate increasing ease of distinction (e.g., from a larger distance), whereas values less than $1 \mathrm{JND}$ are not discriminated. I calculated separate JND values for both chromatic (colour-based) and achromatic (brightness-based) spectral contrasts.

The exact working nature of achromatic or brightness signals in birds is still poorly understood (Campenhausen \& Kirschfeld 1998; Osorio et al. 1999; Hart 2001). Double cones have a broad spectral sensitivity, which overlaps with both long and medium wavelength-sensitive cones, and are used in achromatic signal processing (non-colour based tasks) (Hart et al. 2000; Jones and Osorio 2004; Cuthill 2006). The only available double cone receptor data sensitivity is based on Leiothrix lutea (Red-billed Leiothrix). Detailed description of the methods that I use to quantify leaf reflectance properties are given in appendix 1 .

To test whether $P$. crassifolius seedlings are cryptically coloured, I visually compared the reflectance curves of seedlings and leaf litter. I also tested whether $P$. 
crassifolius seedlings were less conspicuous against a background of leaf litter than P. chathamicus, by comparing the JND values derived from seedling versus leaf litter spectral contrasts between species using t-tests. Two t-tests were conducted, both chromatic and achromatic contrasts.

To test whether $P$. crassifolius advertises the teeth located on its leaf margins with conspicuously coloured tissues, I visually compared the reflectance curve associated with the marginal teeth to the curve characterising the region between margins (i.e. non-marginal teeth). I also tested whether the teeth margins on $P$. crassifolius were more conspicuous than the vestigial margins on $P$. chathamicus, by comparing the JND values derived from marginal teeth versus nonmarginal teeth spectral contrasts between species using t-tests. Separate t-tests were again conducted for chromatic and achromatic contrasts.

To test whether the reflectance properties of adult leaves of $P$. crassifolius were similar to adult leaves of both $P$. chathamicus and other New Zealand tree species, I conducted spectrometric measurements on 29 common tree species using the same protocol described previously (i.e. 1 randomly selected leaf from 10 plants). Spectral readings were replicated five times for each leaf, which were averaged prior to analyses. I then compared the resulting reflectance curves for $P$. crassifolius, P. chathamicus and the other tree species. In this comparison, JND values were not compared statistically, due to the lack of a consistent spectral background for comparative purposes. All data were log-transformed when necessary to improve normality and all analyses were conducted in $R$ ( $R$ Development Core Team, 2008). 


\subsection{Results}

The average reflectance curve obtained for $P$. crassifolius seedlings was strikingly similar to that of leaf litter (Figures 2.1 and 2.2). However, the reflectance curve for P. chathamicus was markedly different. Chromatically, P. crassifolius seedlings had lower JND values against a leaf litter background $(16.6 \pm 3.1)$ than $P$. chathamicus $(47.8 \pm 1.9)(\mathrm{t}=-8.62, \mathrm{df}=18, \mathrm{p}<0.01)$. Achromatically, $P$. crassifolius seedlings also had lower JND values $(-5.74 \pm 3.8)$ than $P$. chathamicus $(4.0 \pm 2.9)(\mathrm{t}=-2.05, \mathrm{df}=18, \mathrm{p}=0.05) . \quad$ Therefore, birds would have greater difficulty distinguishing seedlings of $P$. crassifolius against a background of leaf litter relative to $P$. chathamicus.

Saplings of $P$. crassifolius produce long, narrow, rigid leaves that have teethlike structures along their margins, which are associated with patches of lighter green colouration (Figures 2.1 and 2.3). Conversely, P. chathamicus saplings at a similar phase produce leaves that appear to be phenotypically similar to adult leaves. The colour patches adjacent to marginal teeth in $P$. crassifolius had higher chromatic JND values $(16.4 \pm 1.7)$ against the background of the remainder of the leaf compared to $P$. chathamicus $(6.7 \pm 2.2)(\mathrm{t}=-3.34$, $\mathrm{df}=13, \mathrm{p}=0.05)$. Similar differences between $P$. crassifolius $(10.5 \pm 2.5)$ and $P$. chathamicus $(0.7 \pm 1.8)$ were found in achromatic comparisons $(\mathrm{t}=2.55, \mathrm{df}=13, \mathrm{p}=0.02)$. Therefore, the teeth along the margins of sapling leaves of $P$. crassifolius are made more conspicuous by the colour of adjacent tissue, and this signal has been lost in P. chathamicus.

Adult leaves of $P$. crassifolius and $P$. chathamicus had similar reflectance curves (Figure 2.4). Both were also broadly similar to the adult leaves of the 29 cooccurring adult plant species. Therefore, I failed to find marked differences in adult leaf colours between $P$. crassifolius, $P$. chathamicus and other common tree species. 

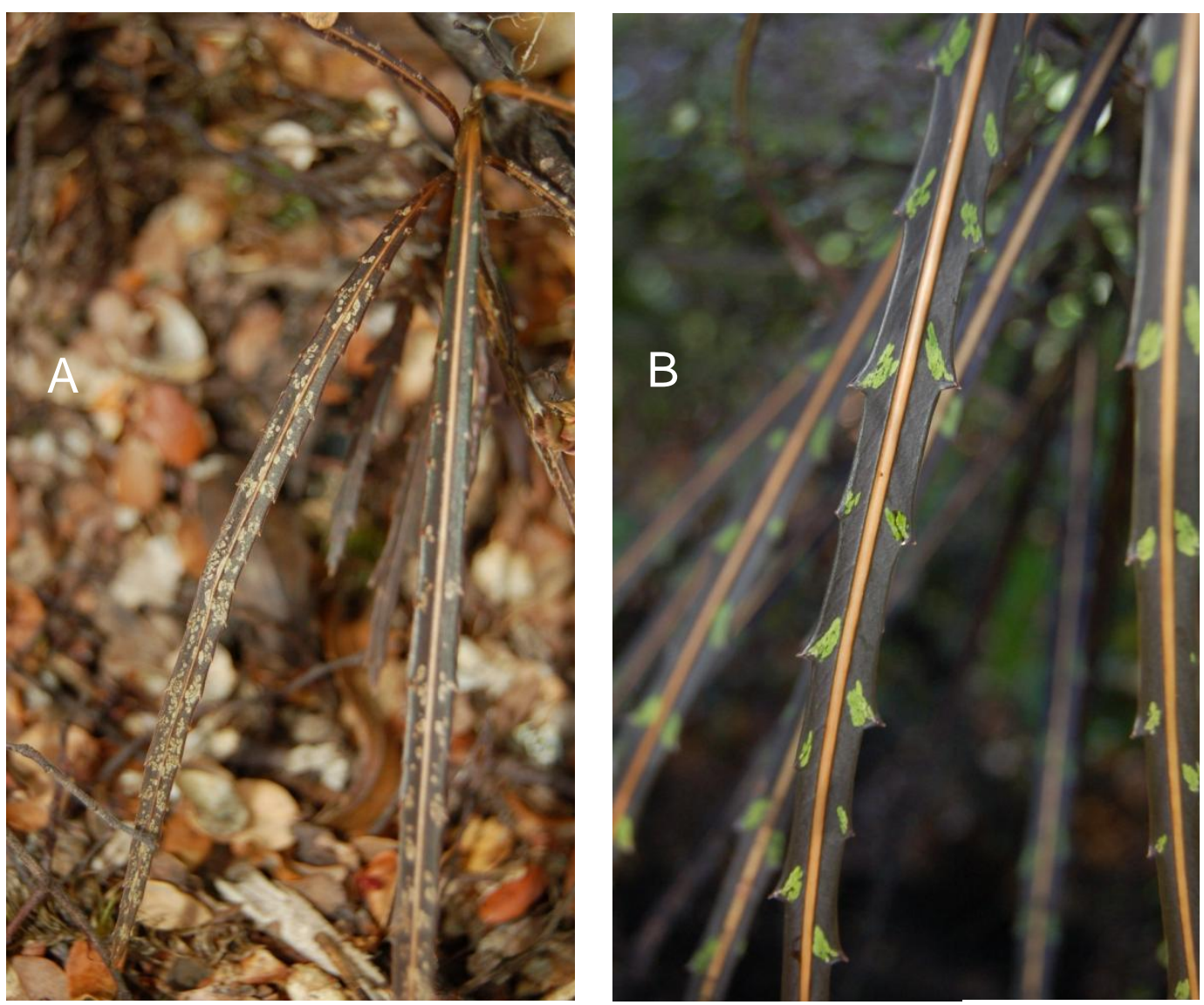

$1: 1 \mathrm{~cm}$

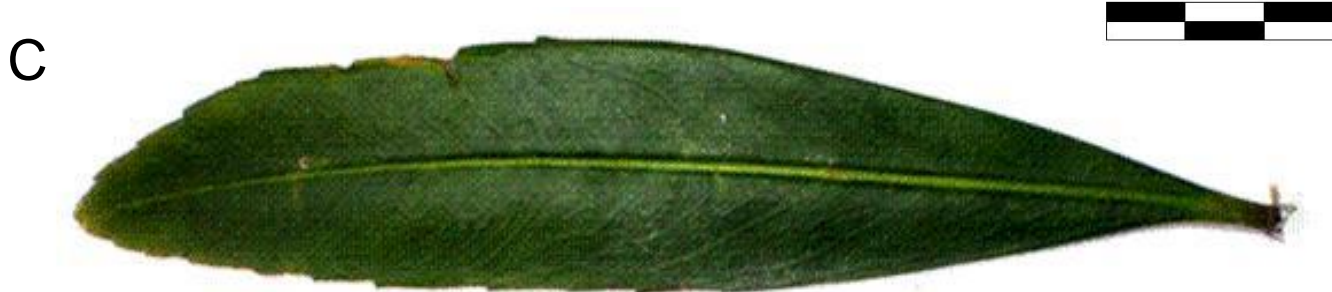

Figure 2.1: A healthy Pseudopanax crassifolius seedling (A), sapling (B) and adult leaf (C), from Nelson Lakes National Park, South Island, New Zealand. 


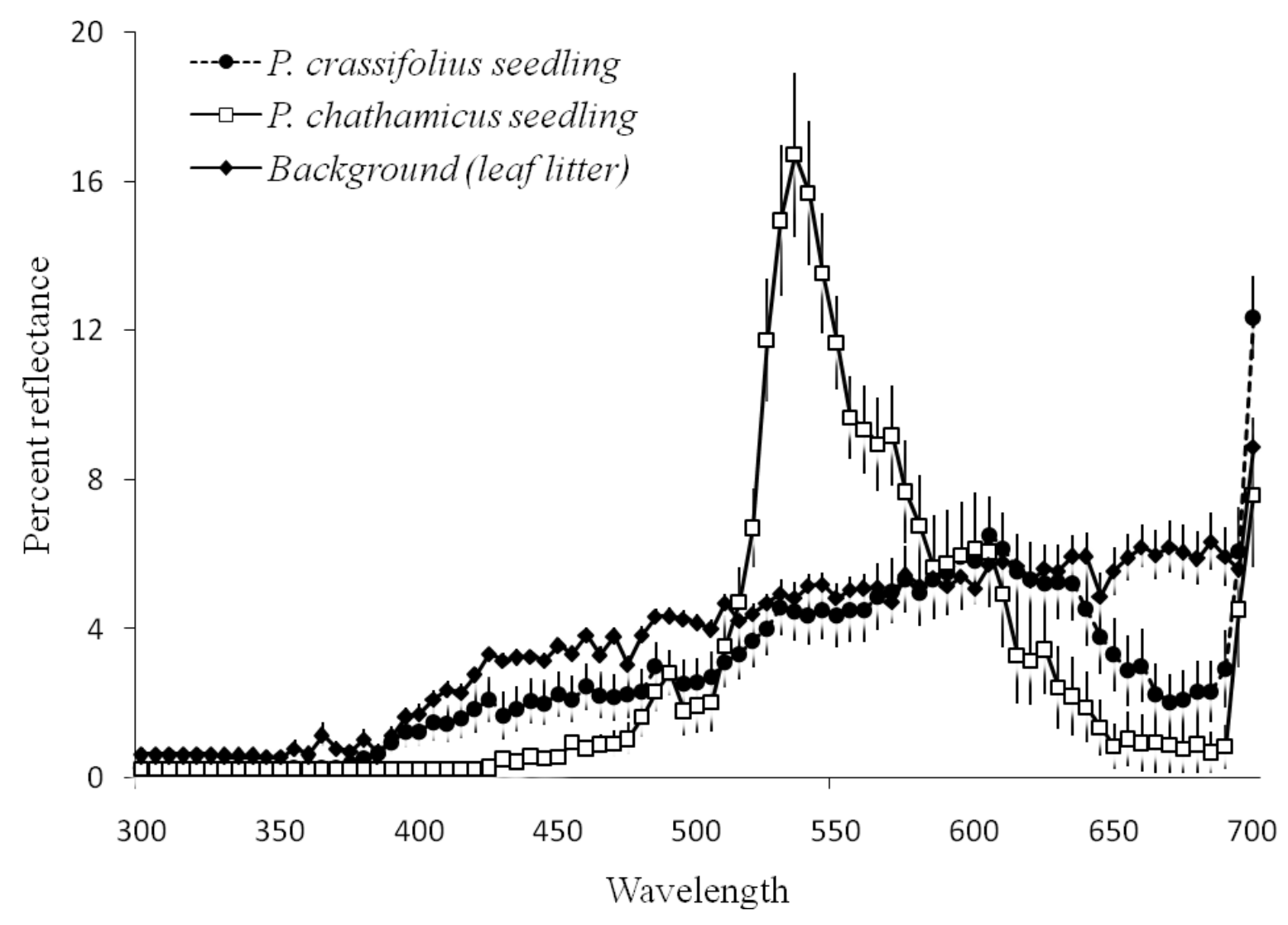

Figure 2.2: Reflectance curves for Pseudopanax chathamicus seedlings, $P$. crassifolius seedlings and leaf litter. Vertical lines refer to \pm standard error $(n=10$ for each components). 


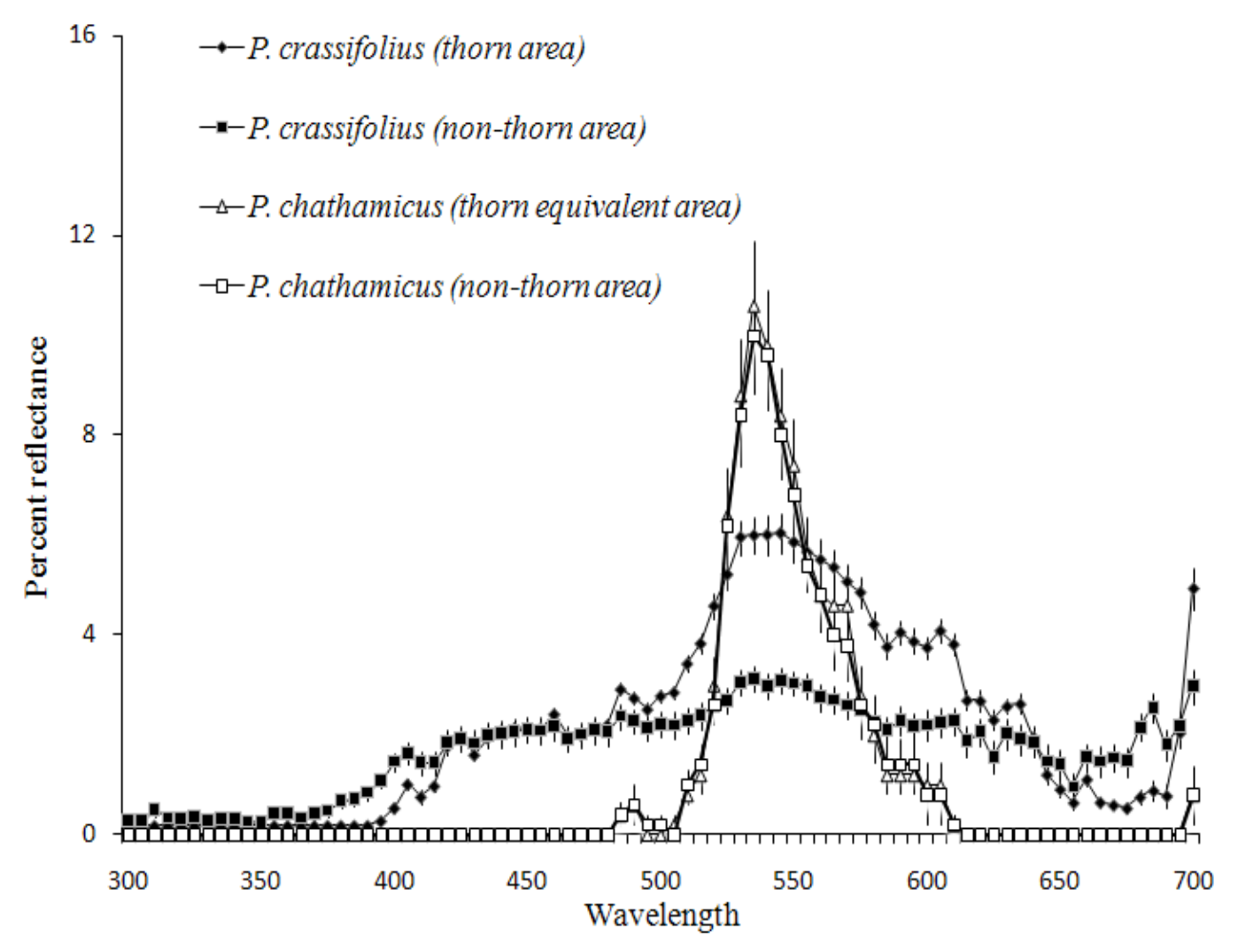

Figure 2.3: Reflectance curves for Pseudopanax chathamicus and P. crassifolius saplings. For each species, separate curves are drawn for tissues adjacent to spines and tissues between spines. Vertical black lines are \pm standard error.( $\mathrm{n}=10$ for each components). 


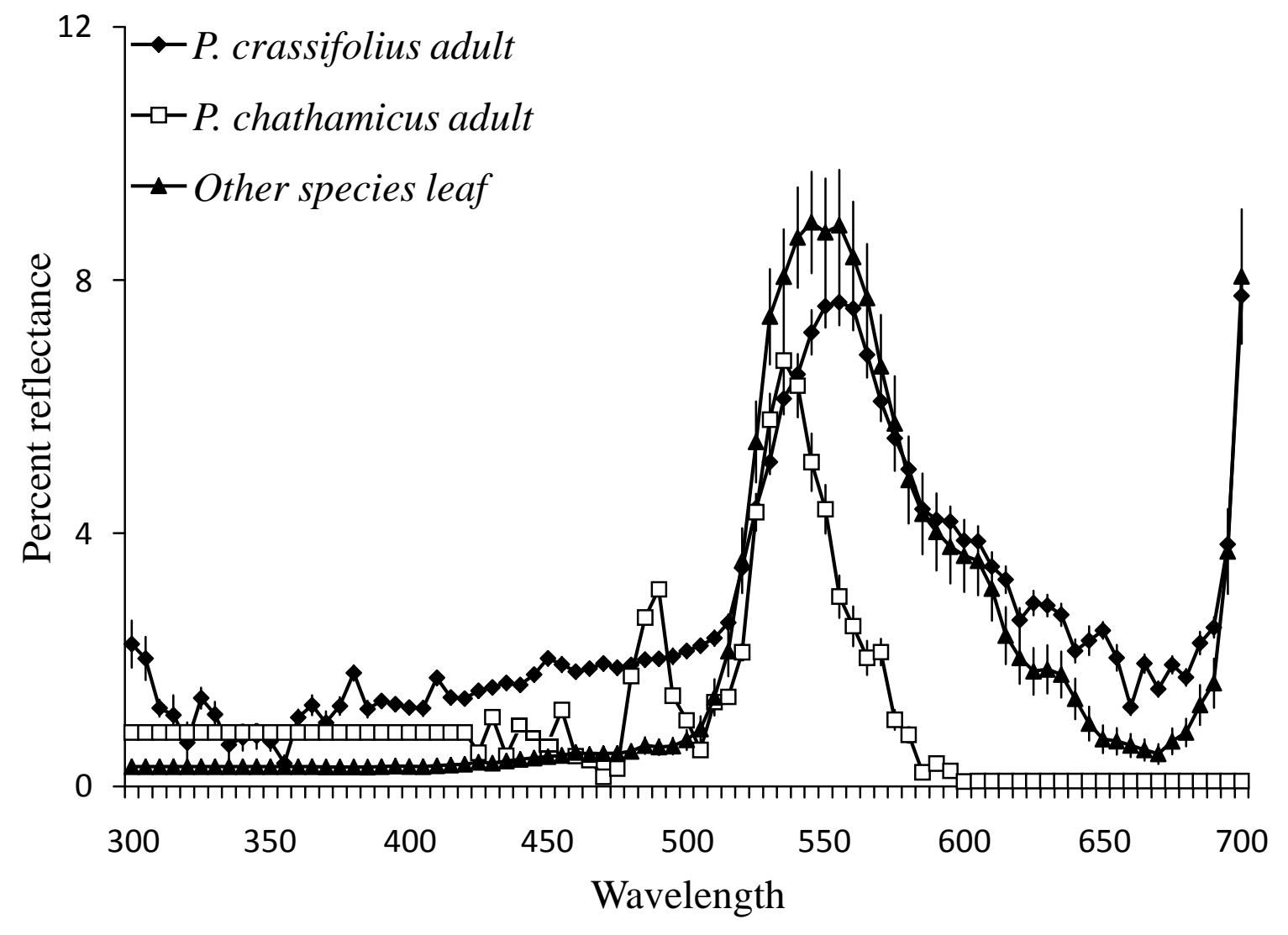

Figure 2.4: Reflectance curves for adult leaves of Pseudopanax chathamicus, $P$. crassifolius and the average of 29 common New Zealand plant species. Vertical black lines are \pm standard error. $(\mathrm{n}=10$ for each components, except for adult $P$. chathamicus where $\mathrm{n}=2$ ). 


\subsection{Discussion}

Pseudopanax crassifolius foliage goes through a remarkable series of colour changes during ontogeny. Foliage of seedling is mottled in appearance and similar in colour to leaf litter. Saplings produce long, rigid leaves with spine-like projections on their margins, each of which is typically associated with a patch of brightly coloured tissue. Once plants grow above 3 meters in height, they abruptly begin to produce leaves that are typical in size, shape and color to co-occurring tree species. Similar color changes were not observed in $P$. chathamicus, which produces similarly coloured leaves throughout ontogeny. Changes in the colour of leaves produced by $P$. crassifolius through ontogeny are similar to ontogenetic colour changes in many insects, which shift from being cryptically coloured; to aposematically coloured during development (see Grant 2007).

The unusual leaf colours in $P$. crassifolius could be a series of adaptations to enhance physiological performance in the changing environmental conditions experienced by plants as they grow from the forest floor into the canopy (Day 1998; Howell et al. 2002). Pseudopanax crassifolius seedlings are known to possess traits (e.g. thin lamina and low specific weight) that promote photosynthetic capability under low-light conditions (Gould 1993; but see Gamage \& Jesson 2007). Furthermore, phenotypic differences between P.chathamicus and P.crassifolius could result from historical differences in climate between New Zealand and the Chathams Islands (McGlone \& Webb 1981). New Zealand was heavily glaciated during the last glacial maximum, but the Chatham Islands were substantially warmer due to the ameliorating climatic effects of the ocean. The unusual leaf colours in $P$. crassifolius could increase leaf temperatures, which may have enhanced photosynthetic efficiency in the colder conditions that occurred in New Zealand 
(Gould 1993). However, for climate to provide a convincing explanation for results, vertical gradients in environmental conditions (i.e. from the ground into the forest canopy) would need to be more pronounced in New Zealand than in the Chathams. Although these data are unavailable, forest structure appears to be broadly similar in both locales, which suggests that this explanation is unlikely.

Alternatively, ontogenetic changes in leaf colours may represent a series of adaptations to first avoid and later deter moa browsing. The mottled colours of seedling leaves are similar to the appearance of leaf litter, which would reduce the probability of their detection by avian herbivores. Their unusual colouration may reduce the appearance of leaf outlines and camouflage leaves against the sunlightdappled forest floor (Givnish 1990). Saplings produce long, rigid leaves with spine-like projections on their margins that are consistently associated with bright colour patches that produce high achromatic contrasts. Interestingly, achromatic contrasts are particularly important in the detection of object borders in birds, humans and insects (Osorio et al. 1999), and may explain why plant spines are often coloured white or associated with white markings (Lev-Yadun 2001, 2003, 2009b; Midgley 2004). Furthermore, the avian eye consists of four types of single cones and one double cone (Cuthill 2006), which is unique to birds. The double cone has a broad spectral sensitivity and is associated with achromatic perception (i.e. intensity-based tasks). Therefore, birds would be particularly sensitive to the colour of sapling leaf spines, which are characterised by high achromatic contrasts.

A precise quantitative description of the visual acuities of moa is unlikely to be ever obtained because they are now extinct. I chose to make my reflectance calculations using the ostrich ( $\mathrm{V}$ type eye) because this species is a close relative to moa in the ratite family. However, to assess how sensitive results might be to this 
choice of avian cone type, I recalculated the spectral data using receptor sensitivity of a passerine ( $U$ type eye). Results from this analysis were statistically indistinguishable from results based on the ostrich eye. Therefore, results do not appear to be sensitive to avian cone type.

Once plants grow above $3 \mathrm{~m}$, the maximum feeding height of the largest known moa, leaves are typical in size and shape to the adult leaves of many other New Zealand angiosperm tree species (Clearwater \& Gould 1994). Their average spectral properties are also ordinary i.e., mostly within the standard error of the leaves of syntopic species. Their colours are also consistent with the reflectance properties of the primary pigments involved in photosynthesis (chlorophyll a and b), which have peak absorption values above and below the peak in reflectance of adult leaves at $545 \mathrm{~nm}$.

Insects are prominent herbivores in New Zealand, as they are on the Chatham Islands and elsewhere in the world, and may have played a role in the development of unusual colours in P. crassifolius. However, the spine-like projections on saplings are too large to provide protection against insect herbivores. A more likely explanation seems to be browsing by moa, which went extinct following the arrival of man in New Zealand approximately 750 years ago (Gibbs 2006). Because the putative selection agent is now extinct, the effectiveness of leaf colours in deterring moa herbivory cannot be tested directly. However, future work could still test the hypothesised link between leaf reflectance patterns and herbivore damage. For example, cafeteria- style experiments similar to Bond et al. (2004) could be conducted to evaluate whether extant ratites (e.g. emu) have trouble locating seeding leaves against a background of leaf litter, or whether they struggle to swallow sapling leaves and avoid those with brightly coloured spines. 


\section{Chapter 3}




\section{Hiding from the ghost of herbivory past: Evidence}

\section{for crypsis in an insular tree species}

(Published as Nik Fadzly and KC Burns. 2010. Hiding from the ghost of herbivory past: evidence for crypsis in an insular tree species. International Journal of Plant

Sciences. 171(7). DOI: 10.1086/654850 ) 


\section{Chapter 3: Crypsis and Heteroblastic Leaf Morphology}

\subsection{Abstract}

The colour of many animals matches that of their preferred habitats, making them difficult for predators to locate. However, quantitative examples of crypsis in plants are comparatively rare. I conducted morphometric and spectrographic analyses of a heteroblastic tree species that is endemic to New Zealand (Elaeocarpus hookerianus Raoul) to test whether it is cryptic in appearance from the perspective of birds, who were once dominant browsers in New Zealand. The leaves of smaller, juvenile plants are highly variable in size and shape, and are mottled-brown in colour from the perspective of birds, which would make them difficult for herbivorous birds to locate against a background of leaf litter. However, once plants grow to above 3 meters in height, beyond the reach of the largest herbivorous bird known to inhabit New Zealand, plants suddenly produce leaves that are ordinary in size, shape and colour. Results provide quantitative support for the hypothesis that E. hookerianus is cryptically coloured when within reach of flightless browsing birds. 


\section{Chapter 3: Crypsis and Heteroblastic Leaf Morphology}

\subsection{Introduction}

There is a long history of speculation that some plants are coloured and shaped in ways that make them difficult to be located by predators. For example, the size and shape of leaves produced by many species of Australian mistletoes match their hosts, which may make them difficult for herbivores to distinguish (Barlow \& Weins 1977; Canyon \& Hill 1997). Similarly, stone plants (Lithops spp.) that grow in arid, rocky habitat in Southern Africa closely resemble small pebbles, which may make them difficult for herbivorous mammals to locate (Barlow \& Weins 1977; Nobel 1989). However, these and other examples of crypsis in plants have yet to be thoroughly tested and there is little quantitative evidence for the evolution of crypsis in plants (Everard \& Morley 1970; Wiens 1978; Stone 1979; Atsatt 1983; Lev-Yadun 2006; Schaefer \& Ruxton 2009; but see Klooster et al. 2009).

Like most other isolated islands, New Zealand lacked herbivorous mammals before the arrival of humans and instead was home to giant browsing birds, moa. Differences between birds and mammals in foraging behaviour, digestion and vision may have promoted a suite of unusual plant defences. Few New Zealand plants produce thorns, which are known to be effective in deterring mammal herbivory (Ehrlich \& Raven 1964; Grub 1992; Lev-Yadun 2001; Lev-Yadun 2003; Lev-Yadun 2006; Lev-Yadun 2009a; Lev-Yadun 2009b; Midgely et al. 2001). On the other hand, plant species from a diverse array of phylogenetic backgrounds in New Zealand are heteroblastic, with abrupt changes in morphology during ontogeny leading to distinct juvenile and adult forms (Day et al. 1997; Day et al. 1998). Many New Zealand plant species are also divaricately branched, meaning they produce new stems at right angles to one another, which leads to an overall matted appearance (i.e. 'wire plants', sensu 
Bond \& Silander 2007). Moreover, many heteroblastic plant species are divaricately branched in early ontogenetic stages and then more normally branched once they grow above three metres in height, which coincides approximately with the largest known moa (Greenwood \& Atkinson 1977). Although divaricate branching may have evolved to enhance physiological performance (see Day et al. 1997; Day et al. 1998; Howell et al. 2002), it may also have evolved to deter moa browsing. Bond et al. (2004) offered divaricately branched plants to emu (Dromaius baudinianus), a close living relative of moa that is native to Australia, and found that they were damaged less than nondivaricately branched species.

Many heteroblastic species also change colour during ontogeny (Day 1998). Juvenile leaves of some species are coloured mottled-brown, which make them difficult for human observers to locate in leaf litter. Changes in leaf colour during ontogeny have led to the hypothesis that juvenile leaves are cryptically coloured to deter moa browsing (Greenwood \& Atkinson 1977; Brown et al. 1991). However, quantitative tests of this hypothesis are rare (Fadzly et al. 2009) and there are alternate explanations for juvenile leaf colours (Cockayne 1912; Godley 1985; Gould 1993; Kelly 1994).

Elaeocarpus hookerianus Raoul, displays one of the most striking heteroblastic changes in morphology of any New Zealand tree species (Day et al. 1998). Juvenile plants are divaricately branched and produce leaves that are stunningly variable in morphology, ranging from obovate with smooth edges to linear-lanceolate with heavily serrated margins (Day et al. 1997). Juvenile leaves are also strangely coloured to human observers and range in hue from pale brown to almost black in appearance. When plants grow to a height of three meters, they undergo a sudden shift to a more normal appearance (Allan 1961). Adult plants branch at narrower angles and 
produce leaves that are larger and more consistently elliptical in shape than the juvenile leaves. They are also green in coloration, similar to other common tree species.

I conducted a series of morphological and spectrographic analyses to evaluate whether heteroblastic changes in the morphology of E. hookerianus could have evolved to deter avian browsers. First, I compared the spectral properties of seedling leaves to leaf litter, to test whether they are cryptically coloured from the perspective of birds. Second, given that leaf litter is comprised of diverse array of objects including twigs, rocks and decomposing leaves, I tested whether juvenile leaves are more variable in size and shape than their adult counterparts, which may have made them more difficult to locate against variable leaf litter backgrounds.

\subsection{Materials and methods}

All data were collected from Nelson Lakes National Park, South Island, New Zealand (41.81' S, 172.85 E). Ten leaves were randomly selected from ten juvenile plants $(<300 \mathrm{~cm}$ tall $)$ and ten adult plants $(>300 \mathrm{~cm}$ tall $) . \mathrm{I}$ chose this height to delineate juvenile and adult plants because it appeared to be the height at which plants switched from producing juvenile to adult morphological characteristics and has been recorded previously in the literature (e.g. Greenwood \& Atkinson 1977). Ten reflectance measurements of leaf litter (i.e. dead leaves, earth, rocks and fallen branches) were collected in ten random locations within old-growth forest (Uy \& Endler 2004) and were averaged prior to analyses.

Leaf spectra were measured with a USB Ocean Optics 2000 spectroradiometer and Xenon Pulse X2 lamp Ocean Optics light source. An object's reflectance properties were measured as the proportion of a diffuse reflectance standard (Teflon coated-white standard). The fiber optics probe was mounted inside a matte black 


\section{Chapter 3: Crypsis and Heteroblastic Leaf Morphology}

plastic tube to exclude ambient light. The distance between each object and the probe was fixed at $1 \mathrm{~cm}$ with the angle of illumination and reflection was fixed at $45^{\circ}$ to minimize glare. Irradiance was measured with a cosine corrected sensor and a D65 (normal daylight) light bulb as a reference. Spectra were calculated at $5 \mathrm{~nm}$ intervals from 300 to $700 \mathrm{~nm}$ with SpectraSuite software.

I used an eye model based on the spectral sensitivities and receptor noise of the four avian cone types ( $\mathrm{u}, \mathrm{s}, \mathrm{m}$ and $\mathrm{l})$. I quantified the appearance of leaves using the contrast comparison method, which follows simple colour pattern measures related to photon capture (Vorobyev et al. 1998b; Endler \& Mielke 2005). A detailed explanation of the mathematical formulation model is given elsewhere (Osorio \& Vorobyev 1996; Vorobyev et al. 1998b), but they are sufficient to predict the discriminability of any two of spectra, provided only that receptor spectral sensitivities and noise can be estimated. The calculation provides photon capture values for each type of cone receptor in the bird's eye. The receptor spectral sensitivity values were obtained from Endler and Mielke (2005) for both the $U$ and $V$ avian cones. Since exact spectral discrimination data are not available for Moa, I used the $V$ model based on its closest living relative, the ostrich (Struthio camelus). I chose to use the ostrich because of its close phylogenetic relation to moa and widespread evolutionary conservatism in avian colour vision (Odeen \& Hastad 2003; Turvey et al. 2005).

Colour can be defined as a point in a perceptual space whose co-ordinate axes represent quantum catches of optical receptors (Poirson \& Wandell 1990). Colour perception is comprised of two components, chromatic (spectral distribution) and achromatic (brightness of all wavelengths) contrasts between an object and its visual background. For chromatic comparisons I used Endler and Mielke's (2005) analytical 


\section{Chapter 3: Crypsis and Heteroblastic Leaf Morphology}

technique. The outputs for each of the four retinal cones (u, s, m and l) were transformed into points in tetrahedron with a height of 1 , resulting in $x, y$ and $z$ Cartesian coordinates in three dimensional space (Aitchison 2003). The chromatic contrast (C) between any two samples (for example leaf $a$ and background $b$ ) are then calculated as the Euclidean distance between the two points in tetrahedral colour space.

$$
C=\sqrt{\left(x_{a}-x_{b}\right)^{2}+\left(y_{a}-y_{b}\right)^{2}+\left(z_{a}-z_{b}\right)^{2}}
$$

Greater Euclidean distances between points indicate greater colour contrasts and a more visually apparent object. Since the height of the tetrahedron is set to 1; values range from zero (indicating no contrast at all) to one (highest contrasting colour). I used a different analytical technique to make achromatic comparisons because the exact working nature of achromatic signals in birds is still poorly understood (Campenhausen \& Kirschfeld 1998; Osorio et al. 1999; Hart 2001). Birds possess 'double cones' that have broad spectral sensitivities that overlap with both long and medium wavelength-sensitive cones and are used in achromatic signal processing (non-colour based tasks) (Hart et al. 2000; Jones \& Osorio 2004; Cuthill 2006). Achromatic $(\Delta S)$ contrasts were calculated as:

$$
\Delta S=\left|\Delta f_{i} / \omega_{D}\right|
$$

, where $\Delta f_{i}$ is the difference in the stimulus of receptor mechanisms between signals (refer to Osorio \& Vorobyev 1996; Vorobyev et al. 1998b), and $\omega_{D}$ is the value of double cones. Because $\omega_{D}$ is the same for all targets, it does not affect relative achromatic contrasts. I used the only available data on double cone receptor sensitivity, which is based on red-billed Leiothrix (Leiothrix lutea), where $\omega_{D}$ is valued at 0.05 . Discriminability of any two objects is described by the "distance" $(\Delta S)$ between them in units of 'just noticeable differences' (JND). A JND value of 1 is at 


\section{Chapter 3: Crypsis and Heteroblastic Leaf Morphology}

the threshold of discrimination. Increasing JND values indicate increasing ease of distinction, whereas values less than 1 JND are unlikely to be discriminated.

To test the hypothesis that E. hookerianus juveniles are cryptically coloured from the perspective of birds against leaf litter backgrounds, I compared the chromatic and achromatic contrasts of juvenile and adult leaves against leaf litter using a general linear model. Euclidean distances in tetrahedral colour space and JND values were used as dependent variables and life stage (adult versus juvenile) was considered a fixed factor in separate analyses. Because multiple leaves were sampled from each plant, individual plants were also included in the model as random factor to account for the independence problem associated with sampling multiple leaves from the same individual.

To test whether juvenile plants show greater morphological variability than adult plants, I quantified the size and shape of 10 leaves from each of 10 juvenile and 10 adult plants, leading to an overall sample size of 100 leaves from each life history stage. I scanned each leaf electronically using a flatbed scanner and then used ImageJ software (Abramoff et al. 2004) to calculate total leaf area, circularity, length to width ratio and the dissection index, which characterises leaf lobbing (Mclellan \& Endler 1998). Next I used the technique described by Beaumont and Burns (2009) to test whether morphological variability is higher in juveniles than adults. I used multidimensional scaling (PROXSCAL) to transform these four variables into two dimensions, such that points situated close together in multivariate space represent morphologically similar leaves, while points that are widely separated represent morphologically divergent leaves. To test whether adult leaves were more variable morphologically than juvenile leaves, we conducted a t-test to compare the Euclidean distances from each leaf to the centroid of their respective ontogenetic grouping. All 


\section{Chapter 3: Crypsis and Heteroblastic Leaf Morphology}

data were log-transformed when necessary to improve normality and all analyses were conducted in R (R Development Core Team, 2010).

Quantitative comparisons between the morphology of juvenile leaves and leaf litter would provide a valuable, additional test of the hypothesis that heteroblastic changes in the morphology of E. hookerianus has evolved to deter avian browsers. However, 'leaf litter' is comprised of a variety of very different objects, including dead leaves, twigs, stones and soil. Although the measurements used to quantify leaf morphology (length, width, area, circularity and lobbing) can be made accurately on recently abscised leaves, much of the leaf litter is comprised of heavily decomposed leaves, which are often loosely stuck together in brittle mats. Many decomposed leaves are also contorted in three dimensions and have large open spaces where the lamina has rotted away from the mid-vein. These attributes of decomposing leaves renders accurate, quantitative comparisons with healthy juvenile leaves intractable. Quantifying the length, width, area and lobbing of twigs, stones and soil in a way that can be compared quantitatively with live leaves is also impossible, rendering quantitative comparisons between juvenile leaves and leaf litter impossible.

\subsection{Results}

The average reflectance curve for E. hookerianus juvenile leaves was similar to the average reflectance curve for leaf litter (Figure 3.1). Juvenile leaves had significantly lower chromatic contrasts $(0.21 \pm 0.11)$ with leaf litter than the adult leaves $(0.53 \pm 0.12)$ based on Euclidean distances in tetrahedral colour space $(\mathrm{F}=$ $65.20, \mathrm{df}=1, \mathrm{p}<0.001)$. Juvenile leaves also showed lower achromatic contrasts $(-$ $4.50 \pm 22.08)$ compared to the adult leaves $(11.17 \pm 12.20)$ based on JND values $(\mathrm{F}=$ $7.60, \mathrm{df}=1, \mathrm{p}=0.01)$. 


\section{Chapter 3: Crypsis and Heteroblastic Leaf Morphology}

Juvenile leaves were more variable in size and shape than adult leaves (Figure 3.2). Like all multivariate procedures, multi-dimensional scaling seeks to reduce a large number of variables (four in our case) into two dimensions, which inevitably results in the loss of information. An inverse goodness-of-fit measure called 'stress' can be used to determine the accuracy of the two dimensions in describing variability in the original four variables. In this instance, normalised raw stress was 0.1 , indicating that that the two dimensions generated by the MDS analysis provided an accurate representation of leaf size and shape (see Sturrock \& Rocha 2000). Juvenile leaves exhibited greater variability in their multivariate distributions than adult leaves, which instead formed a tight cluster of points in multidimensional space. Euclidean distances between each leaf and the centroid for its ontogenetic group were higher in juvenile leaves than adult leaves (t-test $=-5.93$, df $=198, \mathrm{p}=0.01$ ), indicating juvenile leaves had higher leaf shape diversity.

\subsection{Discussion}

Results are consistent with the hypothesis that heteroblasty in E. hookerianus evolved as a defensive strategy to deter moa browsing. Juvenile leaves displayed low chromatic and achromatic contrasts against litter backgrounds, which likely made them difficult for moa to locate. Results also showed that juvenile leaves were highly variable in both size and shape. Given that, leaf litter is composed of a variety of objects that are highly variable in size and shape, morphological variability may have contributed to the cryptic appearance of juvenile leaves. However, there are other plausible explanations for heteroblastic changes in morphology (see Cockayne 1912; McGlone \& Webb 1981; Godley 1985; Kelly 1994; Gamage \& Jesson 2007), so this explanation for my results remains speculative. 


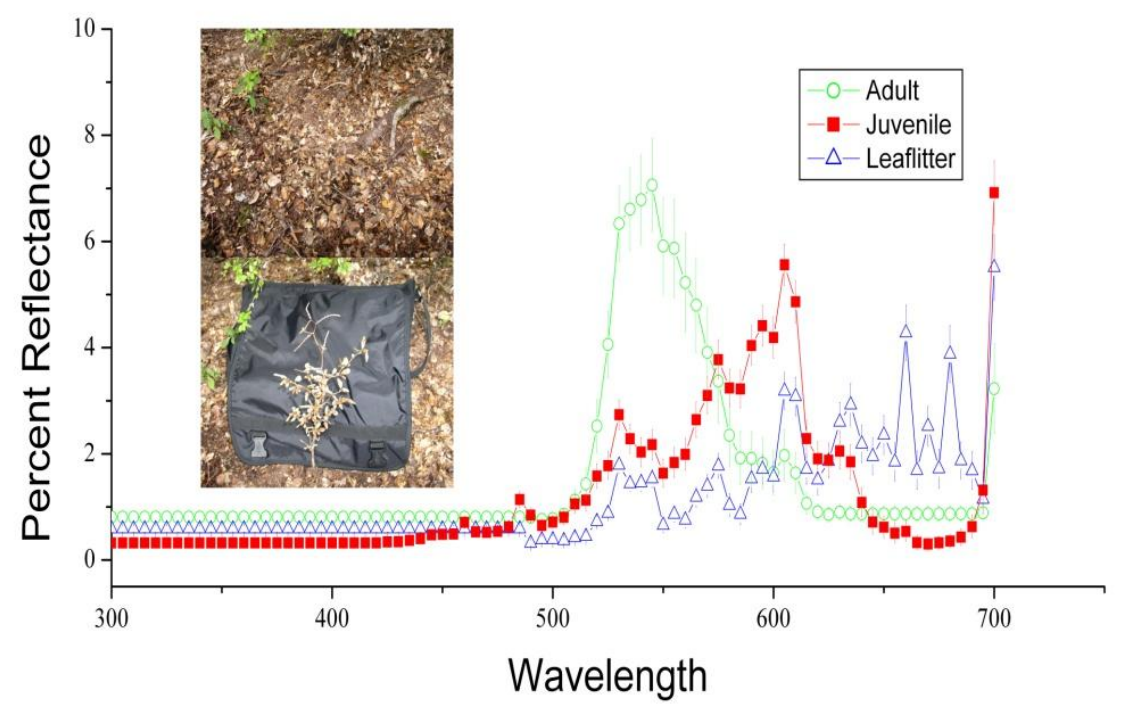

Figure 3.1: Average reflectance curves (with standard error lines) for the adult and juvenile Elaeocarpus hookerianus and the leaf litter background $(\mathrm{n}=10)$. (Inset picture) Two pictures of a single seedling taken from the same location after changes in its background. 


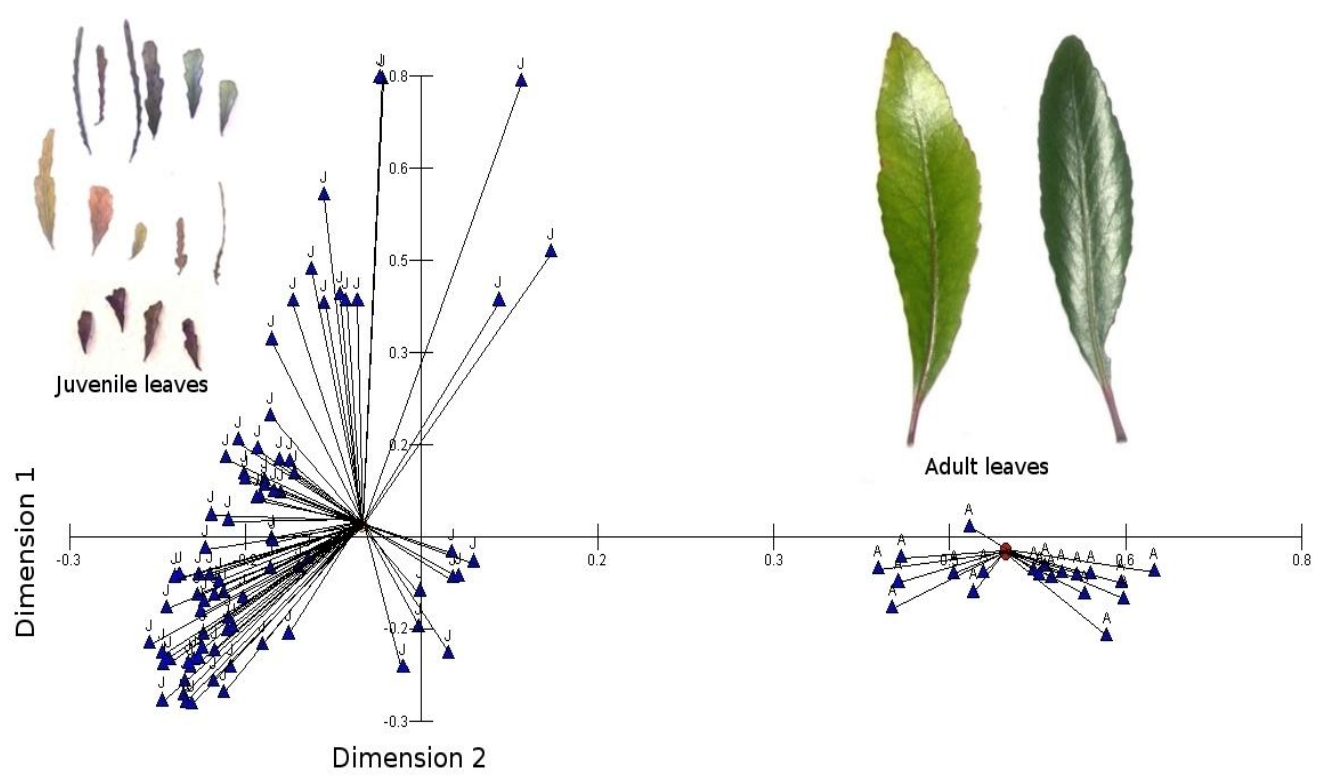

Figure 3.2: Multidimensional scaling analyses $(A=$ adult leaves, $J=$ juvenile leaves; $\mathrm{n}=100$ for each component). Lines are distances between each sample to their group centroid. Points for adult leaves appear to be less as most of them are overlapped. Inset pictures Juvenile leaves (left) have a varied leaf shape pattern compared to the typical adult leaves (right). 
There are many putative examples of reduce visual apparency in the New Zealand flora (see Burns 2010). For example, Celmisia lyalli and C. petrei appear to mimic structurally defended species of Aciphylla and Parsonia capsularis leaves look strikingly similar to dead twigs to the human eye (Brown et al. 1991). However, until recently, quantitative tests for reduced visual apparency in the New Zealand flora were lacking. Fadzly et al. (2009) recently documented that Pseudopanax crassifolius seedlings are strikingly similar to the colour of leaf litter to the avian eye, which they interpret as evidence for crypsis. However, as plants grow taller they begin to produce long, rigid leaves with spine-like projections on their margins, which would have made them difficult for toothless browsers to swallow. Each lateral spine is also associated with a patch of brightly coloured tissue, which appears to serve as an honest signal of defence (aposematism).

Similar to E. hookerianus, once $P$. crassifolius plants grow above 3 meters in height, they begin to produce leaves that are typical in size and shape. The average spectral properties of adult leaves are also ordinary and are consistent with the reflectance properties of the primary pigments involved in photosynthesis (chlorophyll $a$ and $b$ ), which have peak absorbance values above and below the peak in reflectance at $545 \mathrm{~nm}$. However, there are several notable differences between species. First, $E$. hookerianus displays a different morphological form of heteroblasty (i.e. divaricately branched juveniles) to $P$. crassifolius, which is completely unbranched until it matures (Burns \& Dawson 2009). Second, P. crassifolius goes through two very obvious morphological transitions during ontogeny (cryptic seedlings, aposematic saplings and adults that are typical in appearance), while E. hookerianus only goes through a single transition (cryptic seedlings, typical adults, see also Day et al. 1995). Lastly, E. hookerianus displays exceptional variability in the size and shape of juvenile leaves, 
which is absent from $P$. crassifolius and may further enhance their similarity in appearance to leaf litter.

Klooster et al. (2009) provide another quantitative test for plant crypsis in another part of the world. Monotropsis odorata is a non-photosynthetic plant native to Eastern North America that acquires carbon resources from mycorrhizal fungi (i.e. mycoheterotrophic). In the case of $M$. odorata, their reproductive structures are covered in bracts that strongly resemble leaf litter, effectively camouflaging stem and floral tissues from herbivory in a somewhat similar way to E. hookerianus. However, in this instance the authors experimentally removed the bracts and showed that they effective deter herbivores. The authors also suggest that colour-based defence might be particularly common in mycoheterotrophic plants, because they do not need to use photosynthetic pigments to meet their energetic needs.

Divaricate branching, high variability of leaf shapes along with low chromatic and achromatic contrasts with leaf litter may create an isodipole texture in which visual processing cannot discriminate textures which have the same power spectrum or whose statistics are identical (Julesz 1962; Caelli \& Julesz 1978a, b). In this way, E. hookerianus juveniles may have been difficult for browsing moa to distinguish. However, crypsis is unlikely to be a fully effective defensive strategy on its own, as many animals including birds can learn to locate highly cryptic prey items. For instance, poultry chicks can be trained to pick up odd from even isodipole textures provided there is high enough chromatic and achromatic contrast (Osorio et al. 1999; Jones \& Osorio 2004).

Although these results are consistent with the moa-browsing hypothesis, other causal factors cannot be ruled out. The unique architecture of juvenile E. hookerianus could be a physiological adaptation to environmental conditions. Day and Gould (1997) 
suggest that the unusual morphology of E. hookerianus juveniles could be a strategy to exploit spatial variation in environmental conditions. Divaricate branching may help plants 'explore' new light environments both laterally and vertically, in addition to 'exploiting' previously sequestered regions within their canopy (see also Day et al. 1997). Variable leaf shapes may also have a physiological explanation. Linearlanceolate type leaves, although costly to be produce, could provide greater energetic returns to the plant if they provide better light penetration into the interior of plants, facilitating greater gas and heat exchange in the shorter, wider, obovate type leaves below (see Horn 1971; Givnish 1986; Kelly 1994).

Because moa are now extinct, the effectiveness of leaf colours in deterring moa herbivory cannot be tested directly. However, future work could be conducted on extant ratites such as emu as a surrogate for moa. A similar experimental approach to Bond et al. (2004) could be employed by manipulating leaf and background colours to test whether ratites have difficulties locating juvenile leaves that match their backgrounds, as their eye physiology suggests. These and other quantitative tests of reduced visual apparency in plants will help to establish whether crypsis is a common strategy of plant defence. 


\section{Chapter 4}




\title{
Are fruit colours adaptively significant? A test of
}

\section{two hypotheses}

\author{
(Under major \\ corrections at \\ Population Ecology)
}




\subsection{Abstract}

Phenotypes of fruits are often hypothesized to be affected by frugivores selection. I tested two hypotheses concerning frugivore-fruit interaction from the perspective of fruit colours. I measured the spectral properties of 26 fruits and associated leaves of plants from two main islands in New Zealand. Visual observations were also made on birds that feed on the fruits. I tested the (I) fruit-foliage hypothesis where fruit colours are assumed to be evolutionary constrained by own leaf colour in order to maximise colour contrast and fruit conspicousness. I ran a null model analysis comparing fruit colour contrast using avian eye model. I then tested the (II) frugivore specificity hypothesis where specific fruit colours are thought to be connected with a specific bird frugivore. I performed a regression on the number of bird visits against the fruit colour in tetrahedral colour space based on avian eye calculation using Mantel's test. My result shows that fruit colours are not constrained by its own leaf colours. There is also no relation or pattern suggesting a linkage between a specific fruit colour to a specific bird visitors. I suggest that although fruit colour is one of the most highly discussed components, it is not the most important single deciding factor in frugivore fruit selection. 


\subsection{Introduction}

Plants produce fleshy fruits that are consumed by animals that subsequently act as seed vectors. The size, shape and colour of fruits vary enormously among plant species and a diverse array of animals, including fish, mammals, reptiles, insects and birds include fleshy-fruits in their diets. Fruit phenotypes have long been hypothesised to results from selection by different types of frugivores. However, support for this hypothesis is equivocal.

Fruits and flowers are often brightly coloured to attract frugivores and pollinators (see van der Pijl 1972; Janson 1983; Willson et al. 1990; Kelber 1996; Burns \& Dalen 2002; Raine \& Chittka 2007; Pohl et al. 2008). Animal colour vision capability has been discovered for more than 100 years (see Lubbock, 1881); with most studies focusing on the floral colour signal and insect pollinators; predominantly concerning bees (Lunau \& Maier 1995; Chittka \& Wells 2004; Raine \& Chittka 2005; Raine \& Chittka 2007). While initially colour remains an abstract component, the advancement of animal eye photoreceptor sensitivities has enabled colour to be quantitatively assessed based on the animal's eye receptor capabilities (Backhaus 1991; Chittka 1992, Vorobyev et al. 1998b Hart et al. 2000; Hart 2001; Endler \& Mielke 2005).

Here, I test two hypotheses that predict the colours of fleshy fruits result from selection by seed dispersing birds based on the avian eye receptor capabilities. First, I tested the fruit-foliage contrast hypothesis, which predicts that fruits colours are more conspicuous when displayed against their own leaves relative to leaves of 
other species. For example, Burns and Dalen (2002) found that the colours of fruits in coastal British Columbia, Canada vary through time according to the seasonal changes in the colour of foliage. Similarly, Lee et al. (1994) found that the colour of New Zealand Coprosma varies interspecifically with leaf size. Larger-leaved species at lower altitudes tend to have red fruits, perhaps to maximise their conspicuousness against green backgrounds. More recently, Burns et al. (2009a) found little support for the fruit-foliage contrast hypothesis in five geographic locales scattered across the globe.

Fruit colouration is the most frequently studied plant signals (Schaefer et al. 2004a; Voigt et al. 2004; Lomascolo et al. 2008; Lomascolo \& Schaefer 2010). While some studies have shown that frugivores display consistent colour preferences (Burns \& Dalen 2002; Burns 2005b; Lomascolo et al. 2008, Lomascolo \& Schaefer 2010), others have documented variable fruit colour preferences (Dominy \& Lucas 2001; Schmidt et al. 2004). Most studies of fruit colours preference test whether one or a small number of frugivore species prefer certain fruit colours (Whitney \& Rudgers 2009). However, the question of why fleshy-fruits come in a wide assortment of colours is still open for discusion (Whitney \& Lister 2004; Whitney 2005). Selection on fruit colour could drive a diversification in fruit colours. For example, if a plant species had a wide distribution, overlapping two distinct ranges of dispersers, and had variance in the colour genes of fruit production, then different colour preferences (or requirements) of the disperser animals could promote fruit colour diversification. Strong and opposing selection pressures from the dispersers would favour different fruit colours across species 
range. Eventually, two emergent species would form with a low fitness hybrid zone (where mating of the two species would produce a fruit colour not favoured by either disperser) between the species reinforcing the diversification. Selection pressures such as these could produce a diversification in fruit colours. The second hypothesis I tested to explain fruit colour diversity is refered as the frugivore specificity hypothesis; where different frugivorous bird species is hypothesized to select different colours. A new method to approach the hypothesis is possible due to availability of information on animal eye photoreceptor sensitivities. I performed a regression analysis between colour (based on bird eye cone excitation values) and number of bird visits.

I measured the spectral properties of fruits and leaves from 26 species of plants from two main islands (North and South) in New Zealand. Observations were also made on the number of bird species that feed on the fruits. I conducted spectrometric analyses based on the avian eye model to assess whether 1) leaves constrain the colour of fleshy fruits based on the fruit-foliage hypothesis, 2) specific fruit colours are coupled with specific birds?

\subsection{Materials and Method}

\subsubsection{Fruit colour analyses}

A total of 26 species of fleshy-fruited plants were sampled from two study sites in New Zealand. Nine species were sampled from Nelson Lake National Park, South Island $\left(41^{\circ} 81^{\prime} \mathrm{S}, 172^{\circ} 85^{\prime} \mathrm{E}\right)$ and 17 species were sampled from Otari-Wilton ${ }^{\text {ee }}$ Bush, Wellington, North Island $\left(41^{\circ} 15^{\prime} \mathrm{S}, 174^{\circ} 45^{\prime} \mathrm{E}\right)$. Nelson lakes receives 
approximately $1000 \mathrm{~mm}$ of rainfall and frosts and snow are common in the winter. The vegetation consists predominantly of Nothofagus trees. There are high diversity of small trees and shrubs, mostly dispersed by birds. Most of the forest area remains undisturbed by human activities. Otari-Wilton's bush receives annual rainfall of 1250 $\mathrm{mm}$. Most of the forest area consists of mature and regenerating coniferbroadleaf forest (see Burns \& Dawson 2005). The plants were the most common fleshy-fruited species at either site and were included on the basis that they were encountered during foraging observations of fruit eating birds. Five fruit and leaf sample were taken from each of five individual plants from all species. For each fruit and leaf collected, five spectrometric readings were taken and averaged prior to analyses.

Spectral analysis of each fruit and leaf was conducted using an USB OceanOptics 2000 spectroradiometer and Xenon Pulse X2 lamp (OceanOptics) was used as light source. Reflection was measured as the proportion of a Diffuse Reflectance Standard (white standard). The fiber optics probe was mounted inside a matte black plastic tube to exclude biases by ambient light. The distance between the probe and the leaf was set at one centimeter. The angle of illumination and reflection was fixed at $45^{0}$ to minimize the object's glare. Spectra was processed with SpectraSuite software and calculated in $5 \mathrm{~nm}$ intervals from 300 to $700 \mathrm{~nm}$. Irradiance was measured by using a cosine corrected sensor and a D65 light (normal daylight) bulb was used as a reference.

I used an eye model based on the spectral sensitivities and receptor noise of the four cone types possessed by birds (u, s, m and l) to quantify fruit and leaf colours as they would appear to a typical avian frugivore. I quantified the appearance 
of leaves using the contrast comparison method, which follows simple colour pattern measures related to photon capture (Vorobyev et al. 1998b; Endler \& Mielke 2005). A detailed explanation of the mathematical formulae are given elsewhere (Osorio \& Vorobyev 1996; Vorobyev \& Osorio 1998a), but the model is sufficient to predict the discriminability of any two of spectra, provided only that receptor spectral sensitivities and noise can be estimated. The calculation provides photon capture values for each type of cone receptors in the bird's eye. The receptor spectral sensitivity values were obtained from Endler and Mielke (2005).

Colour is defined as a point in a perceptual space whose co-ordinate axes represent quantum catches of receptors (Poirson \& Wandell 1990). An object's appearance is a function of two components, namely chromatic (wavelengths) and achromatic (brightness) contrasts between an object and its spectral background. I used Endler and Mielke's (2005) method to characterise the chromatic contrasts. First, the output of each the four cones (u, s, m and l) is transformed into points in tetrahedral space with a height of 1 , resulting in $x, y$ and $z$ Cartesian coordinates in 3 dimensional space (Aitchison 2003).

$$
x=\frac{1-2 s-m-u}{2} \sqrt{\frac{3}{2}} \quad y=\frac{-1+3 m+u}{2 \sqrt{2}} \quad z=u-\frac{1}{4}
$$

The Euclidean distance between any two points in tetrahedral colour space (C) represents the difference between the between the chromatic component of their appearance. 


$$
C=\sqrt{\left(x_{a}-x_{b}\right)^{2}+\left(y_{a}-y_{b}\right)^{2}+\left(z_{a}-z_{b}\right)^{2}}
$$

For example, a large Euclidean distance between points representing a fruit and its corresponding leaf background would indicate a chromatically conspicuous fruit display.

Achromatic (brightness) contrasts were calculated in a different way because the exact working nature of achromatic signals in birds is still poorly understood (Campenhausen \& Kirschfeld 1998; Osorio et al. 1999; Hart 2001). Some birds have double cones with broad spectral sensitivities that overlap with both long and medium wavelength-sensitive cones, and facilitate achromatic signal processing (non-colour based tasks) (Hart et al. 2000; Jones \& Osorio 2004; Cuthill 2006). Achromatic $\left(\Delta f_{i}\right)$ contrasts were calculated as:

$$
\Delta f_{i}=\left|\Delta f_{i} / \omega_{D}\right|
$$

$\Delta f_{i}$ represents the difference between two objects in their capacity to stimulate receptor mechanisms (refer to Osorio \& Vorobyev 1996; Vorobyev et al. 1998b) and $\omega_{D}$ represents the value of double cones. Because $\omega_{D}$ is the same for all targets, it does not affect relative achromatic contrasts. The only available double cone receptor data sensitivity is based on Leiothrix lutea and the $\omega_{\mathrm{D}}$ is valued at 0.05 . Discriminability of any two colours is described by the "distance", $\Delta f_{i}$ , between them in JND units (“just noticeable differences"). This method 
produces negative values, which simply indicates that one object is darker than the other and its sign depends on which reflectance data set is entered first in the calculation. For statistical analysis, all the values were transformed into absolute values. All eye model calculations and statistical analyses were conducted in $\mathrm{R}$ 2.10.1 (R Development Core Team 2010).

\subsubsection{Frugivore sampling}

Observations of birds foraging for fruits were conducted using the protocol described by Burns and Lake (2009b); Burns (2006a). Over the course of three fruiting seasons on the North Island (November to June from 2006-2008) and two fruiting seasons on the South Island (March to May from 2007-2008) I walked a series of trails and observed birds foraging for fruits. I classified a "visit" when a bird approached a plant and consumed at least one fruit. Observations were halted after each sighting to avoid repetition, and continued again 10 meters down the track on different trees. Each observation session was conducted in the morning from 8.00 a.m until 11.00 a.m. There were three trails selected at Nelson Lakes (two hiking trails, one leading up to St Arnaud Mountain and the other to Mount Roberts; one walking trail along Lake Rotoiti). Four trails were selectted at Otari- Wilton's Bush area (one walking trail around the native garden area and the remaining three are within the hiking trail inside the bush area). More than 80 hours of observation were conducted in the South Island and more than 100 hours for North Island. The fruiting season on the North Island (November-June) is more protracted than the South Island (March-May) (Burns \& Lake. 2009b), requiring a longer 
observation period on the North Island to adequately characterise bird-fruit interactions.

\subsubsection{Statistical analysis}

First, I examined fruit colour variation by comparing the chromatic and achromatic values between fruits gathered from North and South Island. The values were compared statistically using a t-test. Second, to test the fruit-foliage hypothesis; I compared the chromatic and achromatic contrast of a fruit matched with its own leaf (observed value) against the average contrast value from the same fruit matched with the leaves of other plants excluding its own (expected value). Contrary to Burns et al. (2009a) methods, I suggest that the null model value should be from the comparison of a specific fruit (for example fruit $a$ ) against the leaf reflectance of all other fruits (excluding fruit $a$ 's leaf reflectance). The values were compared statistically using ANOVA with the observed and expected values designated as the dependent variables. To test for geographical factor, I set the locality (North or South) as the random factor. Since observed value is a single value compared against the expected values which are derived from an average (calculated from (n-1) number of plants), there might be variability in the expected value data spread. To resolve this issue, I calculated $z$ score values from each of the expected results. I then performed one sample t test on the $z$ score values with the test value set at 0 . A no significant result would show that data variability has no effect on the overall results. The test was performed on both chromatic and achromatic comparison for North and South Island. 
Third, to test for the frugivore specificity hypothesis, I composed two matrices (for North and South Island) based on the number of visitation by a bird species to a specific plant species. The values were first transformed (using square root transformation) to conform to data normality and homogeneity. Since certain birds only visit certain plants for each island group, my data matrix is prone to heteroscedasticity. I experimented with several data transformation methods. As the results do not change qualitatively, I only report the results of the analysis based on the square root transformation method. I then conducted PROXSCAL multidimensional scaling (MDS) following Beaumont and Burns (2009). MDS analysis was conducted separately for North and South Island. The corresponding information is then transformed into two dimensions. Each data point represents a plant from both islands that were plotted in a two dimensional area. Points situated close together represent fruits that might share the same bird visitors while widely separated points represent a totally different type of bird visitors. I then proceeded to calculate the Euclidean distance between each of the points. I converted the fruit reflectance values into coordinates in tetrahedral colour space (see Endler \& Mielke 2005). Now each fruit colour is represented by $\mathrm{x}, \mathrm{y}$ and $\mathrm{z}$ coordinates in tetrahedral colour space. Points that are situated close represents fruits that are identical in colour, while widely separated points represent different coloured fruits. Similar to the previous method, I then calculated the Euclidean distance between each one of the points. I then performed Mantel's test on the distance values obtained from the MDS against the distance values obtained from the tetrahedral colour space. Both groups of values were first transformed into matrices before performing Mantel's test. Mantel's (1967) test is an approach that overcomes some of the problems 
inherent in explaining species-environment relationships. The calculation utilizes regressions in which the variables are themselves distance or dissimilarity matrices summarizing pair wise similarities among sample locations. Mantel's test was conducted using R 2.10.1 (R Development Core Team 2008) (with additional “ecodist" package) and each permutation is repeated for 1000 times. Mantel's test was conducted separately for both North and South Island. All the values used in each comparison were tested for homogeneity and normality. If the values did not fulfil the parametric test requirement; the data were then normalized either using $(\log (y+1))$ or square root transformation. All the calculations were performed using R 2.10.1 and SPSS 16.

\subsection{Results}

On the North Island a total of 12 species of birds were recorded and six species for South Island. A total number of 1253 observations were recorded for the North Island. Relative frequency of the 12 species of birds recorded in North Island are: waxeye Zosterops lateralis, $\mathrm{n}=592$; European blackbird Turdus merula, $\mathrm{n}=235 ;$ tui Prosthemadera novaeseelandiae, $\mathrm{n}=181$; stitchbird Notiomystis cincta, $\mathrm{n}=92$; whitehead Mohua albicilla, $\mathrm{n}=44$; bellbird Anthornis melanura, $\mathrm{n}=22$; kaka Nestor meridionalis, $\mathrm{n}=16$; saddleback Philesturnus carunculatus, $\mathrm{n}=62$; European Starling, $\mathrm{n}=$ Sturnus vulgaris; European songthrush Turdus philomelos; Malard Anas platyrhynchos, $\mathrm{n}$ $=1$; Kereru Hemiphaga novaeseelandiae, $\mathrm{n}=3$. A total number of 158 observations were recorded for the South Island. Relative frequency of the nine species of birds recorded in South Island are: waxeye Zosterops lateralis, $\mathrm{n}$ 
= 126; European blackbird Turdus merula, $\mathrm{n}$ = 18; brown creeper Mohиоиа novaeseelandiae, $\mathrm{n}=4$; European songthrush Turdus philomelos, $\mathrm{n}=3$; bellbird Anthornis melanura, $\mathrm{n}=5$, tui Prosthemadera novaeseelandiae, $\mathrm{n}=2$. A total of 17 species of plant from 14 family were sampled in North Island and nine species from seven families in the South Island (refer to table 4.1).

There was no significant difference in the colour (chromatic), between North island $($ mean $=0.56 \pm 0.20)$ and South island fruits (mean $=0.47 \pm 0.47)(\mathrm{t}$-test $=$ $1.174, \mathrm{df}=24, \mathrm{p}=0.25)$. The results were also similar for achromatic contrasts between North island $($ mean $=23.28 \pm 12.67)$ and South island fruits $($ mean $=25.22$ $\pm 21.08)(\mathrm{t}$-test $=-0.30, \mathrm{df}=24, \mathrm{p}=0.77)$. Figure 4.1 shows the average percent reflectance between fruits and leaves gathered from North and South Island.

There was no support for the fruit foliage contrast hypothesis based on my results (Figure $4.2 \mathrm{a} \& 4.2 \mathrm{~b}$ ). There was no significant difference between the observed value and the expected value for chromatic contrast (ANOVA F $=7.412$, df $=1, p=0.224)$. The result applies to both North and South Island based on the locality interaction (ANOVA $\mathrm{F}=0.020$, df $=1, \mathrm{p}=0.887$ ). Further supplemental $\mathrm{z}$ score distribution analysis shows no data variability effect for North $(\mathrm{t}=0.259, \mathrm{df}=$ 16, $\mathrm{p}=0.799)$ and South Island $(\mathrm{t}=-0.545, \mathrm{df}=8, \mathrm{p}=0.601)$. Achromatic comparison yields the same conclusion. There was no significant difference between the observed value and the expected value for achromatic contrast (ANOVA $\mathrm{F}=0.692$, df $=1, \mathrm{p}=0.558$ ). There was also no significant difference in the locality interaction (ANOVA $\mathrm{F}=3.674$, $\mathrm{df}=1, \mathrm{p}=0.070$ ). $\mathrm{z}$ score distribution analysis also shows no effect of data variability for North $(\mathrm{t}=1.533$, $\mathrm{df}=16, \mathrm{p}=$ $0.145)$ and South Island $(\mathrm{t}=-1.789, \mathrm{df}=8, \mathrm{p}=0.111)$. 
Based on the MDS analysis, the plants are distributed across the two dimensions with some degree of clumping in some species and scattered data points based on geographical location (Figure 4.3). Since MDS reduces the information into two dimensions, this inevitably results in the lost of some information. An inverse goodness-of-fit stress measure is needed to determine the accuracy of the two dimensions. Based on the Normalised Raw Stress value of 0.001 for both North and South Island MDS, plot dimension appear accurate. Sturrock and Rocha (2000) reported that a stress value 0.1 and under is a good indication of plot dimension accuracy. Figure 4.4 shows the fruit colour distribution in a tetrahedral colour space. Mantel's test correlates distance value within these two graphs (Figure 4.3 \& Figure 4.4). Simulated correlation results for North island (Mantelr $=0.025, \mathrm{p}=0.144)$ and South island, $($ Mantelr $=0.101, \mathrm{p}=0.963)$ shows that I could not reject the null hypothesis that, the MDS distances and the tetrahedral distances are unrelated at alpha $=0.05$ (Figure 4.5). This means that there is no significant support for the frugivore specificity hypothesis. 
Table 4.1: Full list of plants (with abbreviations used for other figures), sampled location, and the chromatic and achromatic contrasts (observed values) along with the total number of bird visits. (Values in brackets refer to standard error values).

\begin{tabular}{|c|c|c|c|c|c|}
\hline \multirow[t]{2}{*}{ Name } & \multirow[t]{2}{*}{ Abbreviation } & \multirow[t]{2}{*}{$\begin{array}{l}\text { Plant } \\
\text { location }\end{array}$} & $\begin{array}{l}\text { Chromatic } \\
\text { contrast } \\
(\mathrm{SE}= \pm 0.19)\end{array}$ & $\begin{array}{l}\text { Achromatic } \\
\text { contrast } \\
(\mathrm{SE}= \pm 15.71)\end{array}$ & \multirow[t]{2}{*}{$\begin{array}{l}\text { Total number } \\
\text { of bird visits }\end{array}$} \\
\hline & & & $\begin{array}{l}\text { Euclidean } \\
\text { distance }\end{array}$ & JND & \\
\hline $\begin{array}{l}\text { Coprosma } \\
\text { grandifolia }\end{array}$ & C.g & North Island & 0.61 & 12.5 & 118 \\
\hline $\begin{array}{l}\text { Melicytus } \\
\text { ramiflorus }\end{array}$ & M.r & North Island & 0.6 & -27.98 & 347 \\
\hline Solanum aviculare & S.a & North Island & 0.31 & 14.55 & 5 \\
\hline Coprosma robusta & C.r & North Island & 0.75 & 27.34 & 218 \\
\hline Pratia angulata & P.an & North Island & 0.61 & -33.41 & 1 \\
\hline Aristottelia serrata & A.s & North Island & 0.41 & -23.53 & 13 \\
\hline Coprosma repens & C.re & North Island & 0.77 & 41.47 & 2 \\
\hline $\begin{array}{l}\text { Podocarpus } \\
\text { acutifolius }\end{array}$ & P.ac & North Island & 0.71 & -20.32 & 25 \\
\hline $\begin{array}{c}\text { Passiflora } \\
\text { tetrandra }\end{array}$ & P.t & North Island & 0.99 & 49.09 & 3 \\
\hline Coriaria arborea & C.a & North Island & 0.35 & 6.09 & 27 \\
\hline $\begin{array}{c}\text { Muehlenbeckia } \\
\text { australis }\end{array}$ & M.a & North Island & 0.32 & 22.43 & 43 \\
\hline
\end{tabular}




\begin{tabular}{|c|c|c|c|c|c|}
\hline Schlefera digitata & S.d & North Island & 0.35 & -14.77 & 162 \\
\hline $\begin{array}{c}\text { Pseudopanax } \\
\text { arboreus }\end{array}$ & P.a & North Island & 0.46 & -13.71 & 137 \\
\hline Hedycrya arboreus & H.a & North Island & 0.71 & 30.78 & 16 \\
\hline Myoporum laetum & M.1 & North Island & 0.46 & 12.96 & 55 \\
\hline $\begin{array}{l}\text { Ripogonum } \\
\text { scandens }\end{array}$ & R.s & North Island & 0.75 & -5.06 & 4 \\
\hline $\begin{array}{l}\text { Pittosporum } \\
\text { euginoides }\end{array}$ & P.e & North Island & 0.35 & -39.77 & 77 \\
\hline Griselinia littoralis & G.1 & South Island & 0.44 & -45.99 & 5 \\
\hline $\begin{array}{l}\text { Coprosma } \\
\text { linariifolia }\end{array}$ & C.1 & South Island & 0.38 & 32.92 & 6 \\
\hline $\begin{array}{l}\text { Carpodetus } \\
\text { serratus }\end{array}$ & C.s & South Island & 0.52 & -16.94 & 17 \\
\hline $\begin{array}{c}\text { Coprosma } \\
\text { foetidissima }\end{array}$ & C.f & South Island & 0.56 & 2.09 & 13 \\
\hline Leucopogon fraseri & L.f & South Island & 0.29 & -0.34 & 11 \\
\hline $\begin{array}{l}\text { Pseudopanax } \\
\text { crassifolius }\end{array}$ & P.c & South Island & 0.35 & -0.93 & 81 \\
\hline $\begin{array}{l}\text { Elaocarrpus } \\
\text { hookerianus }\end{array}$ & E.h & South Island & 0.55 & -32.01 & 5 \\
\hline $\begin{array}{l}\text { Halocarpus } \\
\text { bidwillii }\end{array}$ & H.b & South Island & 0.38 & 57.35 & 4 \\
\hline $\begin{array}{l}\text { Pseudopanax } \\
\text { colensoi }\end{array}$ & P.co & South Island & 0.76 & -38.47 & 16 \\
\hline
\end{tabular}




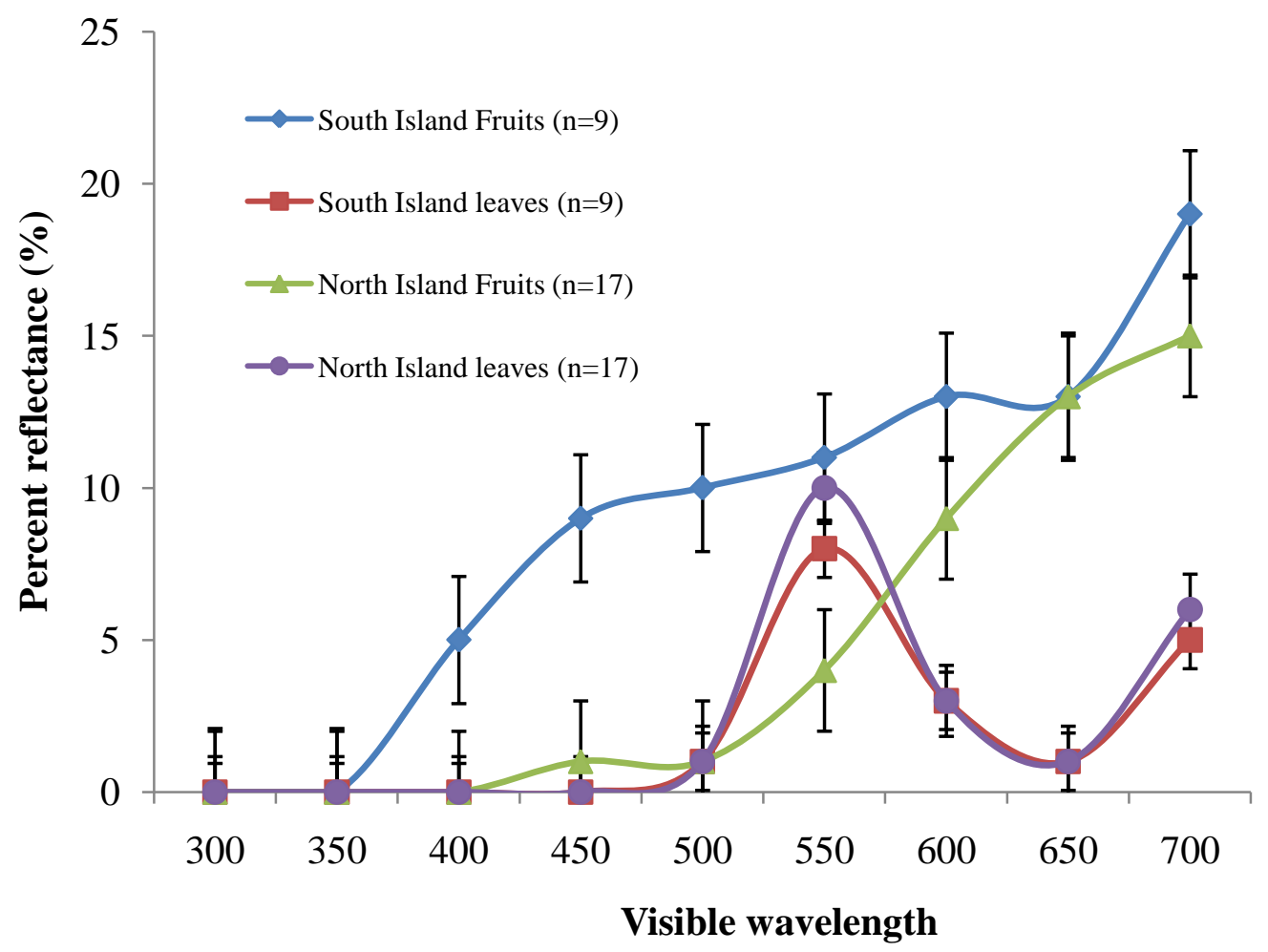

Figure 4.1: The average percent reflectance curve comparison between fruits and leaves gathered from North and South Island. Vertical lines refer to standard error. 

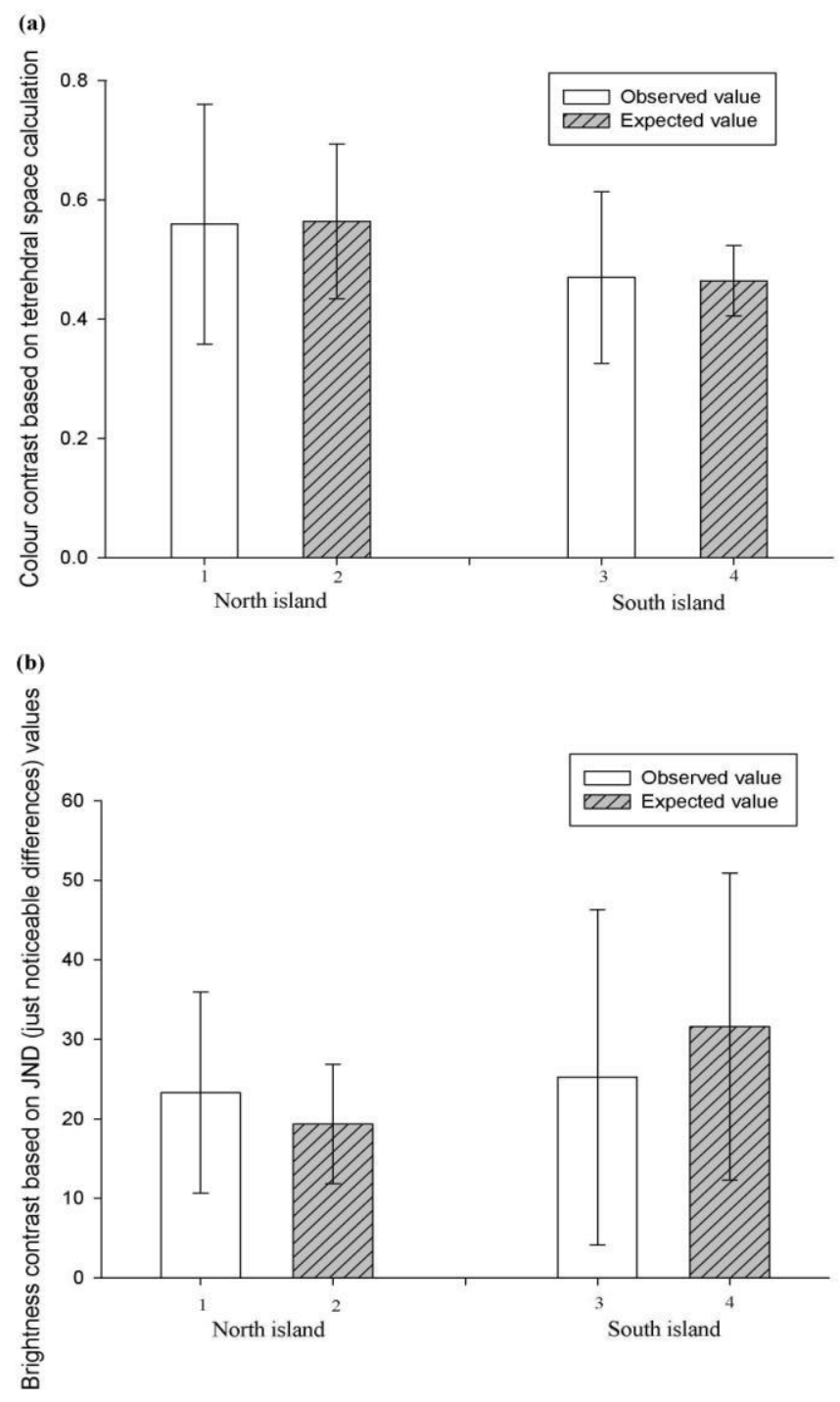

Figure 4.2: The observed and expected values of fruit colour contrast. (a) Chromatic contrast refers to the Euclidean distance in tetrahedral colour space. $1=($ mean $=0.56$ $\pm 0.20), 2=($ mean $=0.56 \pm 0.13), 3=($ mean $=0.47 \pm 0.14), 4=($ mean $=0.47 \pm$ 0.06), (b) Achromatic contrast refers to the JND values from the avian eye model calculation. $1=($ mean $=23.27 \pm 12.66), 2=($ mean $=19.36 \pm 7.51), 3=($ mean $=$ $25.22 \pm 21.08), 4=($ mean $=31.59 \pm 19.30)$. 


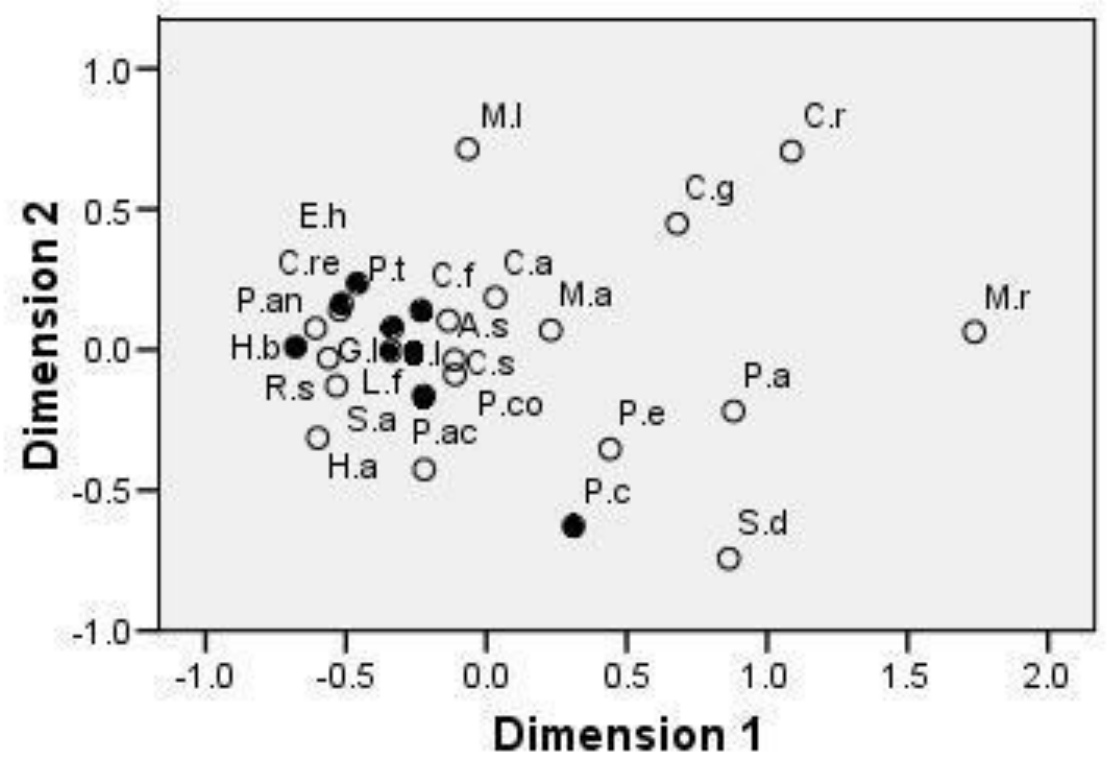

Figure 4.3: Multidimensional scaling of plant species based on bird visitation. (Refer to Table 1 for abbreviation description, black circles represent South Island plants and open circles represents North Island plants). 


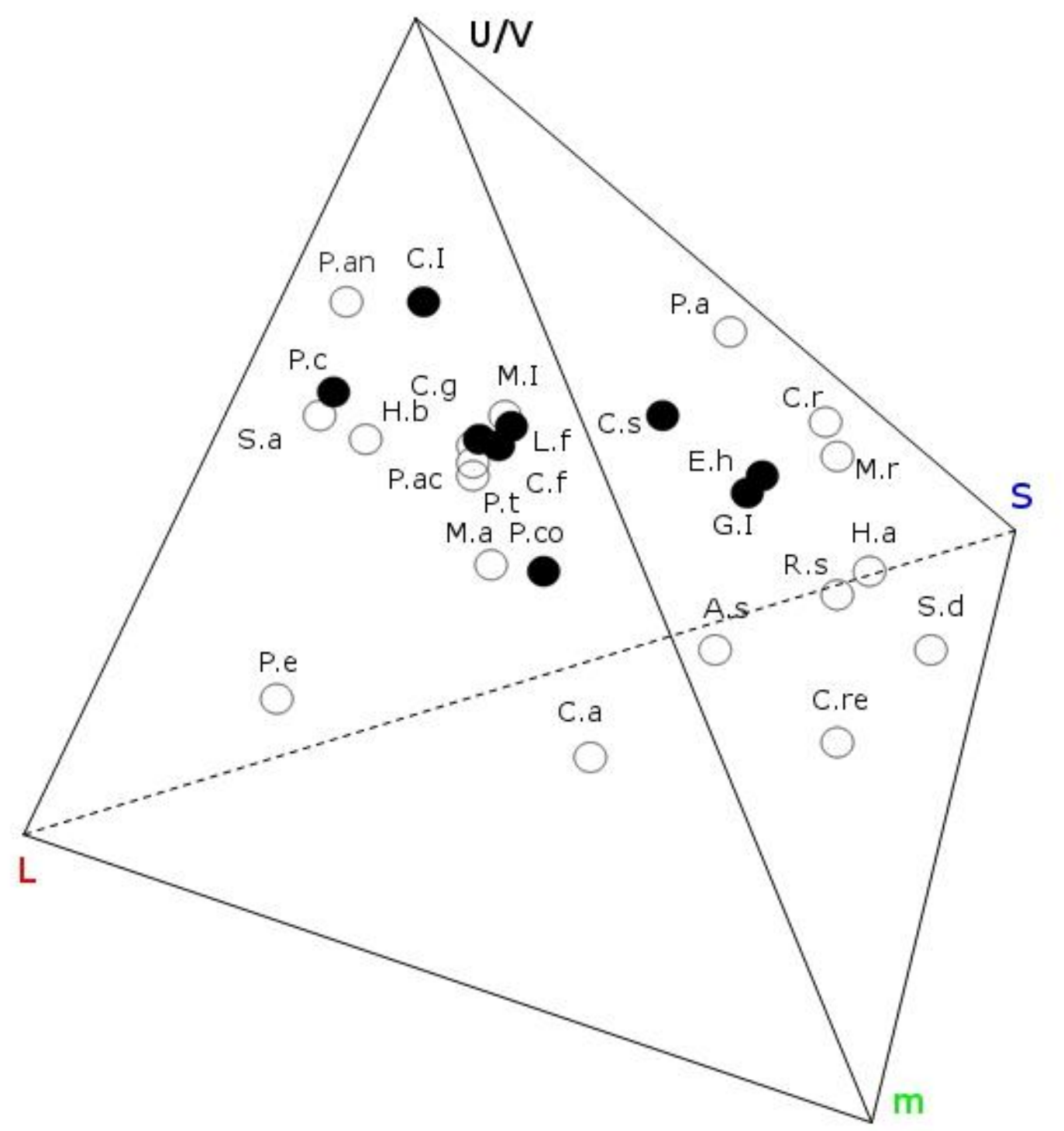

Figure 4.4: A tetrahedral colour space representation of the fruit colours. Each point represents how the specific colour of a fruit is processed by the bird eye receptors. (Refer to Table 1 for abbreviation description, black circles represent South Island plants and open circles represents North Island plants). 


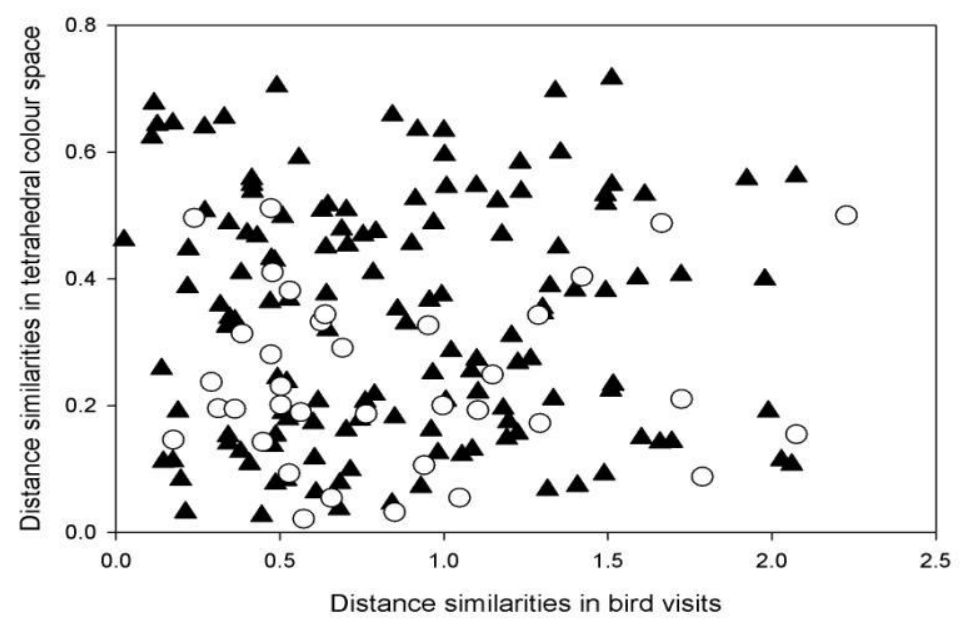

Figure 4.5: Mantel's test correlation results for North Island (dark triangles) and South Island (open circles) between the distances from the multidimensional scaling based on bird visits and distances in the tetrahedral colour space. 


\subsection{Discussion}

North and South island fruit colours were perceived similarly by birds both chromatically and achromatically. Although the sample size is relatively small compared to Burns et al. (2009a), both results indicate that colour foliage contrasts do not differ based on geographical location. My results also shows no support for both fruit-foliage and frugivore specificity hypothesis. The latter tested at a very fine level of specificity.

My result suggested no evidence for fruit-foliage hypothesis following Burns et al. (2009a). Although the Burns et al. (2009a) hypothesis was generated based on the avian eye model, I detected a slight inaccuracy in their null model calculations. Burns et al. (2009a) selected random points inside the tetrahedral space for comparison between fruit colour and leaf colour, and calculated the distance between them. This procedure was then iterated for 1000 times using Mathematica. This method only generates averages of distances between points inside the tetrahedral, and does not generate an accurate null model value. My null model provides a more precise calculation and possible data variability issue were addressed accordingly. Furthermore, there are two components involved in colour vision which are chromatic/colours and achromatic/brightness; the latter component was not included in Burns et al. (2009a).

A possible explanation to reject the fruit-foliage hypothesis is that both leaf and fruit colours do not remain constant throughout a plants' life stage. Fruit and leaf colours changes throughout different season (Sanger 1971; Lev-Yadun \& Gould 2007; Archetti 2009b), different environmental stresses (Lev-Yadun et al. 2007; Archetti 2009a) and changes in chemical content (Schaefer \& Schmidt 2004b). 
Therefore it is quite impossible for a fruit colour to remain exclusively significant only to its own leaf colour. Another possibility is that the conspicuousness of fruit colours is not targeted exclusively for avian vision (Schaefer et al. 2007). Birds are known to select fruits based on content availability rather than conspicuousness (Schaefer et al. 2003a;b).

My results shows that specific birds are not attracted to specific fruit colours. Burns and Lake (2009b) suggest that introduced European birds, because of their limited evolutionary history with New Zealand plants, might exhibit little eslection for fruit colours. Another possibility could be from focusing solely on fruit colours. Although colour is an important cue used by frugivores to find fruits, there are other important cues that could have been overlooked such as fruit density, odours and texture (Dominy \& Lucas 2001). Sanitjan and Chen (2009) found that fruit colour and fruit size of Ficus did not significantly influence the number of bird species, whereas habitat context appeared to influence the composition of visiting birds. Similarly, plant-frugivore analysis at major river basins across Europe found that avian frugivore richness was more dependent on environmental factors than on fleshy fruited plant species richness (Marquez et al. 2004). Another example of habitat specific effect is the distribution of polymorphic colour fruits of Alepis flavida in New Zealand. The mistletoes were mostly affected by habitat differences than avian frugivory (Bach \& Kelly 2004a; Bach \& Kelly 2004b). Different levels of available light (caused by the thickness of canopy cover) between habitats have also influenced frugivore selection, rather than colour preferences (Cazetta et al. 2007). Most fruit-eating bird species do not specialize on the fruits of a particular plant species (Kissling et al. 2007). Instead, 
frugivorous bird species often treat fleshy fruited plant species as interchangeable (Zamora 2000; Herrera 2002). Plants with similar fruits might be used by a similar variety of frugivores, and subsequently might have similar distributions of dispersed seed (Pizo, 2002). Another similar example is the study generalization in pollination system. Evolutionary biologists mostly prefered extreme specialization in pollination system, regarding generalization as a rarity. Waser et al (1996), however argued that generalization-the use of several plant species by a pollinator and of several pollinator species by a plant-appears to be the rule rather than the exception. This indicates that narrow specialization rarely occurs and could not be expected on theoretical grounds.

Other fruit traits that might be equally important for frugivore selection are fruit size, fruit protection, fruit phenology, seed size, seed number and nutritional aspect of the fruits (Herrera 1982; ; Willson \& Thompson 1982; Janson 1983; Knight \& Siegfried 1983; Wheelwright \& Janson 1985; Gautierhion et al. 1985; Willson et al. 1989a; Willson et al. 1990; Schaefer et al. 2003b; Chen et al. 2004). Conspicuousness of fruit colours is not optimized specifically to bird vision, and there are other suggested fruit dispersers in New Zealand such as bats, birds, lizards and weta. Each of these taxa sees and has different vision capabilities and eye structure (Lord et al. 2001; Lord et al. 2002; Wotton 2002; Burns 2006b; Duthie et al. 2006). There is evidence that fruit colour can explain differences in frugivore assemblage, at least interguild comparison (e.g. when comparing primates and birds; (Voigt et al. 2004; Lomascolo \& Schaefer 2010). Evidence for specific animal species to specific fruit colour analysis is almost unknown. 
The preference analysis I performed are based on the avian eye model, therefore providing a more accurate result than previous studies. I acknowledged that my correlation analysis only involves the chromatic component, which allows me to calculate distances in tetrahedral colour space whereas the achromatic component could not allow me to emulate the same procedure. There is a possibility of spatio-temporal scale effect, where larger scale dataset and different taxonomic comparison could produce different results (Burns 2004). However, based on my results; where I lacked quantity, I make up with quality and finesse. With a refined null model calculation and inclusion of achromatic component, my results provide a better understanding in the dynamics of fruit and leaf colour.

In conclusion, there was no evidence of colour constraints between fruits and leaves based on the fruit-foliage hypothesis. There is also no support for the frugivore specificity hypothesis. Colour alone does not exclusively affect interaction between plants and animals. Instead, I suggest that colour component (both chromatic and achromatic) if coupled with other fruit traits might produce different results. 
Chapter 5: Colour Preferences of a Frugivorous Insects

\section{Chapter 5}




\section{What weta want: Colour preferences of a}

\section{frugivorous insect}

(Under major corrections at Arthropod

Plant Interaction) 


\subsection{Abstract}

Plants use colours as signals to attract mutualists and repel antagonists. Fleshy-fruits are often conspicuously coloured to signal different types of information including fruit maturity and spatial location. Previous work on fruit colour selection focus on large diurnal vertebrates, yet fruit colours are perceived differently by frugivores with different types of visual systems. Here, I tested whether a nocturnal, frugivorous, seed-dispersing insect selects fruits based on their colour and whether different lighting conditions affect fruit colour selection. I captured 20 Wellington tree weta (Hemideina crassidens) from a forest reserve on the North Island of New Zealand and brought them into laboratory conditions to test their fruit colour preferences. The fruits of Coprosma acerosa, a native shrub species that naturally produces translucent, blue-streaked fruits, were dyed either red or blue. Fruits were then offered to weta in a binary (y-maze) choice test in two light conditions, either at night during a full moon or under artificial light conditions in the lab. Weta preferred unmanipulated, naturally blue-streaked fruits and artificially-blue coloured fruits over those dyed red. Furthermore, their colour preferences were unaffected by light environment. My results therefore suggest that weta can discriminate between hues (using colour vision) in both light and dark light environments. Their consistent preferences for colours other than red indicate that weta might be responsible for the unusual colours of fleshy-fruits in New Zealand. 


\subsection{Introduction}

Most plants are sessile and often rely on animals for the movement of seeds and pollen. In order to attract animal mutualists, plants often use colour signals. Fruits and flowers are often brightly coloured to attract frugivores and pollinators (see van der Pijl 1972; Janson 1983; Willson et al. 1990; Kelber 1996; Burns \& Dalen 2002; Raine \& Chittka 2007; Pohl et al. 2008). Different lineages of animal mutualists often have unique eye structures with different photosensitive receptor cells and spectral sensitivities (Osorio \& Vorobyev 2008). Therefore, a fruit colour that is highly conspicuous to birds, might not be as conspicuous to other frugivores, such as mammals, lizards and insects (Osorio \& Vorobyev 2005; Osorio \& Vorobyev 2008).

Previous work on fruit colour preferences has focused on birds (e.g. Schaefer et al. 2003a; Schaefer et al. 2006; Lomascolo \& Schaefer 2010) and mammals (e.g. Endler 1978; Dominy \& Lucas 2001; Endler \& Mappes 2004; Lomascolo et al. 2008). Comparatively little work has been conducted on lizards (Whitaker 1987; Lord \& Marshall 2001; Lord et al. 2002; Roth \& Kelber 2004; Kelber \& Roth 2006). Although insect colour vision capability has been discovered for more than 100 years (see Lubbock, 1881); most studies focuses on the floral colour signal and insect pollinators; most predominantly concerning bees, lacking any focus on frugivorous insects (Lunau \& Maier 1995; Chittka \& Wells 2004; Raine \& Chittka 2005; Raine \& Chittka 2007). Insect frugivores comprises from diverse taxa from Orders such as lepidoptera, hemiptera, coleoptera and diptera (Sallabanks \& Courtney 1992). However, current understanding of insect frugivore interactions is mostly simplified 
because knowledge of insect frugivores outside of pollination biology or an agricultural context remains largely untested (Wilson 2008). Little is known about fruit colour selection by frugivorous insects.

Weta are an entirely unique type of seed disperser that is endemic to New Zealand. Weta are massive, nocturnal orthopterans. Giant Weta ( Deinacridia sp) are known to grow up to nearly ten centimetres in length and weighting 20 to 70 grams (Gibbs 2001). They are the only insect known to consume entire fleshy-fruits and pass seeds in viable condition after ingestion (Duthie et al. 2006). However, their importance to plants as seed dispersers is largely unknown and their capacity to select for particular fruit characteristics such as colour has been debated (Burns 2006b; Burns 2008; Morgan-Richards et al. 2008; King et al. 2010). Very little is known about their eye receptors sensitivities. However, based on electroretinogram analyses, weta appear to be blind at the red end of the visible spectrum, similar to most insects (Field 2001). Orthopteran insects such as weta have rarely been studied with respect to wavelength selective behavorials, spectral preferences, colour vision or colour learning ( Zufall et al 1988; Behmer et al 2005, but see Wasserman \& Kong 1982; Bernays \& Wrubel 1985). Therefore specific information on weta vision capabilities and colour selection are lacking.

New Zealand's fruit colours are unusual from a human perspective. There are no green fruits at maturity and white fruits, which are comparatively rare elsewhere in the world, make up $21.2 \%$ of the 246 fleshy-fruited floras (Lee et al. 1988; Willson et al. 1989a; Lee et al. 1990; Lee et al. 1994; Lord et al. 2002). New Zealand is home to an unusual and diverse array of seed dispersers, including bats, birds, lizards and weta. 
Because each of these taxa have different visual systems and activity periods, the unusual fruit colours present in the New Zealand flora may be a reflection of differential selection by different types of frugivores (Lord \& Marshall 2001; Lord et al. 2002; Wotton 2002; Burns 2006; Duthie et al. 2006). However, this explanation for the evolution of fruit colour diversity has received little evidence to date (Willson \& Whelan 1990; Herrera 2002).

Past studies on the fruit colour preferences of frugivores have focused on diurnal seed dispersers and previous experiments have been conducted in daytime light conditions. The effect of varying light environments on fruit colour selection is therefore poorly understood. Light conditions are known to have a pronounced affect on the foraging behaviour of animals (Willmer \& Stone 2004; Kelber et al 2005; Somanathan et al. 2008a; Somanathan et al. 2008b; Caine et al. 2009; Somanathan et al. 2009a; Somanathan et al. 2009b ). Daytime environments are illuminated by either direct or diffuse sunlight. While most available light remains constant at specific solar inclinations, other factors such as cloud cover, canopy cover and humidity are known to affect the lighting environment. In contrast, crepuscular and nocturnal light environments are influenced by multiple sources with different spectra, such as airglow emissions, scattered, low-inclination sunlight and moonlight (Leinert et al. 1998). Each of these potential influences varies in intensity and spatial extent resulting in fluctuating light environments that can change rapidly (Johnsen et al. 2006). Different light conditions can have a substantial effect on the appearance and visibility of objects and organisms (Endler 1993; Johnsen et al. 2006). Little is known about how light environments affect colour preferences in frugivorous animals and in particular how crepuscular and nocturnal seed dispersers use colour signals to make fruit choices. 


\section{Chapter 5: Colour Preferences of a Frugivorous Insects}

Here, I investigate how light conditions affect fruit colour selection by New Zealand weta. I conducted an experiment where I dyed the fruits of Coprosma acerosa, an endemic plant species that we show is dispersed by weta after gut passage, either red or blue. Different coloured fruits were then presented to weta in paired choice tests under two light conditions, full moonlight and under artificial lights. Results were then used to determine whether weta make consistent fruit choices based on their colour and whether these choices are affected by the ambient light environment.

\subsection{Materials and methods}

\subsubsection{Weta}

New Zealand weta are a group of insects in the order Orthoptera and are related to grasshoppers, locusts, katydids and crickets (Gibbs 2001; Gorochov 2001). All of the experiments were conducted using a single species, the Wellington tree weta (Hemideina crassidens, Blanchard) (Figure 5.1a), a common species of weta, in New Zealand. Wellington tree weta are nocturnal and spend most of their time foraging arboreally. They are primarily herbivorous, feeding on the leaves, flowers and fruit of a wide range of trees and shrubs, but they will also take living or recently dead invertebrates when they get the opportunity (Gibbs 2001). Twenty adult animals (10 male and 10 female) were collected from Otari-Wilton Bush, which is located on the Southern tip of the North Island of New Zealand $\left(41^{\circ} 15^{\prime} \mathrm{S}, 174^{\circ} 45^{\prime} \mathrm{E}\right)$, for use in the experiment. Each weta was housed in its own $(180 \mathrm{~mm} \times 180 \mathrm{~mm} \times 90 \mathrm{~mm})$ plastic container (containing air holes) that was lined with damp paper towel. The containers are kept in the laboratory illuminated by fluorescent lights (Philips TL R5 64 15L, 


\section{Chapter 5: Colour Preferences of a Frugivorous Insects}

$230 \mathrm{~V}, 60 \mathrm{~Hz}$ ). The illumination is kept consistent with the natural light-dark cycle to prevent disruption to the animals' normal circadian cycle. All animals were fed daily with commercially bought fruit (sliced apples, white coloured) and carrots (dull orange colour), as well as leaves from native plant species. The food colours were carefully chosen to prevent pre-exposure to the test colours.

\subsubsection{Coprosma acerosa}

I used a common, naturally occurring fruit species Coprosma acerosa (A Cunn), in all of our experiments on fruit colour preferences. Coprosma acerosa is a small-statured, divaricate shrub with branches and branchlets often forming a cushion like mass up to two meters in diameter and height. Commonly known as Tatarakehe, C. acerosa belongs to the Rubiaceae family. Coprosma acerosa produces fleshyfruits that are globose, 7 millimetres in diameter (Figure 5.1b) and each contain two flattened seeds. Unlike most fleshy-fruits, which are typically coloured either red or black, C. acerosa fruits are translucently white coloured and are sometimes streaked with blue.

\subsubsection{Spectrographic analyses}

To test whether weta respond consistently to the reflectance properties of fleshy-fruits, I dyed fruits either red or blue. To reduce odour effect, all the fruits were carefully washed with cold water. To completely alter fruit colours, fruits were left to soak in a strong concentration of food dye (Star Brand, Bright Blue and Red) for two hours. Spectrographic analyses were then conducted with a USB Ocean Optics 2000 spectroradiometer and Xenon Pulse X2 lamp (Ocean Optics) light source 
to establish precisely how the dyeing procedure affected the reflectance properties of fruits. An object's reflectance properties were measured as the proportion of a diffuse, Teflon- based, white reflectance standard. The fiber optics probe was mounted inside a matte black plastic tube to exclude ambient light. The distance between each object and the probe was fixed at $1 \mathrm{~cm}$. The angle of illumination and reflection was fixed at $45^{\circ}$ to minimize glare. Spectra were calculated at $5 \mathrm{~nm}$ intervals from 300 to $700 \mathrm{~nm}$ with SpectraSuite software. The reflectance property of any object is determined by two components. The chromatic component refers to how specific eye receptor types and post processing reacts to the signal received and permits the discrimination of stimuli by spectral composition regardless of relative intensity; giving animals colour vision. The achromatic component is the perception of intensity (disregarding colour), and are particularly important in the detection of object borders in birds, humans and insects (Osorio et al. 1999)

\subsubsection{Y maze test}

I tested weta fruit colour preferences using a Y-maze, which is a common experimental design that forces an animal to make a choice between two objects (Wehner 1971; Chen et al. 2003; Behmer et al 2005; Kapustjansky et al. 2010). I constructed three sets of Y-mazes using white polyurethane plastic measuring $10 \mathrm{~cm}$ (width) X $10 \mathrm{~cm}$ (height) X $20 \mathrm{~cm}$ (arm length), with the arms set at a $60^{\circ}$ angle from each other. The base length is $15 \mathrm{~cm}$ (Figure 5.2). The top was covered with clear plastic to allow sufficient illumination while preventing weta from climbing out. Weta fruit colour preferences were evaluated by offering animal a choice between each paired combination of colours (natural vs. dyed red; natural vs. dyed blue; dyed 


\section{Chapter 5: Colour Preferences of a Frugivorous Insects}

blue vs. dyed red). Three fruits were placed at the end of each maze along with their leaves as background. The leaves of $C$. acerosa are quite small in size $(6-16 \mathrm{~mm}$ in length). However, the matted branching pattern of adult plants makes it so the fleshyfruits are typically displayed against a solid mass of leaves and branches. In an effort to reduce the artificial nature of experimental fruit displays, I stacked multiple branchlets (approximately 10 branchlets that were $60 \mathrm{~mm}$ long) at the end of each maze arm immediately behind fruit displays.

For each colour combination, all weta were placed in the maze individually and once they moved beyond the intersection of the two arms of the y-maze (i.e. they chose to move down a single arm towards the fruit located at the end) the trial was halted. If no movement was detected after 20 minutes (i.e. weta remained still), the trial was stopped and the trial was not included in statistical analyses. Weta were deprived of food for 24 hours before each experiment to increase the likelihood they would participate. Tests were conducted an hour after sunset and before sunrise to coincide with the natural circadian rhythm of weta (Lewis \& York 2001). The identity of fruit colours placed at each arm of the Y maze was randomly allocated for each trial to remove the potentially confounding effect of directional preferences.

To test whether weta made different fruit colour choices under different lighting conditions, I conducted trials for each fruit colour combination in two light environments. The first was in "artificial" light, where the y-maze was illuminated by fluorescent, light (4100 K, Philips TL R5 64 15L, 230 V, 60 Hz). The second was natural "moonlight", which was conducted in the dark during full moons, with the Ymazes positioned near a window in the laboratory to provide natural illumination. All 
trials for each colour combination and light condition were conducted on a separate nights. Figure 5.3 shows the spectra properties of the fluorescent lamp and full moonlight conditions. There are essentially three sets of binary tests. Each binary test under different light conditions (two light conditions) was replicated twice (total number of binary test $=12$ ).

To test the effect of light conditions on fruit colour selection statistically, I performed a contingency table analysis. Each light environment was treated as a separate row and each fruit colour was treated as a separate column, to form a $2 \times 2$ table with counts of animals in each cell. If the results from these tests were not statistically significant, the results for both light conditions were pooled for each colour combination and a binomial test was used to compare overall fruit colour preference regardless of light environment. Binomial tests calculate the probability of obtaining a certain number of 'successes' in a sequence of $n$ trials and in this context tests whether an observed number of choices for a particular fruit colour deviates from randomised expectations.

A benefit of running contingency tables tests followed by binomial tests for fruit colour preferences is that both are standard procedures that will be familiar to most readers. A disadvantage is that contingency tables only test for an interactive effect of fruit colour and light environment; it does not assess whether weta prefer certain fruit colours, regardless of light environment. Further the binomial test for fruit colour preferences suffers from independence problems associated with light environments. Therefore, I conducted a simple computer simulation to determine how frequently observed results could be replicated by simulated weta making 
random fruit colour decisions. I simulated the experiment using the observed number of successful trials (excluding those where weta neglected to make a choice) for each light environment 1000 times in $\mathrm{R}$ 2.10.1(R Development Core Team 2010). For example, in comparison of weta selection between natural colour fruits and red coloured fruits in artificial daylight, 13 weta chose natural colour fruits and one chose a red fruit. This total up to 14 successful trials. I then calculated the probability of weta choosing a set number of fruits (zero, one, two, three and so forth until 14). This is repeated 1000 times by a randomization code in $\mathrm{R}$ software. Based on the probability values, I then calculated the probabilities of weta choosing all the possible number combination selection between the two colours. Therefore, if weta were to choose 13 natural fruit and one red fruit, the result would be from the total probability of weta selecting 13 out of 14 fruits added with the probability of weta selecting one out of 14 fruits. During each simulation replicate, simulated weta made a random choice between each fruit colour and the fraction of trials that were equal to or less probable than that observed was taken as the type-one error rate for non-random fruit colour preferences.

To evaluate whether weta pass seeds intact after consumption, three $C$. acerosa fruits were offered to five randomly selected weta over the course of 3 consecutive nights. All fruits were completely consumed, leading to a total sample size of 30 ingested seeds (all species of Coprosma consistently produce two seeds per fruit). All scat produced by weta during the ingestion trials and for three days afterward were collected all seed material was examined under a light microscope. Seeds were then tested for viability by staining them with ${ }^{2,3,5}$ triphenyl tetrazolium chloride (1\%). A small longitudinal cut was made alongside each seed to allow the 


\section{Chapter 5: Colour Preferences of a Frugivorous Insects}

stain to seep in through the seed coat. Imbibed seeds were placed in a petri dish inside an incubator with a temperature of $40^{\circ}$ Celsius for 24 hours and then examined under a light microscope. Viable seeds turned a distinctive reddish hue (Marrero et al. 2007).

\subsection{Results}

Spectrographic results showed that natural C. acerosa fruits reflect light throughout the visible spectrum range $(300-700 \mathrm{~nm})$ with the intensity (achromatic) peaking around 400-490 $\mathrm{nm}$. The high brightness level of the natural fruit colour is caused by the translucent white colours while the peak (400-490) is from the blue streak lines.The dying process lowered the intensity of fruits significantly (reduced the achromatic signal), but changed their colour (altered chromatic signal) to either blue $(400-490 \mathrm{~nm})$ or red $(630-700 \mathrm{~nm})$ (Figure 5.4). Therefore, the three fruit colour treatments were unmanipulated natural bright blue, dyed dull blue and dyed dull red. All colours mentioned are based on the human perception.

Contingency table analyses showed that fruit colour preferences did not differ between light conditions. All three colour combinations, natural vs. red $\left(\chi^{2}=0.29 \times\right.$ $10^{-2}$, df $\left.1, \mathrm{p}=0.96\right)$, natural vs. blue $\left(\chi^{2}=0.37 \times 10^{-1}, \mathrm{df}=1, \mathrm{p}=0.85\right)$ and blue vs. $\operatorname{red}\left(\chi^{2}=0.51 \times 10^{-1}, \mathrm{df}=1, \mathrm{p}=0.83\right)$, did not interact with light environment. After pooling results from both lighting conditions (Table 5.1), binomial tests showed that weta preferred naturally coloured blue fruits to red fruits $(\mathrm{p}=0.01)$ and artificially coloured blue fruits to red fruits $(\mathrm{p}=0.01)$. Weta chose naturally coloured blue fruits and artificially coloured blue fruits at similar rates $(\mathrm{p}=1.00)$. 


\section{Chapter 5: Colour Preferences of a Frugivorous Insects}

Simulation analyses confirmed these results (Fig. 5.5) Weta selectively chose naturally coloured bright blue fruits over fruits dyed dull red $(\mathrm{p}<0.01)$ (Figure 5.5a). Naturally coloured bright blue fruits and fruits dyed dull blue were chosen at equal frequencies. ( $\mathrm{p}=0.85$ ) (Figure 5.5b). Fruits dyed dull blue were also selectively chosen more than fruits dyed dull red $(\mathrm{p}<0.01)$ (Figure 5.5c). The five additional trials conducted to determine whether weta interacted mutualistically with $C$. acerosa fruit showed that they passed $C$. acerosa seeds in viable condition after gut passage. Weta consumed all fruits offered to them during these trials and $27 \%$ (eight out of 30) of seeds passed in apparently viable condition. Seedling viability tests revealed that $63 \%$ (five out of eight) of the intact seeds are viable.

Table 5.1: Total number of fruit colour selection by weta. The results for both light conditions were pooled for each colour combination and a binomial test was used to compare fruit colour selection regardless of light environment.

\begin{tabular}{lcccccc}
\hline & \multicolumn{2}{c}{ Natural vs. red } & \multicolumn{2}{c}{ Natural vs. blue } & \multicolumn{2}{c}{ Blue vs. red } \\
\hline & $\begin{array}{c}\text { Artificial } \\
\text { light }\end{array}$ & Moonlight & $\begin{array}{c}\text { Artificial } \\
\text { light }\end{array}$ & Moonlight & $\begin{array}{c}\text { Artificial } \\
\text { light }\end{array}$ & Moonlight \\
\hline Natural & 13 & 12 & 7 & 6 & & 7 \\
Blue & 1 & 1 & 6 & 6 & 9 & 2 \\
Red & 1 & & & & 2 & \\
\hline
\end{tabular}


Chapter 5: Colour Preferences of a Frugivorous Insects
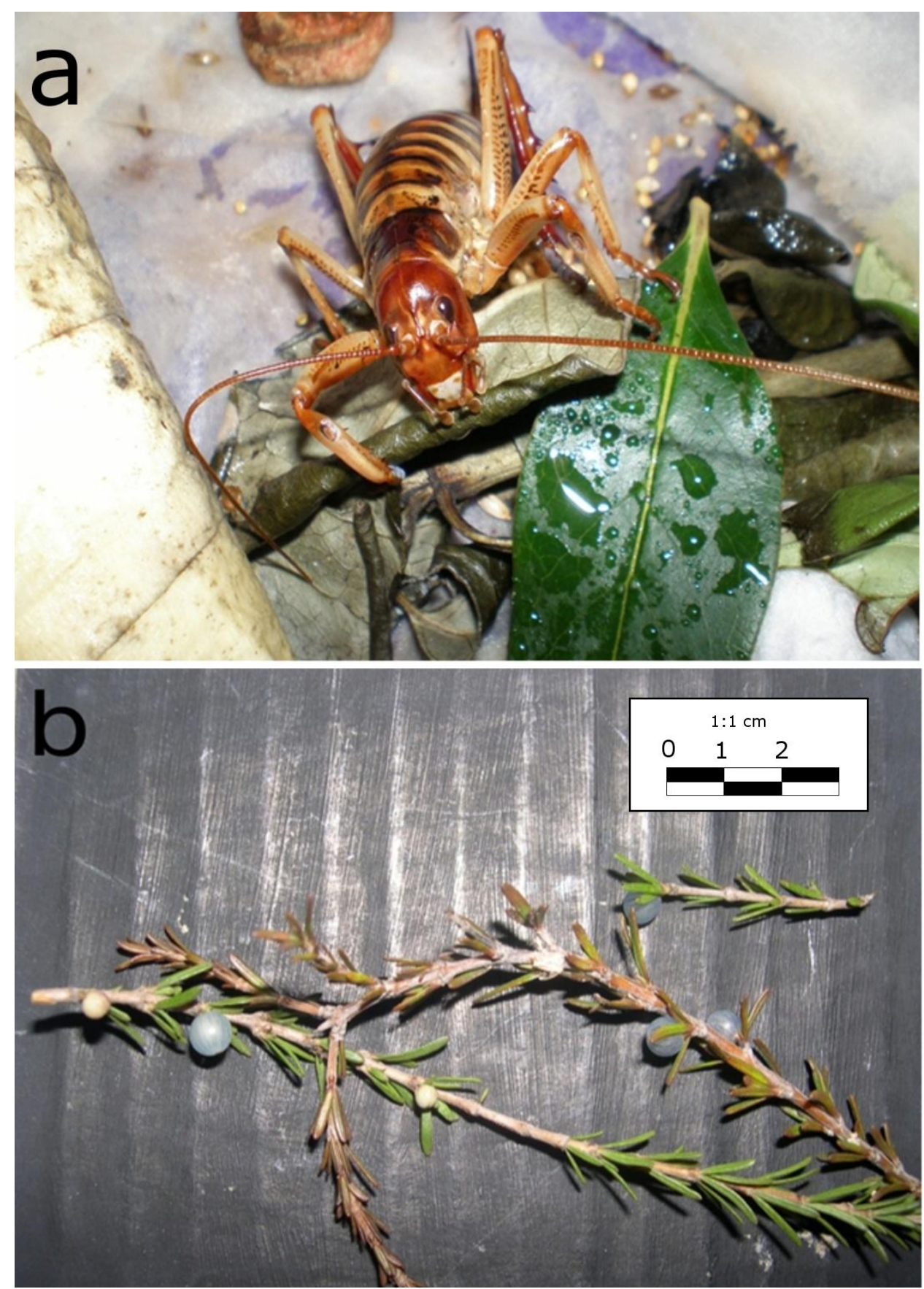

Figure 5.1: (a) A close up of a female Wellington Tree Weta (Hemideina crassidens). (b) Coprosma acerosa fruit natural colouration. 


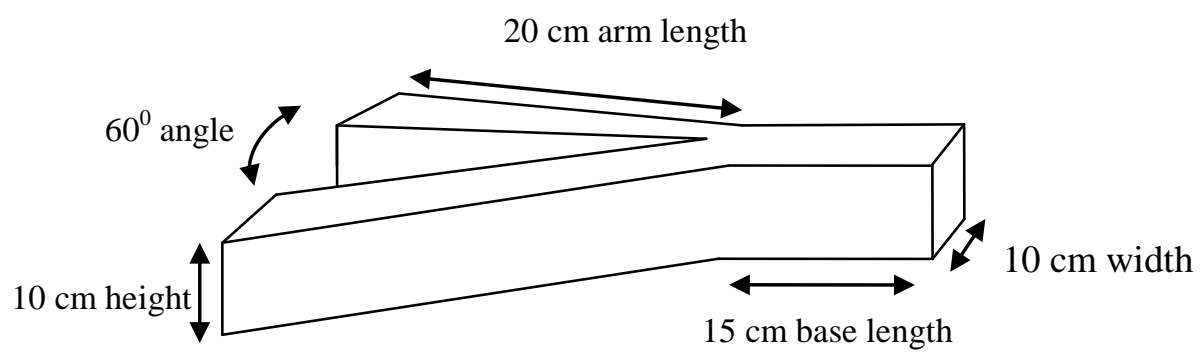

Figure 5.2: Y- maze diagram used in the binary test

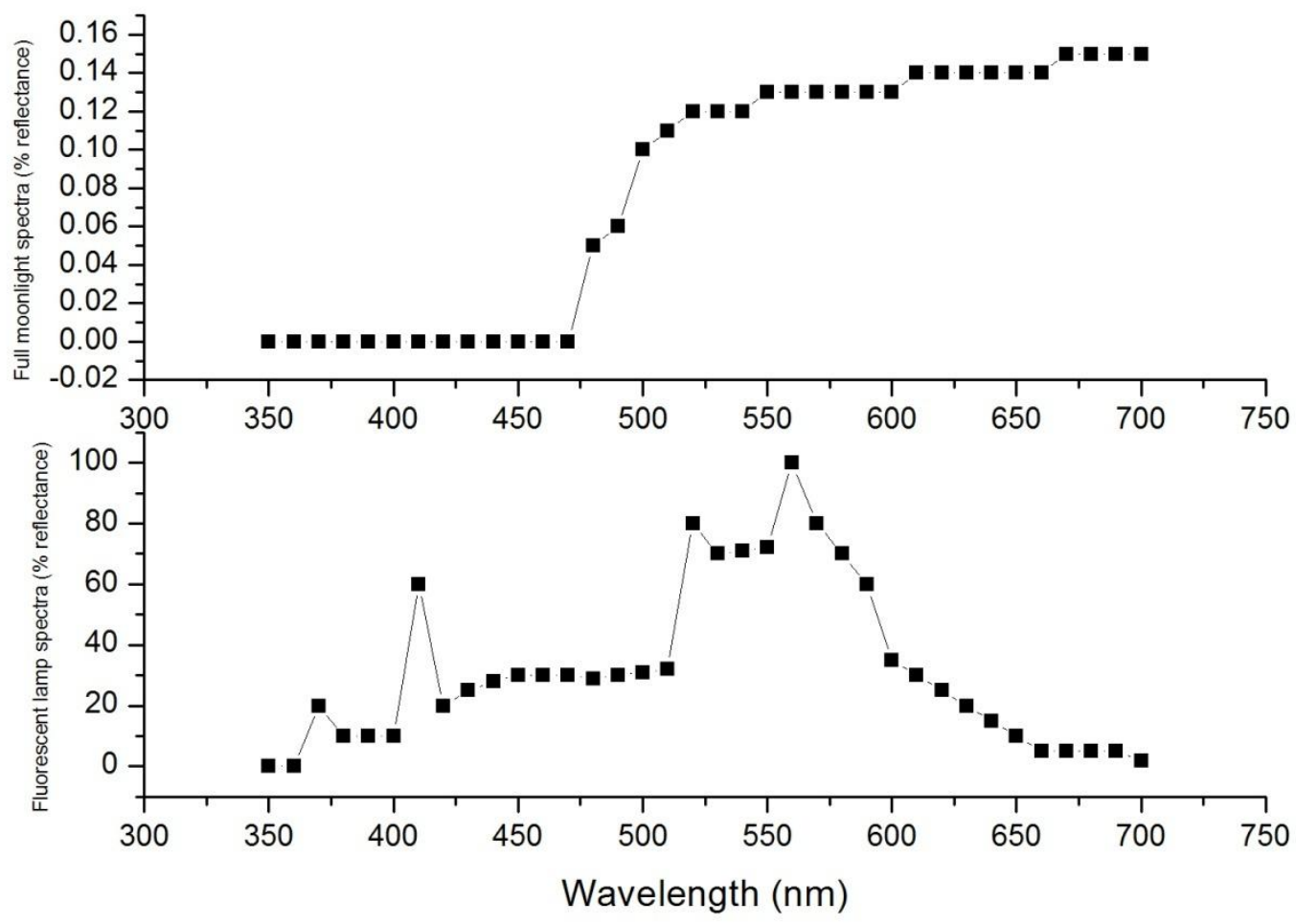

Figure 5.3: Spectra properties of full moonlight (top) and fluorescent light (bottom) condition. The intensity level for moonlight is very low; full moon is about 250000500000 times fainter than the sun. 


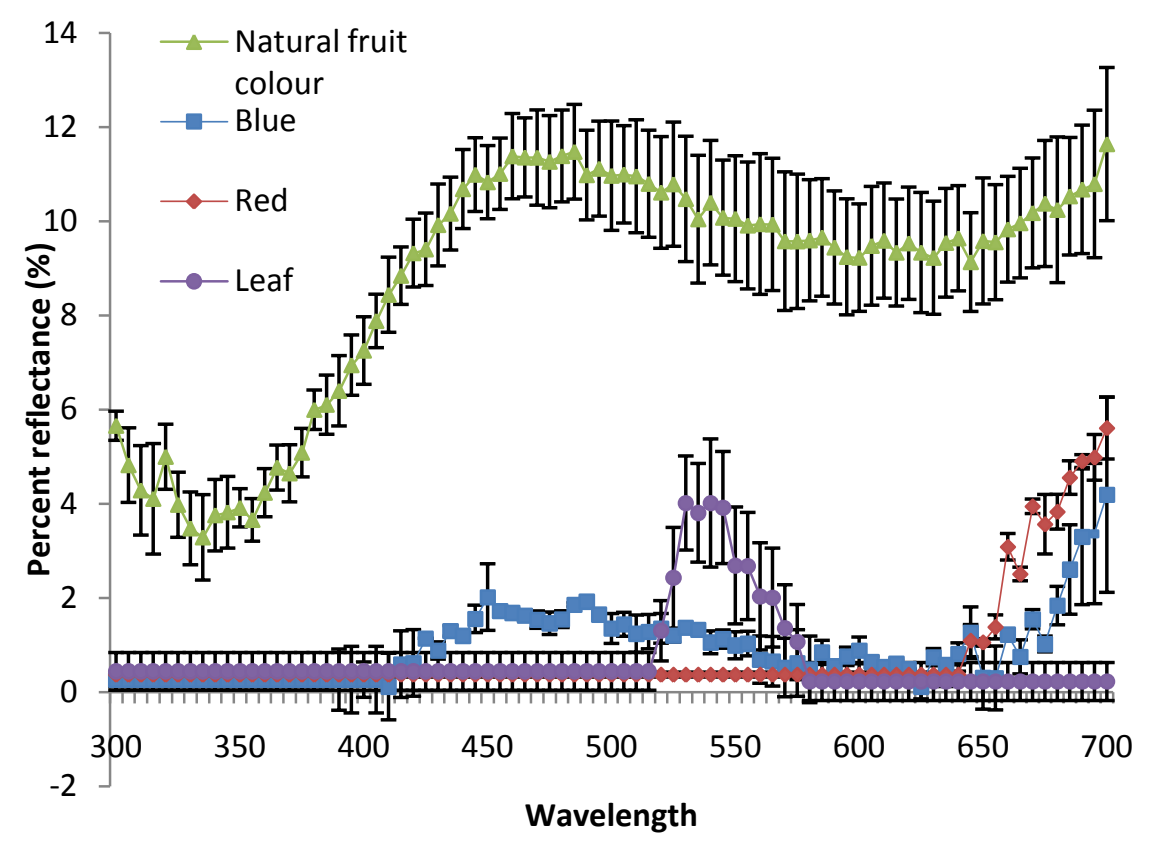

Figure 5.4: Reflectance spectra of natural C. acerosa fruits (triangle), fruits dyed blue (square), fruits dyed red (diamond) and the leaves (circle). Each spectral results were obtained from the average reading of 10 samples $(\mathrm{N}=10)$. Error lines represent standard error. 


\section{Chapter 5: Colour Preferences of a Frugivorous Insects}

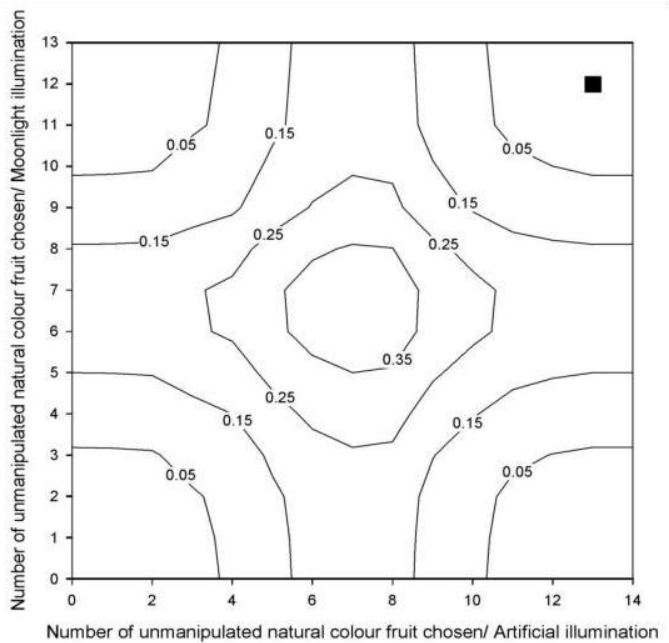

(a) Natural vs. Red fruit colour selection

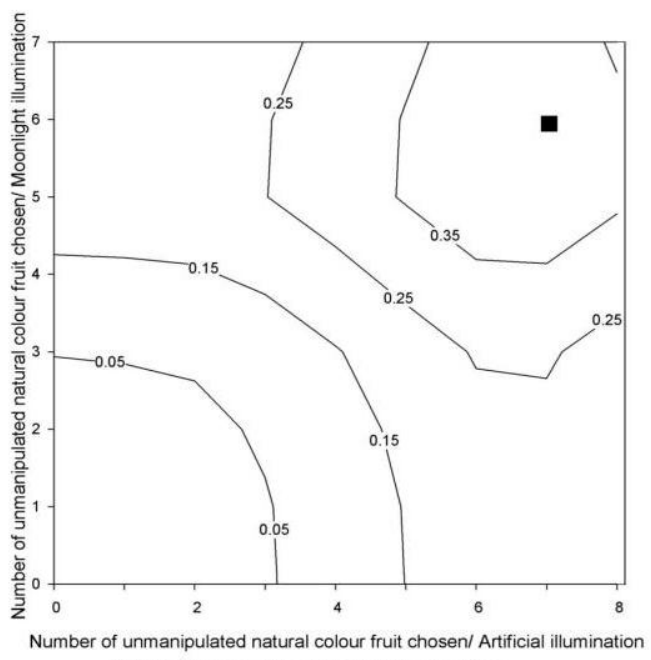

(b) Natural vs. blue colour fruit selection

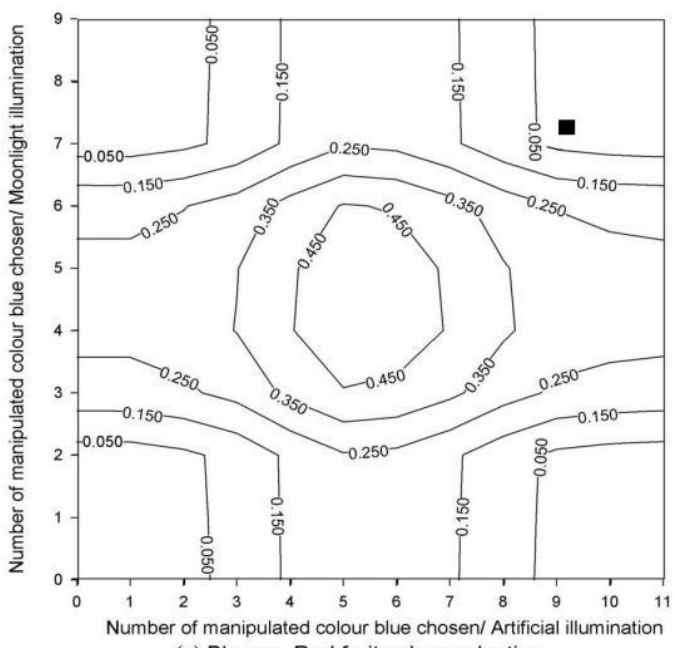

(c) Blue vs. Red fruit colour selection

Figure 5.5: Observed and expected probabilities of weta fruit colour choices obtained in a computer simulation. Contour lines represent the expected number of fruits consumed under artificial illumination ( $\mathrm{x}-$ axis) and natural moonlight (y-axis) if weta foraged for fruits randomly. Symbols represent the observed number of fruits consumed of each colour combination. 


\section{Chapter 5: Colour Preferences of a Frugivorous Insects}

\subsection{Discussion}

Weta showed consistent preferences for particular fruit colours. They preferentially selected unmanipulated, blue fruits and fruits dyed a blue hue over fruits dyed red (all colours described are based on human perception). Interestingly, based on the reflectance curves, the main difference in the spectral properties of unmanipulated and blue-dyed fruits was their achromatic signal. Unmanipulated fruits showed higher intensity curve than those dyed blue. However, weta showed similar foraging preferences for both, suggesting they made foraging decisions based on colour alone.

Weta therefore appear to have colour vision at low-light conditions. They showed the same colour preferences in moonlight and in artificial light environments. Similar results have been found in other animals. For example, dichromatic marmosets (Callithrix geoffroyi) excel in foraging at low light intensity conditions (Caine et al. 2009). The nocturnal helmet gecko (Tarentola chazaliae) also has colour vision both in starlight and dim moonlight (Roth \& Kelber 2004; Kelber \& Roth 2006). Certain insects have excellent colour vision in low light environments, for example grasshoppers, hawkmoths and some nocturnal bees have unique eye structures (i.e. large facet lenses and wide, very long rhabdoms) that help them distinguish between objects in dim light environments (Warrant et al. 1996; Warrant et al. 2004; Balkenius \& Kelber 2004; Johnsen et al. 2006). The Indian Carpenter Bee (Xylocopa tranquenarica) is the only known species of bee to fly during the night even at extremely low light intensities (Somanathan et al. 2008a; Somanathan 2009a). This obligate nocturnal bee navigates through landmark colours in starlight (Somanathan 2008b). 


\section{Chapter 5: Colour Preferences of a Frugivorous Insects}

Although very little is known about the visual properties of weta, my results suggest that they have greater preference for blue colour than for red colour. Electroretinogram tests conducted on another species of Tree Weta (Hemideina femorata) and Giant Weta (Deinacrida mohoeunui) showed that both species have peak sensitivities in blue ( 440-490 nm wavelengths) and green (520-530 nm wavelengths) (Field 2001). The spectral sensitivities are similar to the cricket (Gryllus bimaculatus), with spectral sensitivities at $332 \mathrm{~nm}$ (UV), $445 \mathrm{~nm}$ (blue) and $515 \mathrm{~nm}$ (green) (Zufall et al. 1989). Another orthopteran that shares the same similarity is Locusta migratoria with spectral sensitivities at $360 \mathrm{~nm}$ (UV), $430 \mathrm{~nm}$ (blue) and 530 nm (green) (Vishnevskaya \& Shura-Bura 1990).

Several factors prevented me from using a theoretical eye model (an assessment of photon absorbance by the specific eye photoreceptors) in my analyses of fruit colour (Osorio \& Vorobyev 1996; Vorobyev \& Osorio 1998; Endler \& Mielke 2005; Schaefer et al. 2006; Fadzly et al. 2009). It is possible to quantify how birds perceive objects visually based on our understanding of the physiology of the avian eye (e.g. Fadzly et al. 2009). Similarly, Chittka (1992) proposed the chromaticity diagram to illustrate colour opponency based on the hymenopteran species. However, vertebrate and insect visual pigments, although structurally and functionally similar, generally differ in a number of important ways (Briscoe \& Chittka 2001). Because the eye physiology of weta has yet to be fully documented we lack an accurate understanding of how they see the world (Field 2001). Many insects are also nocturnal or crepuscular, so there is less available environmental light/illuminant during their active browsing period to provide a single visual pigment matching analysis. 


\section{Chapter 5: Colour Preferences of a Frugivorous Insects}

The New Zealand flora has an unusually high abundance of opaque or pale blue coloured fleshy fruits, which are often displayed in the inner recesses of the plant canopies (Lord et al. 2002). The numbers of opaque or pale blue fleshy fruits are collectively a higher proportion compared to others in the temperate floras (Iberan Peninsula, Florida and Europe) (see Lord et al. 2002; Herrera 1989). Fruit production within canopies of divaricating (the divaricate habit is characterised by small leaves, with thin interlaced stems at wide branch angles) plants would appear to restrict access to larger frugivores, such as birds and facilitate access to smaller frugivores such as weta (Burns 2006). Strong preferences for pale blue fruits suggest that weta may interact with fleshy-fruited plant traits evolutionarily. However, weta are not the only small-sized frugivore that might select for translucent, pale blue fruits in low light environments within divaricating plants. Nocturnal geckos are capable of distinguishing blue colour at very dim light levels when humans are colour-blind (Roth and Kelber 2004; Kelber and Roth. 2006). Other insects such as ants are known to disperse seeds without ingesting them (Boulay et al. 2005). However, myrmecochory is rare in New Zealand (Gibbs 2006).

Results from seed viability trials indicated that weta are viable seed dispersers, although only a fraction of seeds passed through weta intact. As discussed in detail elsewhere, some seed damage during ingestion does not necessarily imply that a particular frugivore is an antagonist (Burns 2006; King et al. 2010). Janzen (1979) describes a variety of plant species that "pay in seeds for the dispersal of other seeds", and a similar situation may occur with weta.

My results suggest that weta are capable of colour vision and select fruits based on colour at night. Weta prefer blue colour over red colour suggesting that the 
preponderance of opaque-blue fruits in matted divaricate shrubs in New Zealand may be an adaptation to promote seed dispersal by weta. However, there are other explanations that could be offered. Weta equal selection between natural fruit colour and dyed blue in moonlight setting could also be attributed to behavioural mechanism based on achromatic vision and brightness threshold. It is possible that in lowlight conditions, weta perceived both colours as black. Another alternative explanation is the possibility of wavelength-dependent behaviour rather than full colour vision. For example, Whiteflies Trialeurodes vaporariorum, are strongly attracted to UV light, possibly induces migratory behaviour whereas green-yellow light promotes landing (Coombe 1981). Wavelength-dependent behaviour occurs when different behaviour patterns of an animal have markedly different spectral sensitivities (Menzel 1979). This refers to how different behavioural patterns are controlled or triggered by different spectral sensitivities but the outputs of these receptors are not integrated in the central nervous system (Coombe 1981). Certain selection responses (such as honeybees colour selection) might indicate a "primitive" hard wiring between spectral receptors and motor circuits, but is also possible that both colour vision and wavelength-dependent behaviour are processed serially, so that stereotypic motor patterns are elicited when objects in the animal's visual field are perceived in certain colour (Skorupski \& Chittka 2009). Furthermore, wetas are not laboratory raised and might have the opportunity to learn fruit colours in nature. It is therefore uncertain whether the colour selections were based on innate or learned behaviour.

These multiple explanations show that how little known about weta's impact on New Zealand's natural history. I believe that this study provides the initial step towards a better understanding on the evolution of fruit colours and a frugivorous 


\section{Chapter 5: Colour Preferences of a Frugivorous Insects}

insect. A more holistic research program involving comparisons of various fruit colour selection by a variety of seed dispersers is needed to fully elucidate how frugivore visual systems and foraging behaviour have influenced the evolution of plant traits in New Zealand. 


\section{Chapter 6 \\ (General discussion)}




\subsection{General discussion}

This thesis is the combination between a theoretical component (avian eye modelling), and colour research component. The first component is the study of colour based on the eye model calculation. Endler and Mielke (2005) first led the way, with Ender's initial work with bowerbirds on how to quantify colour for sexual selection. The subject of colour had previously been considered as purely subjective and abstract. Although there is the CIE XYZ colour space, which was developed in 1931, the definition of colour was confined to human perception. Advancement in eye photoreceptor sensitivities led to a new branch of vision research. By identifying the biological construct of the eye, we can now calculate and theoretically quantify colour based on the specific receptor capability of humans, birds, lizards and even insects (Briscoe \& Chittka 2001; Osorio \& Vorobyev 1996; Osorio \& Vorobyev 2005; Osorio et al. 1999; Stuart-Fox et al. 2004; Vorobyev \& Osorio 1998a; Vorobyev et al. 1998b).

The second component in the thesis investigates how either plants to avoid or facillitate animal herbivory utilizes colours. Colour in plants had been connected with multiple theories regarding seed dispersal, fruiting syndrome, pollination, and fruit flag (Stiles 1982; Janson 1983; Wheelwright \& Janson 1985; Willson et al. 1990; Willson \& Whelan 1990; Herrera 1992; Burns \& Dalen 2002). However, most studies are based on human colour vision perception, which differs substantially from most other seed dispersers, and may therefore quite be unreliable (Burns et al. 2009a).

The aim of the thesis is to combine these two components to discover how visual signals/colours are actually perceived and the effects of these signals on the receivers, using where possible the receiver's perception. In chapter one, I highlighted two basic research questions. The first question was how plants utilize 
aposematic and cryptic colours? And the second question was how animals are affected by the colour signals broadcasted by plants?

\subsection{The how-and-why of plant colours function}

Why plants use colours as signals had already been discussed and debated for decades. Two seldom-discussed sub-topics in plant colouration are aposematism and crypsis in plants. There is a long history of speculation that some plants are coloured in ways that make them difficult to be located by predators. However, most are speculations based on human perception. My first two chapters review aposematism and crypsis from the perspective of the extinct herbivores.

\subsection{A tree stuck in a time warp}

To answer the question of why plants use colours, I examined the signals that were broadcasted by these two heteroblastic plants (Pseudopanax crassifolius and Elaeocarpus hookerianus). Pseudopanax crassifolius foliage goes through a series of colour changes throughout the plants ontogeny. Seedlings have leaves that are mottled in appearance and are similar in colour to forest leaf litter. Saplings produce long, rigid leaves with spine-like projections on their margins, each of which is typically associated with a patch of brightly coloured tissue. Once plants grow above 3 meters in height, they abruptly begin to produce leaves that are typical in size, shape and colour to co-occurring tree species. Similar colour changes were not observed in Pseudopanax chathamicus, which produces similarly coloured leaves throughout ontogeny. Pseudopanax crassifolius is capable of switching colouration strategy depending on life stage and environmental conditions. Seedlings remain cryptic via colourations matching the leaf litter, whereas juveniles plainly advertised the marginal teeth on their leaf. 
While the initial results were notable enough on its own, the second chapter had gathered a considerable amount of scientific debate when I proposed the Moa browsing theory (refer to Torrice 2009 and Lee \& Gould 2009). Detractors of the Moa browsing hypothesis argued that the colourations could be adaptations to changing environmental conditions, structural design of the leaf and the chemical content (Gould 1993; Day 1998). I viewed my results as being similar to Janzen and Martin's (1982) work about jicaro (Crescentia alata) and guanacaste (Enterolobium cyclocarpum) plants. These two plants remain stuck with strange anachronistic features since the mega herbivores that dispersers their seeds are extinct. Pseudopanax crassifolius is simply an anachronistic plant, a tree stuck with defensive and cryptic colours in the present, against a predator that had long gone in the past.

Another interesting result is the usage of achromatic contrast on the marginal teeth by the juveniles. Achromatic contrasts are particularly important in the detection of object borders in birds, humans and insects (Osorio et al. 1999), and may explain why plant spines are often coloured white or associated with white markings (Lev-Yadun, 2001, 2003, 2009b; Midgley, 2004). Furthermore, the avian eye consists of four types of single cones and one 'double cone' (Cuthill, 2006), which is unique to birds. The double cone has a broad spectral sensitivity and is associated with achromatic perception (i.e. intensity-based tasks). Therefore, birds would be particularly sensitive to the colour of sapling leaf spines, which are characterised by high achromatic contrasts. Does this mean New Zealand plants are specifically using achromatic signals since the largest browsing herbivore (before the arrival of man) are birds? It is a plausible scenario, but it is one that will remain a mystery since the putative selection agent (Moa) had gone 
extinct.

\subsection{The illusive life of Elaeocarpus hookerianus}

Elaeocarpus hookerianus was the second heteroblastic species investigated. Although Elaeocarpus hookerianus lacks defensive structures. The foliage is cryptically coloured until plants reached a certain heights. Furthermore, even from a human eye perspective, the juvenile plants are quite hard to distinguish from the leaf litter. My results showed that E. hookerianus is cryptically defended by displaying low chromatic and achromatic contrasts; mimicking the leaf litter background. My results also showed that the E. hookerianus juvenile heteroblastic leaf shape might also contribute to camouflage the whole plant from browsing large Moa birds. The diverse juvenile leaf shape might serve to mimic the leaf litter background; given that, leaf litter is composed of plant debris that is highly variable in size and shape.

A unique pattern that emerges from this study is the possibility of using divaricating branching patterns as a supplementary to the camouflage tactics by the juvenile trees. There are multiple evolutionary theories concerning divaricating branching pattern, however camouflage tactics had never been proposed before. The divaricating branching pattern, high variability of leaf shapes, low chromatic and achromatic contrasts possibly serves to create an isodipole texture in which visual processing cannot discriminate textures which have the same power spectrum or whose statistics are identical. However, we could only speculate on the pattern, as the working process could not be tested due to the absence of Moa.

\subsection{Effects of colour signals on animals}

Animals respond to colour signals based on their needs and requirement. Colour signals transmitted by plants however, carry out different meaning such as fruit 
ripeness, conspicuousness, nutrient availability and to some extent as warning signal. In chapter four and five, I examined the effects of visual signalling from the animals' perspective.

\subsection{Do different colours attract different birds?}

In chapter four, I reviewed two hypotheses in plant and animal interaction. I reviewed and tested the fruit-foliage hypothesis that fruit colours are constrained by the colours of its own leaf. My result suggested no evidence of leaves constraining fruit colours. There were also no significant differences in the fruit-foliage colour contrasts based on geographic location. Fruit and leaf colours are overall interlinked with multiple species, chemical, habitat and many other types of interaction. A constrain on either one, would likely to be disadvantageous to the overall development of plants.

Fruiting plants distribution is influenced by the overall activity of seed dispersers; however specific effect of the relationship (i.e. fruit traits) still remains a controversy. I examined the pattern of fruit colours and frugivore assemblages by comparing the spectral results of the fruits with the number of bird that feeds on them. The question that I asked is; based on the frugivore specificity hypothesis, is it possible for fruits to promote a specific assemblage of frugivores (birds) based on fruit colours?

The answer is no, I did not find any significant patterns or correlation between specific fruit colours and specific bird visitors. It could be assumed that introduced European birds might present a limited evolutionary history with New Zealand plants therefore having little impact towards fruit colours and frugivore assemblage interaction. Other reasons could have been caused by the over emphasis on colours while disregarding other aspects such as habitat assemblages, nutrients, 
texture, odour, secondary content and many others that might be as equally important. There is also the possibility of not all fruit colours are targeted for avian vision and there are other types of suggested seed dispersers in New Zealand. Birds have excellent vision compared to human. If selective fruit colour preference is to affect frugivore assemblage, it could be due to the learning capability of the birds. Birds learn how to discriminate ripe or unripe fruits (Schaefer \& Schmidt 2004b), but then again the deciding factor is based on taste. Fruit colour would only be an added cue rather than the main cause.

Colour alone does not exclusively affect interaction between plants and animals. Instead, I suggest that colour component with other fruit traits analysis might produce different results. There is also the possibility that different scale of dataset and different taxon comparison might produce an entirely different conclusion.

\subsection{Weird world of weta}

Weta is an endemic New Zealand invertebrate, complete with a rich natural history background. Nicknamed 'mouse of New Zealand', weta had undoubtedly filled the niche similar to a small mammal role in other parts of the world. Although the specific role of weta as seed dispersers remains arguable, Duthie et al. (2006) had shown that weta are capable seed dispersers.

In the fifth chapter, I approached the subject of invertebrate frugivore fruit colour selection. I used weta, a seed dispersing frugivorous insect and I tested the effect of lighting condition (artificial daylight and low-light condition) on fruit colour selection. Weta significantly preferred natural blue streaked colour and artificially blue coloured fruits over those of coloured red. Weta are nocturnal browsing animals and our result show they have colour vision at night (or under low-light condition) and are able to discriminate between colours. There are several 
inferences from these results. First, weta colour preference adds to the ongoing debate whether frugivores select specific colourations. Second, weta affinity towards blue colour could be linked with New Zealand's unique fruit colours (which has a high number of blue fruits). The second inference is also connected to the role of weta as seed dispersers. The only caveat in this connotation is the low percentage of passed seeds. This however, is compensated by the high germination rates of the seeds. I also discussed other possibilities such as achromatic brightness threshold and wavelength-dependent behaviour as an alternative theory to the weta colour selection behaviour.

\subsection{Putting together the how-why- and- what of visual signaling in plant- animal interaction}

In conclusion, my thesis had been about an anachronistic tree, an illusive tree, community level fruit colours and an insect that is regarded similar to rats or mice. As different and diverse they may sound, the entire above are bound together by a single focus; colour of actual or potential food. I had provided quantitative results that plants do indeed use aposematic and cryptic colourations. Furthermore, the results that I presented are based on the perception of birds not based on humans. Based on my results I suggest that even though colour signals works very well for warning signals, the same could not be inferred for frugivore fruit colour selection and assemblage interaction. Colours alone are not sufficient to shape or change a specific frugivore assemblage (birds). Other environmental factors and other species interaction must be taken into account. Shifting focus on the weta, I discovered that these amazing nocturnal creatures have amazing colour vision even in low-lighted environment. My results would present an initial step for further 
research to discover where exactly does weta niche fits in the New Zealand natural history. Perhaps it is not too bold to assume that the fruit colours of New Zealand are shaped by the combination of birds, lizards and weta. This seemingly contradicts my previous conclusion concerning frugivore specificity hypothesis. However, as I iterated earlier in chapter five, different level of data scale and different taxon comparison could very well produce different results. Further study is needed to provide more information on the unique natural history of New Zealand.

\subsection{Future research}

My research is not without faults nor in any way encompasses every single component in natural history research. As stated in chapter one and two, my results could be strengthened with a cafeteria style feeding experiment using emus (as a proxy for Moa). Such experiment had already been conducted before (refer to Bond et al. 2004) however I suggest that the juvenile P. crassifolius leaf colours are manipulated to change the chromatic and achromatic contrast. The goal is to discover whether the emus are capable of detecting the marginal teeth if the bright accessory colours are removed.

The same cafeteria style feeding experiment could also be conducted on the E. hookerianus. Emus would be presented with the juvenile plants and the herbivory rate (the amount of leaves eaten) would be counted. Similar to the $P$. crassifolius experiment, the leaf colours could be manipulated also. Based on my conclusion that fruit colours alone are not important in fruit-frugivore assemblage, I suggest a more general approach to be undertaken.

Additional data such as fruit phenology, physical characteristics and chemical analysis would certainly make a more compelling study in the future. Since my work on weta had provided initial framework for fruit colour-frugivore 
selection, it is suggested that the study to be repeated using either nocturnal lizards or geckos. A compilation of birds, lizards and weta fruit colour selection would certainly provide further knowledge of New Zealand's natural history. 


\section{Appendices}


Appendix A 


\section{Avian Eye Model}

\section{Material and Methods - Equations}

Spectral analyses were made using a USB Ocean Optics 2000 spectroradiometer and Xenon Pulse X2 lamp (Ocean Optics) light source. An object's reflectance properties were measured as the proportion of a diffuse reflectance standard (white standard). The fiber optics probe was mounted inside a matte black plastic tube to exclude ambient light. The distance between each object and the probe was fixed at $1 \mathrm{~cm}$. The angle of illumination and reflection was fixed at $45^{\circ}$ to minimize glare. Spectra were calculated at $5 \mathrm{~nm}$ intervals from 300 to $700 \mathrm{~nm}$ with SpectraSuite software. Irradiance was measured with a cosine corrected sensor and a D65 (normal daylight) light bulb as a reference.

We quantified the appearance of leaves using the contrast comparison method, which follows simple colour pattern measures related to photon capture (Endler \& Mielke 2005; Vorobyev et al. 1998). A detailed explanation of the mathematical formulation model is given elsewhere (Osorio \& Vorobyev 1996; Vorobyev et al. 1998), but the following formulae suffice to predict the discriminability of any two of spectra, provided only that receptor spectral sensitivities and noise can be estimated. For an eye with $n$ spectral classes of photoreceptor viewing a surface with a reflectance spectrum, $S(\lambda)$, receptor quantum catches are given by:

$$
Q_{i}=\int R_{i}(\lambda) S(\lambda) I(\lambda) d \lambda
$$

Where $\lambda$ denotes wavelength, $i=1 ; 2 ; \ldots ; \mathrm{n} ; Q i$ is the quantum catch of receptor $i$, $R(\lambda)$ spectral sensitivity of receptor $i, I(\lambda)$ the spectrum of light entering the eye, and integration is over the visible spectrum. The $R(\lambda)$ values were obtained from (Endler \& Mielke, 2005) for both $U$ and $V$ type eye. Since the exact spectral discrimination 
data is not available for Moa, we used the $V$ model based on its closest living relative, Struthio camelus (Ostrich). To take account of receptor adaptation, receptor quantum catches, are normalized to the background to give a value:

$$
q_{i}=k_{i} Q_{i}
$$

The coefficients $k_{i}$ describe the von Kries transformation, and they are chosen so that the quantum catches for adapting background is constant:

$$
k_{i}=1 / \int I(\lambda) R_{i}(\lambda)
$$

Let $f_{i}$ be the signal of receptor mechanism $i$, and the $\Delta f_{i}$ be the differences of the signals in receptor mechanisms between the stimuli. The coded quantum catches are relative rather than absolute values (according to Weber's law), thus:

$$
\Delta f_{i}=\Delta q_{i} / q_{i}
$$

Where $\Delta q_{\mathrm{i}}$ denotes the differences in the quantum catch between the stimuli. The integration of the Weber-Fechner law gives the signal of the receptor channel that is proportional to the logarithm of the quantum catch with Endler's (2005) modification:

$$
f_{i}=\ln \left(q_{i}\right)
$$

The equation can be simplified as (when comparing chromatic contrast between spectra $a$ and spectra $b)$ :

$$
\Delta f_{i}=\ln \left(q_{i} a\right)-\ln \left(q_{i} b\right)=\ln \left(q_{i} a / q_{i} b\right)
$$

Receptor noise is described by the signal-to-noise ratio, or by its inverse, the Weber fraction, The Weber fraction is calculated independent of intensity (independent of number of absorbed quanta), thus: 


$$
\omega_{i}=v_{i} / \sqrt{\eta_{i}}
$$

Where $v_{i}$ is the noise-to-signal ration of a single cone (in this, we used 0.05, as suggested by (Endler \& Mielke 2005) and (Schaefer et al. 2007). $\eta_{i}$ refers to the number of receptor cells of type $i$ within the receptive field (Endler $\&$ Mielke 2005).

We then proceed to calculate and compare two colour patches by measuring the chromatic differences ( Endler \& Mielke 2005; Vorobyev et al., 1998). The following equation is from (Vorobyev \& Osorio 1998).

$$
\Delta S=\sqrt{\begin{array}{l}
(\omega 1 \omega 2)^{2}(\Delta f 4-\Delta f 3)^{2}+(\omega 1 \omega 3)^{2}(\Delta f 4-\Delta f 2)^{2}+ \\
(\omega 1 \omega 4)^{2}(\Delta f 3-\Delta f 2)^{2}+(\omega 2 \omega 3)^{2}(\Delta f 4-\Delta f 1)^{2}+ \\
\frac{(\omega 2 \omega 4)^{2}(\Delta f 3-\Delta f 1)^{2}+(\omega 3 \omega 4)^{2}(\Delta f 2-\Delta f 1)^{2}}{\left.\left((\omega 1 \omega 2 \omega 4)^{2}+(\omega 1 \omega 3 \omega 4)^{2}+(\omega 2 \omega 3 \omega 4)^{2}+(\omega 1 \omega 2 \omega 3)^{2}\right)\right)}
\end{array}}
$$

Colour is defined as a point in a perceptual space whose co-ordinate axes represent quantum catches of receptors (Poirson \& Wandell 1990). Discriminability of any two colours is described by the "distance", $\Delta \mathrm{S}$, between them in JND units ("just noticeable differences'). A colour patch with a JND value of more than 1 is at the threshold of discrimination from the background. Increasing JND values indicate increasing ease of distinction (e.g., from a larger distance), whereas values less than 1 JND are not discriminated.

Achromatic (brightness) contrasts are calculated similarly:

$$
\Delta S=\left|\Delta f_{i} / \omega_{D}\right|
$$

However, the exact working nature of achromatic signals in birds is still poorly understood (Campenhausen \& Kirschfeld 1998; Osorio et al., 1999; Hart 2001). Double cones have a broad spectral sensitivity, which overlaps both long and medium 
wavelength-sensitive cones, and are used in achromatic signal processing (non-colour based tasks) (Hart et al., 2000; Jones \& Osorio, 2004; Cuthill, 2006). $\omega_{D}$ is therefore regarded as the value of the double cones,. Because $\omega_{D}$ is the same for all targets, it does not affect relative achromatic contrasts. The only available double cone receptor data sensitivity is based on Leiothrix lutea and the $\omega_{D}$ is valued at 0.05 . 
Appendix B 


\title{
個体群生態学会 \\ 第 25 回年次大会 \\ プログラム・講演要旨集
}

\author{
Program and Abstracts \\ The 25th Annual Meeting \\ The Society of Population Ecology
}

\author{
2009 年 10 月 17 日（土）・18日（日） \\ 同志社大学寒梅館（京都市上京区） \\ October 17-18, 2009 \\ Kanbai-kan, Doshisha University (Kamigyo-ku, Kyoto)
}

個体群生態学会

第 25 回年次大会実行委員会 


\title{
農地景観におけるマルハナバチの個体群動態： \\ トラップとDNA分析から推定したコロニーの密度と成長
}

\author{
筑波沙彩・紺野康夫（帯広畜産大）・○永光輝義（森林総研）
}

マルハナバチは、外来種の制御や希少種の保全の対象となっている。そのために、野外で個体群の密度を 推定することが求められている。その推定の方法として、トラップによる捕獲、訪花個体の採集、訪花個 体の遺伝子型によるコロニー判定をとりあげる。帯広郊外の農地景観で2008年に、エゾトラマルハナバチ

(トラマル) とエゾオオマルハナバチ（オオマル）を材料として、それらの方法を比べた。5月29日から 10月30日にかけて林内に設置した12個のトラップによって捕獲されたワーカー数はトラマル15およびオ オマル96だった。6月27日から9月13日にかけて林外で採集された訪花ワーカー数はトラマル184および オオマル179だった。それらの訪花ワーカーの遺伝子型によって判定されたコロニー数はトラマル68およ びオオマル124で、それらを負の二項分布に当てはめて推定したコロニー数はトラマル108およびオオマ ル400だった。よって、トラップによる捕獲と訪花個体の採集から得られた両種の個体数は、林内への選 好性やコロニーサイズなどの種間差によって推定コロニー数から偏ることが示唆された。

$【 \mathrm{P} 1-16 】$

\section{Weta and fruit colour selection}

ONik Fadzly (School of Biological Sciences, Victoria University of Wellington) · Kevin Burns

New Zealand plants are known for unique plant structure (divaricating branching pattern) and unusual fruit colors. There are no green fruits at maturity; species with white or pale blue to sky-blue fruits, simultaneous bicolored fruit in which one color is white or blue pale, or species polymorphic for fruit color in which one morph has white fruit, make up $21.2 \%$ of the fleshy-fruited flora. A large fraction of the native flora (10070 of all woody species) has the divaricating habit, with shrubs that remained permanently divaricated and trees that have divaricating juvenile form. Recent studies had shown the coevolution between certain fruiting mechanisms of certain plants and their seed dispersers; such as the divaricate branching pattern that produces fleshy fruits in the inner most branches, restricting access to birds but facilitating access to smaller organisms such as weta. It has been shown that weta may be the only known seed dispersers within the insect world, fulfilling the vacant role of a small mammalian niche. However, do the frugivory patterns of weta display a preference of fruits based on colours? We tested the fruit colour preferences among Wellington tree weta (Hemideina crassidens) using Y-maze test. We used Coprosma acerosa dyed in red, blue or normal colouration to test for colour preferences. The post-dye fruit colours were tested with a spectrometer to find each fruits specific colour properties for later comparison with consumption patterns. Using this we found that the weta significantly preferred the normal and blue fruits over those of red. Further studies would be required to find preferences of a broader range of colour and species of fruits using a broader range of weta species (e.g. giant and cave weta), as well as background colour tests. Our result coincides with the fact that most insects cannot see far into the red spectrum. It is also possible that most divaricating species has either blue or white fruit colours ( high brightness colourations) in order to attract the nocturnal weta as possible seed dispersers. 
Appendix C 


\title{
Ontogenetic colour changes in an insular tree species: signalling to extinct browsing birds?
}

\author{
Nik Fadzly ${ }^{1}$, Cameron Jack ${ }^{1}$, H. Martin Schaefer ${ }^{2}$ and K. C. Burns ${ }^{1}$ \\ ${ }^{1}$ School of Biological Sciences, Victoria University of Wellington, PO Box 600, Wellington 6140, New Zealand; ${ }^{2}$ Faculty of Biology, Department of \\ Evolutionary Biology and Animal Ecology, University of Freiburg, Hauptstr. 1, 79104 Freiburg, Germany
}

\section{Summary}

Author for correspondence:

K. C. Burns

Tel: +64 44635339

Email: kevin.burns@vuw.ac.nz

Received: 10 March 2009

Accepted: 15 May 2009

New Phytologist (2009)

doi: $10.1111 / \mathrm{j} .1469-8137.2009 .02926 . x$

Key words: aposomatic, birds, coevolution, herbivory, New Zealand, plant defence.
- Animals often use colours to hide from predators (crypsis) or advertise defences (aposematism), but there is little evidence for colour-based defence in plants.

- Here, we test whether ontogenetic changes in leaf colour of lancewood (Pseudopanax crassifolius) may have been part of a defensive strategy against flightless browsing birds called moa, which were once the only large herbivores in New Zealand. We tested this hypothesis by conducting spectrographic measurements on differentsized plants grown in a common garden. We also compared these results with observations on a closely related, derived species that evolved in the absence of moa on the Chatham Islands.

- Spectrographic analyses showed that birds would have difficulty distinguishing seedling leaves against a background of leaf litter. Conversely, brightly coloured tissues flanking spines on sapling leaves are highly conspicuous to birds. Once above the reach of the tallest known moa, adults produce leaves that are typical in appearance to adult leaves. The Chatham Island species lacks ontogenetic colour changes entirely. - Overall, the results indicate that $P$. crassifolius goes through a remarkable series of colour changes during development, from cryptically coloured seedlings to aposematically coloured saplings, which may have formed a defensive strategy to protect against giant browsing birds.

\section{Introduction}

Plants are attacked by a bewildering array of herbivores. In response, plants have evolved a variety of defences to deter herbivores. In addition to defences such as thorns and noxious chemicals, there is growing speculation that plants might also use colours to defend themselves (Stone, 1979; Lev-Yadun \& Inbar, 2002). For example, aposematic or warning colours could be used to signal defensive structures (Lev-Yadun, 2001, 2009a). Alternatively, plants could be cryptically coloured in ways that make them difficult for herbivores to locate (Barlow \& Wiens, 1977; Wiens, 1978; Givnish et al., 1994; Watson, 2004; Lee, 2007). Although aposematic and cryptic colour patterns are common in animals, there is little evidence for their existence in plants.

We investigated ontogenetic shifts in leaf colours of Pseudopanax crassifolius Araliaceae, a heteroblastic tree that is endemic to New Zealand. To the human eye, P. crassifolius goes through a strange series of morphological transitions from germination to maturity (Fig. 1). Seedlings ( $<10 \mathrm{~cm}$ tall) produce small, narrow leaves that are mottled in appearance to the human eye. Saplings $(10-300 \mathrm{~cm}$ tall) produce larger, more elongate leaves that have thorn-like dentitions along their margins, each coinciding with a distinctive patch of different coloured tissue. Adult plants $(>300 \mathrm{~cm}$ tall) produce oblong leaves that are more ordinary in appearance.

These morphological changes could be adaptations to changing environmental conditions as plants grow vertically (Gould, 1993). Alternatively, they might also deter herbivory (Greenwood \& Atkinson, 1977, see also Boege \& Marquis, 2005). Before human arrival, New Zealand lacked native land mammals (except for two species of bat) and, instead, was home to massive, flightless birds called moa (Worthy \& Holdaway, 2002; Wood et al., 2008). If the mottled colours of seedling leaves make them difficult to distinguish against a background of leaf litter, their colours may have provided some defence against moa herbivory. Moa lacked teeth and swallowed leaves by placing them in their bill and snapping their head forward to orient them down the oesophagus (Bond et al., 2004). Several distinctive features of plant species 

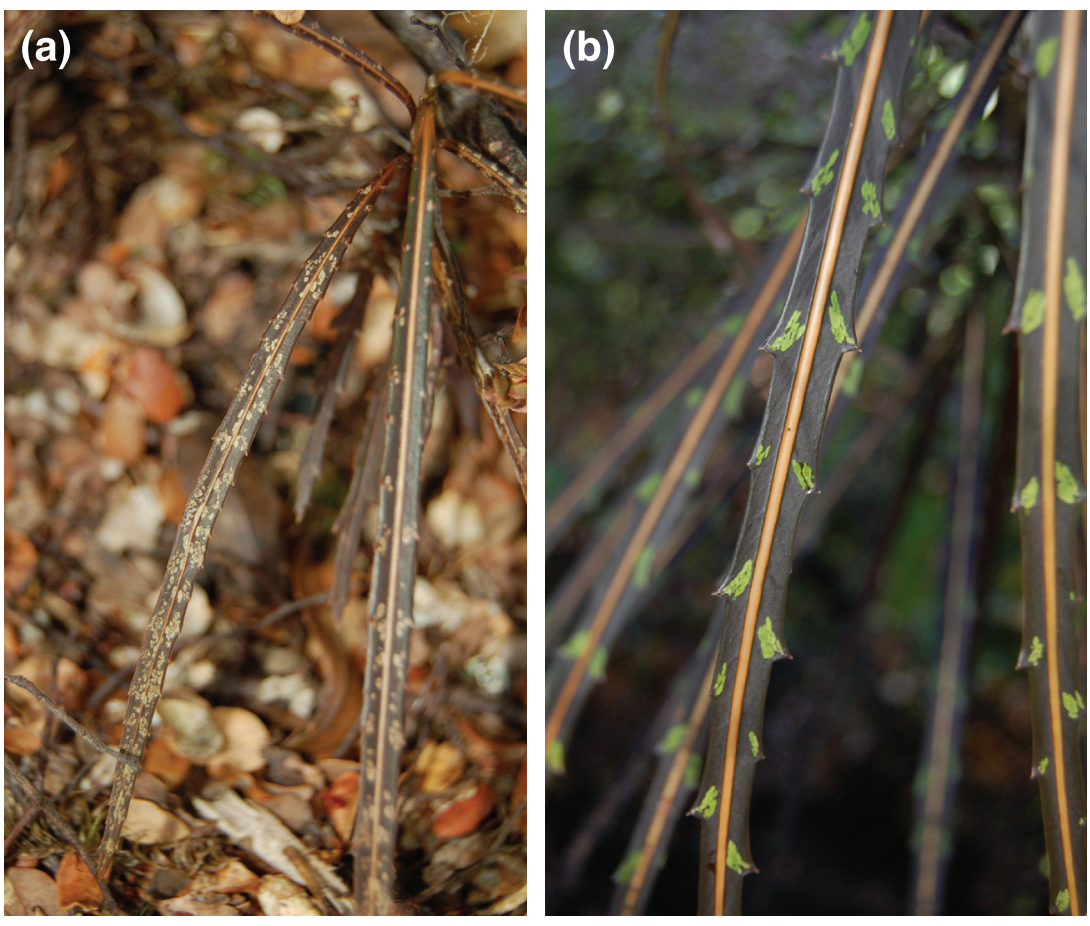

(c)

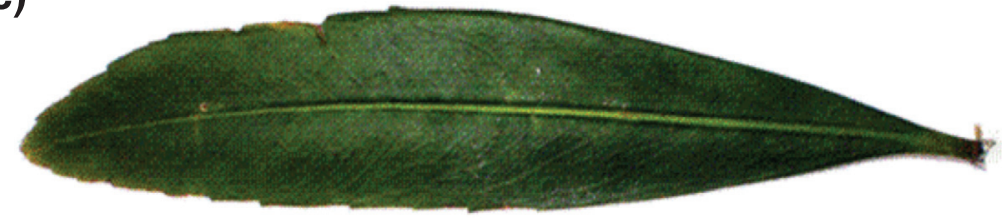

Fig. 1 A healthy Pseudopanax crassifolius seedling (a), sapling (b) and adult leaf (c) from Nelson Lakes National Park, South Island, New Zealand. inhabiting other isolated islands, such as divaricate branching and heteroblastic leaf morphology, may have complicated their ingestion by toothless browsers (Greenwood \& Atkinson, 1977; Diamond, 1990; Givnish et al., 1994; Bond et al., 2004; Eskildsen et al., 2004; Burns \& Dawson, 2006, Bond \& Silander, 2007). Unusual attributes of plants inhabiting other locales, such as excessively large fruits, have previously been linked to extinct 'megafauna' (Janzen \& Martin, 1982; Janzen, 1986; White, 1988; Barlow, 2000; Hansen \& Galetti, 2009). Similarly, the unusually long, rigid leaves produced by $P$. crassifolius saplings, coupled with the spine-like projections on their margins, may have made them difficult for moa to swallow, and the distinctive colour patches associated with spines could have served as a reliable warning signal of structural defence. The maximum browsing height of the largest moa was approximately $300 \mathrm{~cm}$ (Worthy \& Holdaway, 2002). Therefore, colour-based defence would not have been advantageous as plants grew above the reach of moa, perhaps leading to more typical leaf characteristics.

The Chatham Islands are a small group of islands of recent geological origin located $800 \mathrm{~km}$ east of New Zealand. The Chatham Island flora appears to be derived from overseas dispersal from New Zealand (see Trewick, 2000; Tre- wick et al., 2007). A notable example is Pseudopanax chathamicus Araliaceae.

Recent molecular analyses indicate that $P$. chathamicus is derived from a P. crassifolius ancestor in New Zealand (Mitchell \& Wagstaff, 1997; L. Pierre, Museum of New Zealand Te Papa Tongarewa, Wellington, New Zealand, pers. comm.). Unlike New Zealand, the Chatham Islands lacked large browsers, including moa. Dawson (1991) and Greenwood (1992) commented that plant taxa that are heteroblastic in New Zealand appear to have reduced morphological differentiation between adult and juvenile plants in the Chatham Islands (see also Burns \& Dawson, 2009). If ontogenetic changes in the colour of P. crassifolius evolved in response to moa herbivory in New Zealand, ontogenetic colour changes may be reduced in P. chathamicus, which evolved in the absence of moa.

We conducted spectrometric analyses to quantify ontogenetic colour changes in P. crassifolius from the perspective of birds to test four predictions arising from the moa browsing hypothesis: P. crassifolius seedlings resemble the reflectance properties of leaf litter, making them difficult to distinguish against their natural background (i.e. crypsis); as plants grow taller, saplings advertise sharp spines along their leaf margins with conspicuous colour patches (i.e. aposematism); once plants grow above the 
reach of the tallest known moa, they produce leaves that are ordinary in size, shape and colour; P. chathamicus, a closely related species that evolved in the absence of moa, has lost the ontogenetic changes in leaf colour displayed by $P$. crassifolius.

\section{Materials and Methods}

All $P$. crassifolius (A. Cunn) C. Koch and $P$. chathamicus Kirk. plants used in the analyses were grown in a common garden located in Otari-Wilton's Bush, Wellington, New Zealand $\left(41^{\circ} 15^{\prime} \mathrm{S}, 174^{\circ} 45^{\prime} \mathrm{E}\right)$. One randomly selected leaf was collected from 10 plants within three height classes. Seedlings were small enough to be consistently associated with a background of leaf litter. Saplings were too large to be associated consistently with leaf litter, but were within reach of browsing moa. Adults stood above the reach of the largest known moa. Sample sizes of adult plants of $P$. chathamicus were smaller $(n=2)$ because of their limited availability in the garden. Spectral readings were replicated five times for all leaves, which were then averaged before analyses. Leaf litter (i.e. dead leaves, earth and fallen branches) reflectance measurements were collected in 10 random locations within old-growth forest following Albert et al. (2004), which were averaged before analyses.

Spectral analyses were made using a USB Ocean Optics 2000 spectroradiometer and Xenon Pulse X2 lamp Ocean Optics light source. An object's reflectance properties were measured as the proportion of a diffuse, Teflon-based, white reflectance standard. The fibre optics probe was mounted inside a matte black plastic tube to exclude ambient light. The distance between each object and the probe was fixed at $1 \mathrm{~cm}$. The angle of illumination and reflection was fixed at $45^{\circ}$ to minimize glare. Spectra were calculated at $5 \mathrm{~nm}$ intervals from 300 to $700 \mathrm{~nm}$ with SpectraSuite software. We chose to restrict our analyses to wavelengths below $700 \mathrm{~nm}$ because the far-red spectrum cannot be discriminated by birds. Irradiance was measured with a cosine-corrected sensor and a D65 (normal daylight) light bulb as a reference.

We quantified the appearance of leaves using the contrast comparison method, which follows simple colour pattern measures related to photon capture (Vorobyev et al., 1998; Schaefer et al., 2004; Endler \& Mielke, 2005; Schaefer et al., 2007). A detailed explanation of the mathematical model is given elsewhere (Osorio \& Vorobyev, 1996; Vorobyev \& Osorio, 1998; Vorobyev et al., 1998). This method quantifies the discriminability of any two spectra, provided only that receptor spectral sensitivities and noise can be estimated.

The receptor spectral sensitivity values were obtained from Endler \& Mielke (2005) for both the U and V avian cones. As exact spectral discrimination data are not available for moa, we used the V model based on its closest living relative, Struthio camelus (ostrich) (Turvey et al., 2005). We chose to use the ostrich receptor because of the close phylogenetic relatedness to moa and the widespread evolutionary conservatism in avian colour vision (see Ödeen \& Håstad, 2003).
Colour is defined as a point in a perceptual space whose coordinate axes represent quantum catches of receptors (Poirson \& Wandell, 1990). The discriminability of any two colours is described by the 'distance' $\Delta S$ between them in JND ('just noticeable differences') units. A colour patch with a JND value of more than unity is at the threshold of discrimination from the background. Increasing JND values indicate increasing ease of distinction (e.g. from a larger distance), whereas values of less than $1 \mathrm{JND}$ are not discriminated. We calculated separate JND values for both chromatic (colour-based) and achromatic (brightness-based) spectral contrasts.

The exact working nature of achromatic or brightness signals in birds is still poorly understood (Campenhausen \& Kirschfeld, 1998; Osorio et al., 1999; Hart, 2001). Double cones have a broad spectral sensitivity, which overlaps with both long- and medium-wavelength-sensitive cones, and are used in achromatic signal processing (noncolour-based tasks) (Hart et al., 2000; Jones \& Osorio, 2004; Cuthill, 2006). The only available double cone receptor data sensitivity is based on Leiothrix lutea (red-billed Leiothrix). A detailed description of the methods used to quantify leaf reflectance properties is given in Supporting Information Notes $S 1$.

To test whether $P$. crassifolius seedlings are cryptically coloured, we visually compared the reflectance curves of seedlings and leaf litter. We also tested whether $P$. crassifolius seedlings were less conspicuous against a background of leaf litter than were P. chathamicus, by comparing the JND values derived from seedling versus leaf litter spectral contrasts between species using $t$-tests. Two $t$-tests were conducted, both chromatic and achromatic contrasts.

To test whether $P$. crassifolius advertises the spines located on its leaf margins with conspicuously coloured tissues, we visually compared the reflectance curve associated with spines with the curve characterizing the region between spines (i.e. nonspines). We also tested whether the spines on P. crassifolius were more conspicuous than the vestigial spines on P. chathamicus by comparing the JND values derived from spine versus nonspine spectral contrasts between species using $t$-tests. Separate $t$-tests were again conducted for chromatic and achromatic contrasts.

To test whether the reflectance properties of adult leaves of P. crassifolius were similar to those of adult leaves of both P. chathamicus and other New Zealand tree species, we conducted spectrometric measurements on 29 common tree species using the same protocol as described previously (i.e. one randomly selected leaf from 10 plants). Spectral readings were replicated five times for each leaf, which were averaged before analyses. We then compared the resulting reflectance curves for P. crassifolius, P. chathamicus and the other tree species. In this comparison, JND values were not compared statistically because of a lack of a consistent spectral background for comparative purposes. All data were logarithmically transformed when necessary to improve normality, and all analyses were conducted in $\mathrm{R}$ ( $\mathrm{R}$ Development Team, 2008). 

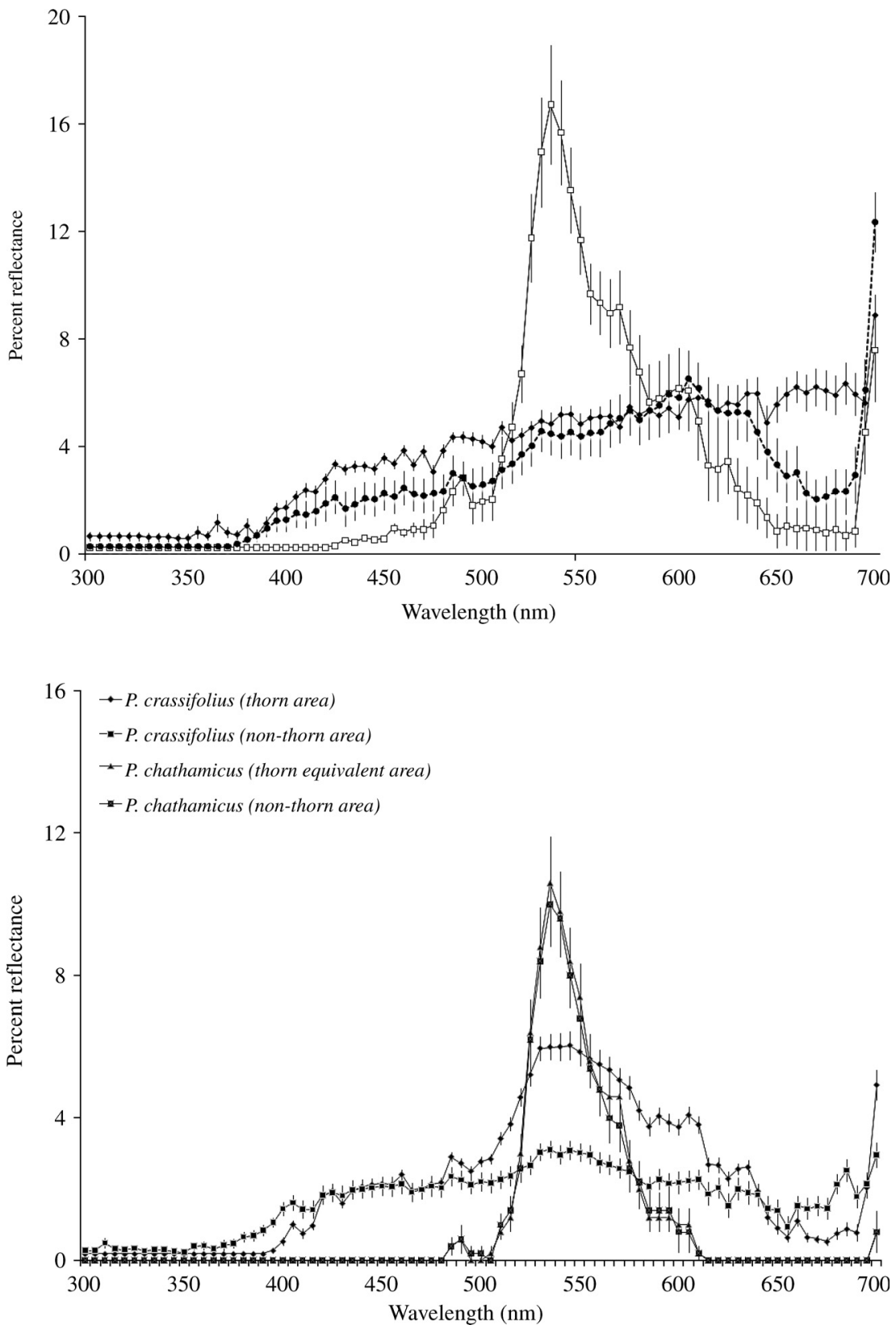

Fig. 2 Reflectance curves for Pseudopanax chathamicus seedlings (squares), $P$. crassifolius seedlings (circles) and leaf litter (diamonds).
Fig. 3 Reflectance curves for Pseudopanax chathamicus and $P$. crassifolius saplings. For each species, separate curves are drawn for tissues adjacent to spines and tissues between spines. Vertical black lines are \pm standard error.

\section{Results}

The average reflectance curve obtained for $P$. crassifolius seedlings was strikingly similar to that of leaf litter (Figs 1,2). However, the reflectance curve for $P$. chathamicus was markedly different. Chromatically, $P$. crassifolius seedlings had lower JND values against a leaf litter background $(16.6 \pm 3.1)$ than did $P$. chathamicus $47.8 \pm 1.9)(t=-8.62$, d.f. $=18, P<0.01)$. Achromatically, $P$. crassifolius seedlings also had lower JND values $(-5.74$ $\pm 3.8)$ than did P. chathamicus $(4.0 \pm 2.9)(t=-2.05$, d.f. $=18$, $P=0.05)$. Therefore, birds would have greater difficulty in distinguishing seedlings of $P$. crassifolius against a background of leaf litter relative to $P$. chathamicus.
Saplings of $P$. crassifolius produce long, narrow, rigid leaves that have spine-like structures along their margins, which are flanked by patches of lighter green coloration (Figs 1, 3). Conversely, P. chathamicus saplings produce leaves that appear to be phenotypically similar to adult leaves. The colour patches adjacent to spines in $P$. crassifolius had higher chromatic JND values (16.4 \pm 1.7$)$ against the background of the remainder of the leaf compared with $P$. chathamicus $(6.7 \pm 2.2)$ $(t=-3.34$, d.f. $=13, P=0.05)$. Similar differences between $P$. crassifolius $(10.5 \pm 2.5)$ and $P$. chathamicus $(0.7 \pm 1.8)$ were found in achromatic comparisons $(t=2.55$, d.f. $=13$, $P=0.02)$. Therefore, the spines along the margins of sapling leaves of $P$. crassifolius are made more conspicuous by 
New

Fig. 4 Reflectance curves for adult leaves of Pseudopanax chathamicus (squares), $P$. crassifolius (diamonds) and the average of 29 common New Zealand plant species (triangles). Vertical black lines are \pm standard error.

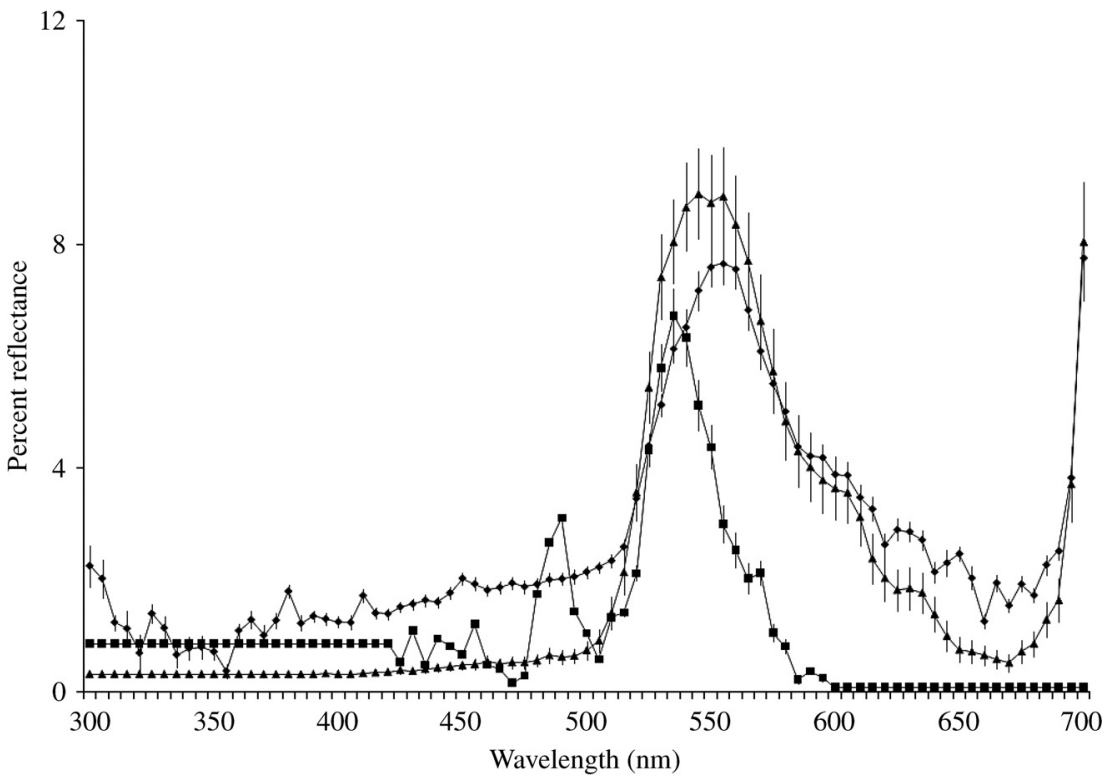

the colour of adjacent tissue, and this signal has been lost in P. chathamicus.

Adult leaves of $P$. crassifolius and $P$. chathamicus showed similar reflectance curves (Fig. 4). Both were also broadly similar to the adult leaves of the 29 co-occurring adult plant species. Therefore, we failed to find marked differences in adult leaf colours between $P$. crassifolius, $P$. chathamicus and other common tree species.

\section{Discussion}

Pseudopanax crassifolius goes through a remarkable series of colour changes during ontogeny. Seedlings are mottled in appearance and are similar in colour to leaf litter. Saplings produce long, rigid leaves with spine-like projections on their margins, each of which is typically associated with a patch of brightly coloured tissue. Once plants grow above $3 \mathrm{~m}$ in height, they abruptly begin to produce leaves that are typical in size, shape and colour to co-occurring tree species. Similar colour changes were not observed in P. chathamicus, which produces similarly coloured leaves throughout ontogeny. Therefore, changes in the colour of leaves produced by $P$. crassifolius through ontogeny are similar to the ontogenetic colour changes in many insects, which shift from being cryptically coloured to aposematically coloured during development (see Grant, 2007).

The unusual leaf colours in P. crassifolius could be a series of adaptations to enhance physiological performance in the changing environmental conditions experienced by plants as they grow from the forest floor into the canopy (Day, 1998; Howell et al., 2002). Pseudopanax crassifolius seedlings are known to possess traits (for example, thin lamina and low specific weight) that promote photosynthetic capability under low-light conditions (Gould, 1993; but see Gamage \& Jesson, 2007). Furthermore, phenotypic differences between P. chathamicus and
P. crassifolius could result from historical differences in climate between New Zealand and the Chatham Islands (McGlone \& Webb, 1981). New Zealand was heavily glaciated during the last glacial maximum, but the Chatham Islands were substantially warmer as a result of the ameliorating climatic effects of the ocean. The unusual leaf colours in P. crassifolius could increase leaf temperatures, which may have enhanced photosynthetic efficiency in the colder conditions that occurred in New Zealand. However, for climate to provide a convincing explanation for the results, vertical gradients in environmental conditions (i.e. from the ground to the forest canopy) would need to be more pronounced in New Zealand than in the Chatham Islands. Although these data are unavailable, forest structure appears to be broadly similar in both locales (K. C. Burns, pers. obs.), which suggests that this explanation is unlikely.

Alternatively, ontogenetic changes in leaf colours may represent a series of adaptations to first avoid and later deter moa browsing. The mottled colours of seedling leaves are similar to the appearance of leaf litter, which would reduce the probability of their detection by avian herbivores. Their unusual coloration may also reduce the appearance of leaf outlines and help camouflage leaves against the sunlight-dappled forest floor (Givnish, 1990). Saplings produce long, rigid leaves with spine-like projections on their margins that are consistently associated with bright colour patches that produce high achromatic contrasts. Interestingly, achromatic contrasts are particularly important in the detection of object borders in birds, humans and insects (Osorio et al., 1999), and may explain why plant spines are often coloured white or associated with white markings (Lev-Yadun, 2001, 2003, 2009b; Midgley, 2004). Furthermore, the avian eye consists of four types of single cone and one 'double cone' (Cuthill, 2006), which is unique to birds. The double cone has a broad spectral sensitivity and is associated with achromatic perception (i.e. intensity-based tasks). Therefore, birds would 
be particularly sensitive to the colour of sapling leaf spines, which are characterized by high achromatic contrasts.

A precise quantitative description of the visual acuities of moa is unlikely to ever be obtained because they are now extinct. We chose to make our reflectance calculations using the ostrich (V-type eye), because this species is a close relative to moa in the ratite family. However, to assess how sensitive the results might be to this choice of avian cone type, we recalculated the spectral data using the receptor sensitivity of a passerine (U-type eye). The results from this analysis were statistically indistinguishable from the results based on the ostrich eye. Therefore, the results do not appear to be sensitive to avian cone type.

Once plants grow above $3 \mathrm{~m}$, the maximum height of the largest known moa, leaves are typical in size and shape to the adult leaves of many other New Zealand tree species (Clearwater \& Gould, 1994). Their average spectral properties are also ordinary, that is mostly within the standard error of the leaves of syntopic species. Their colours are also consistent with the reflectance properties of the primary pigments involved in photosynthesis (chlorophyll $a$ and $b$ ), which have peak absorption values above and below the peak in reflectance of adult leaves at $545 \mathrm{~nm}$.

Insects are prominent herbivores in New Zealand, as they are on the Chatham Islands and elsewhere in the world, and may have played a role in the development of unusual colours in $P$. crassifolius. However, the spine-like projections on saplings are too large to provide protection against insect herbivores. A more likely explanation seems to be browsing by moa, which went extinct following the arrival of humans in New Zealand approximately $750 \mathrm{yr}$ ago. Because the putative selection agent is now extinct, the effectiveness of leaf colours in deterring moa herbivory cannot be tested directly. However, future work could still test the hypothesized link between leaf reflectance patterns and herbivore damage. For example, cafeteria-style experiments, similar to those of Bond et al. (2004), could be conducted to evaluate whether extant ratites (for example, emu) have trouble locating seeding leaves against a background of leaf litter, or whether they struggle to swallow sapling leaves and avoid those with brightly coloured spines.

\section{Acknowledgements}

We would like to thank John Dawson for help with the conceptual development of this study and Professor Simcha Lev-Yadun and two anonymous reviewers for helpful comments on a previous draft. Funding was provided by the Victoria University of Wellington and Universiti Sains Malaysia.

\section{References}

Albert J, Uy C, Endler JA. 2004. Modification of the visual background increases the conspicuousness of golden-collared manakin displays. Behavioral Ecology 15: 1003-1010.

Barlow BA, Wiens D. 1977. Host-parasite resemblance in Australian mistletoes: the case for cryptic mimicry. Evolution 31: 69-84.
Barlow C. 2000. The ghosts of evolution. Nonsensical fruits, missing partners, and other ecological anachronisms. New York, NY, USA: Basic Books, 304.

Boege K, Marquis RJ. 2005. Facing herbivory as you grow up: the ontogeny of resistance in plants. Trends in Ecology and Evolution 20: 441-448.

Bond WJ, Lee WG, Craine JM. 2004. Plant structural defences against browsing birds: a legacy of New Zealand's extinct moas. Oikos 104: 500-508.

Bond WJ, Silander JA. 2007. Springs and wire plants: anachronistic defences against Madagascar's extinct elephant birds. Proceedings of the Royal Society of London, Series B 274: 1985-1992.

Burns KC, Dawson JW. 2006. A morphological comparison of leaf heteroblasty between New Caledonia and New Zealand. New Zealand Journal of Botany 44: 387-396.

Burns KC, Dawson JW. 2009. Heteroblasty on Chatham Island: a comparison with New Zealand and New Caledonia. New Zealand Journal of Ecology 33, in press.

Campenhausen MV, Kirschfeld K. 1998. Spectral sensitivity of the accessory optic system of the pigeon. Journal of Computational Physics 183: 1-6.

Clearwater MJ, Gould KS. 1994. Comparative leaf development of juvenile and adult Pseudopanax crassifolius. Canadian Journal of Botany 72: 658-670.

Cuthill IC. 2006. Color perception. In: Hill GE, McGraw KJ, eds. Bird coloration. Cambridge, MA, USA: Harvard University Press.

Dawson JW. 1991. New Zealand Botany with a difference - the Chatham Islands. Tuatara 31: 23-40.

Day JS. 1998. Light conditions and the evolution of heteroblasty (and the divaricate form) in New Zealand. New Zealand Journal of Ecology 22: 43-54.

Diamond JM. 1990. Biological effects of ghosts. Nature 345: 769-770.

Endler JA, Mielke PW. 2005. Comparing entire colour patterns as birds see them. Biological Journal of the Linnean Society 86: 405-431.

Eskildsen LI, Olesen JM, Jones CG. 2004. Feeding response of the Aldabra giant tortoise (Geochelone gigantea) to island plants showing heterophylly. Journal of Biogeography 31: 1785-1790.

Gamage HK, Jesson L. 2007. Leaf heteroblasty is not an adaptation to shade: seedling anatomical and physiological responses to light. New Zealand Journal of Ecology 31: 245-254.

Givnish TJ. 1990. Leaf mottling: relation to growth form and leaf phenology and possible role as camouflage. Functional Ecology 4: 463-474.

Givnish TJ, Sytsma KJ, Smith JF, Hahn WJ. 1994. Thorn-like prickles and heterophylly in Cynae: adaptations to extinct avian browsers on Hawaii? Proceedings of the National Academy of Sciences, USA 91: 2810-2814.

Gould KS. 1993. Leaf heteroblasty in Pseudopanax crassifolius: functional significance of leaf morphology and anatomy. Annals of Botany 71: 61-70.

Grant JB. 2007. Ontogenetic colour change and the evolution of aposematism: a case study in panic moth caterpillars. Journal of Animal Ecology 76: 439-447.

Greenwood RM. 1992. Some differences between plants of the Chatham Island and the New Zealand mainland. New Zealand Journal of Ecology 16: $51-52$.

Greenwood RM, Atkinson IAE. 1977. Evolution of the divaricating plants in New Zealand in relation to Moa browsing. Proceedings of the New Zealand Ecological Society 24: 21-33.

Hansen DM, Galetti M. 2009. The forgotten megafauna. Science 324: $42-43$.

Hart NS. 2001. The visual ecology of avian photoreceptors. Progress in Retinal and Eye Research 20: 675-703.

Hart NS, Partridge JC, Cuthill IC, Bennet ATD. 2000. Visual pigments, oil droplets, ocular media and cone photoreceptor distribution in two species of passerine bird: the blue tit (Parus caeruleus L.) and the blackbird (Turdus merula L.). Journal of Computational Physics 186: 375-387.

Howell CJ, Kelly D, Turnbull MH. 2002. Moa ghosts exorcised: New Zealand's divaricate shrubs avoid photoinhibition. Functional Ecology 16: 232-240.

Janzen DH. 1986. Chihuahuan desert nopaleras: defaunated big mammal vegetation. Annual Review of Ecology and Systematics 17: 595-636. 
New

Janzen DH, Martin PS. 1982. Neotropical anachronisms: the fruits the gomphotheres ate. Science 215: 19-27.

Jones CD, Osorio D. 2004. Discrimination of oriented visual textures by poultry chicks. Vision Research 44: 83-89.

Lee D. 2007. Nature's palette. The science of plant color. Chicago, MI, USA: University of Chicago Press.

Lev-Yadun S. 2001. Aposematic (warning) coloration associated with thorns in higher plants. Journal of Theoretical Biology 210: 385-388.

Lev-Yadun S. 2003. Why do some thorny plants resemble green zebras? Journal of Theoretical Biology 224: 483-489.

Lev-Yadun S. 2009a. Aposematic (warning) coloration in plants. In: Baluska F, ed. Plant-environment interactions from behavioural perspective, Vol. II. Berlin, Germany: Springer-Verlag, 167-202.

Lev-Yadun S. 2009b. Mullerian and Batesian mimicry rings of white-variegated aposematic spiny and thorny plants: a hypothesis. Israel Journal of Plant Sciences, in press.

Lev-Yadun S, Inbar M. 2002. Defensive ant, aphid and caterpillar mimicry in plants? Botanical Journal of the Linnean Society 77: 393-398.

McGlone MS, Webb CJ. 1981. Selective forces influencing the evolution of divaricating plants. New Zealand Journal of Ecology 4: 20-28.

Midgley JJ. 2004. Why are spines of African Acacia species white? African Journal of Range and Forage Science 21: 211-212.

Mitchell AD, Wagstaff SJ. 1997. Phylogenetic relationships of Pseudopanax species (Araliaceae) inferred from parsimony analysis of rDNA sequence data and morphology. Plant Systematics and Evolution 208: 121-138.

Ödeen A, Håstad O. 2003. Complex distribution of avian color vision systems revealed by sequencing the SWS1 Opsin from total DNA. Molecular Biology and Ecology 20: 855-861.

Osorio D, Vorobyev M. 1996. Colour vision as an adaptation to frugivory in primates. Proceedings of the Royal Society of London, Series B 263: 593-599.

Osorio D, Vorobyev M, Jones CD. 1999. Colour vision of domestic chicks. Journal of Experimental Biology 202: 2951-2959.

Poirson AB, Wandell BA. 1990. The ellipsoidal representation of spectral sensitivity. Vision Research 30: 647-652.

R Development Core Team. 2008. R: a language and environment for statistical computing. Vienna, Austria: R Foundation for Statistical Computing.

Schaefer HM, Schaefer V, Levey DJ. 2004. How plant-animal interactions signal new insights in communication. Trends in Ecology and Evolution 19: 577-584.

Schaefer HM, Schaefer V, Vorobyev M. 2007. Are fruit colors adapted to consumer vision and birds equally efficient in detecting colorful signals? American Naturalist 169: 169-169.
Stone BC. 1979. Protective coloration of young leaves in certain Malaysian palms. Biotropica 11: 126.

Trewick SA. 2000. Molecular evidence for dispersal rather than vicariance as the origin of flightless insect species on the Chatham Islands, New Zealand. Journal of Biogeography 27: 1189-1200.

Trewick SA, Paterson AM, Campbell HJ. 2007. Hello New Zealand. Journal of Biogeography 34: 1-6.

Turvey ST, Green OW, Holdaway RN. 2005. Cortical growth marks reveal extended juvenile development in New Zealand moa. Nature 435: 940-943.

Vorobyev M, Osorio D. 1998. Receptor noise as a determinant of colour thresholds. Proceedings of the Royal Society of London, Series B 265: 351-358.

Vorobyev M, Osorio D, Bennet ATD, Marshall NJ, Cuthill IC. 1998. Tetrachromacy, oil droplets and bird plumage colours. Journal of Computational Physics 183: 621-633.

Watson DH. 2004. Mistletoe: a unique constituent of canopies world wide. In: Lowman MD, Rinker HB, eds. Forest canopies. London, UK: Elsevier Academic Press, 212-224.

White PS. 1988. Prickle distribution in Aralia spinosa (Araliaceae). American Journal of Botany 75: 282-285.

Wiens D. 1978. Mimicry in plants. Evolutionary Biology 11: 365-403.

Wood JR, Rawlence NJ, Rogers GM, Austin JJ, Worthy TH, Cooper A. 2008. Coprolite deposits reveal the diet and ecology of the extinct New Zealand megaherbivore moa (Aves, Dinornithiformes). Quaternary Science Reviews 27: 2593-2602.

Worthy TH, Holdaway RN. 2002. The lost world of the moa: prehistoric life of New Zealand. Christchurch, New Zealand: Canterbury University Press in association with Indiana University Press, 212-229.

\section{Supporting Information}

Additional supporting information may be found in the online version of this article.

Notes S1 Materials and methods - equations

Please note: Wiley-Blackwell are not responsible for the content or functionality of any supporting information supplied by the authors. Any queries (other than missing material) should be directed to the New Phytologist Central Office. 
Appendix D 


$$
\text { PROOF } \square 40850 \square \text { IJPS } \square 171 \square 7 \square 2010 \square \text { JDO } \square \text { CHECKED } \square \text { 06/01/10 }
$$

Int. J. Plant Sci. 171(7):000-000. 2010.

(c) 2010 by The University of Chicago. All rights reserved.

1058-5893/2010/17107-00XX\$15.00 DOI: $10.1086 / 654850$

\title{
HIDING FROM THE GHOST OF HERBIVORY PAST: EVIDENCE FOR CRYPSIS IN AN INSULAR TREE SPECIES
}

\author{
Nik Fadzly ${ }^{1}$ and K. C. Burns \\ School of Biological Sciences, Victoria University of Wellington, P.O. Box 600, Wellington 6140, New Zealand
}

\begin{abstract}
The color of many animals matches that of their preferred habitats, making them difficult for predators to locate. However, quantitative examples of crypsis in plants are comparatively rare. We conducted morphometric and spectrographic analyses of a heteroblastic tree species that is endemic to New Zealand (Elaeocarpus hookerianus Raoul) to test whether it is cryptic in appearance from the perspective of birds, who were once dominant browsers in New Zealand. The leaves of smaller, juvenile plants are highly variable in size and shape and are mottled brown in color from the perspective of birds, which would make them difficult for herbivorous birds to locate against a background of leaf litter. However, once plants grow to above $3 \mathrm{~m}$ in height, beyond the reach of the largest herbivorous bird known to inhabit New Zealand, plants suddenly produce leaves that are ordinary in size, shape, and color. Results provide quantitative support for the hypothesis that E. hookerianus is cryptically colored when within reach of flightless browsing birds.
\end{abstract}

Keywords: color, crypsis, herbivory, heteroblasty, moa, Elaeocarpus hookerianus.

\section{Introduction}

There is a long history of speculation that some plants are colored and shaped in ways that make them difficult to be located by predators. For example, the size and shape of leaves produced by many species of Australian mistletoes match their hosts, which may make them difficult for herbivores to distinguish (Barlow and Weins 1977; Canyon and Hill 1997). Similarly, stone plants (Lithops spp.) that grow in arid, rocky habitat in southern Africa closely resemble small pebbles, which may make them difficult for herbivorous mammals to locate (Barlow and Weins 1977; Nobel 1989). However, these and other examples of crypsis in plants have yet to be thoroughly tested, and there is little quantitative evidence for the evolution of crypsis in plants (Everard and Morley 1970; Wiens 1978; Stone 1979; Atsatt 1983; Lev-Yadun 2006; Schaefer and Ruxton 2009; but see Klooster et al. 2009).

Like most other isolated islands, New Zealand lacked herbivorous mammals before the arrival of humans and instead was home to giant browsing birds, moa. Differences between birds and mammals in foraging behavior, digestion, and vision may have promoted a suite of unusual plant defenses. Few New Zealand plants produce thorns, which are known to be effective in deterring mammal herbivory (Ehrlich and Raven 1964; Grub 1992; Lev-Yadun 2001, 2003, 2006, 2009a, 2009b; Midgely et al. 2001). On the other hand, plant species from a diverse array of phylogenetic backgrounds in New Zealand are heteroblastic, with abrupt changes in morphology during ontogeny leading to distinct juvenile and adult forms (Day et al. 1997, 1998). Many New Zealand plant species are

\footnotetext{
${ }^{1}$ Author for correspondence; current address: School of Biological Sciences, Universiti Sains Malaysia, 11800 Minden, Penang, Malaysia; e-mail: nroselnik@myvuw.ac.nz.
}

Manuscript received February 2010; revised manuscript received May 2010. also divaricately branched, meaning that they produce new stems at right angles to one another, which leads to an overall matted appearance (i.e., "wire plants"; sensu Bond and Silander 2007). Moreover, many heteroblastic plant species are divaricately branched in early ontogenetic stages and then more normally branched once they grow above $3 \mathrm{~m}$ in height, which coincides approximately with the largest known moa (Greenwood and Atkinson 1977). Although divaricate branching may have evolved to enhance physiological performance (see Day et al. 1997, 1998; Howell et al. 2002), it may also have evolved to deter moa browsing. Bond et al. (2004) offered divaricately branched plants to emu (Dromaius baudinianus), a close living relative of moa that is native to Australia, and found that they were damaged less than nondivaricately branched species.

Many heteroblastic species also change color during ontogeny (Day 1998). Juvenile leaves of some species are colored mottled brown, which make them difficult for human observers to locate in leaf litter. Changes in leaf color during ontogeny have led to the hypothesis that juvenile leaves are cryptically colored to deter moa browsing (Greenwood and Atkinson 1977; Brown et al. 1991). However, quantitative tests of this hypothesis are rare (Fadzly et al. 2009), and there are alternate explanations for juvenile leaf colors (Cockayne 1912; Godley 1985; Gould 1993; Kelly 1994).

Elaeocarpus hookerianus Raoul displays one of the most striking heteroblastic changes in morphology of any New Zealand tree species (Day et al. 1998). Juvenile plants are divaricately branched and produce leaves that are stunningly variable in morphology, ranging from obovate with smooth edges to linear-lanceolate with heavily serrated margins (Day et al. 1997). Juvenile leaves are also strangely colored to human observers and range in hue from pale brown to almost black in appearance. When plants grow to a height of $\sim 3 \mathrm{~m}$, they undergo a sudden shift to a more normal appearance 
(Allan 1961). Adult plants branch at narrower angles and produce leaves that are larger and more consistently elliptical in shape than the juvenile leaves. They are also green in coloration, similar to other common tree species.

We conducted a series of morphological and spectrographic analyses to evaluate whether heteroblastic changes in the morphology of E. hookerianus could have evolved to deter avian browsers. First, we compared the spectral properties of seedling leaves to leaf litter to test whether they are cryptically colored from the perspective of birds. Second, given that leaf litter is comprised of a diverse array of objects-including twigs, rocks, and decomposing leaves-we tested whether juvenile leaves are more variable in size and shape than their adult counterparts, which may have made them more difficult to locate against variable leaf litter backgrounds.

\section{Material and Methods}

All data were collected from Nelson Lakes National Park, South Island, New Zealand $\left(41^{\circ} 81^{\prime} \mathrm{S}, 172^{\circ} 85^{\prime} \mathrm{E}\right)$. Ten leaves were randomly selected from 10 juvenile plants $(<300 \mathrm{~cm}$ tall) and 10 adult plants $(>300 \mathrm{~cm}$ tall). We chose this height to delineate juvenile and adult plants because it appeared to be the height at which plants switched from producing juvenile to adult morphological characteristics and has been recorded previously in the literature (e.g., Greenwood and Atkinson 1977). Ten reflectance measurements of leaf litter (i.e., dead leaves, earth, rocks, and fallen branches) were collected in 10 random locations within old-growth forest (Uy and Endler 2004) and were averaged before analyses.

Leaf spectra were measured with a USB Ocean Optics 2000 spectroradiometer and Xenon Pulse X2 lamp Ocean Optics light source. An object's reflectance properties were measured as the proportion of a diffuse reflectance standard (Teflon coated white standard). The fiber optics probe was mounted inside a matte black plastic tube to exclude ambient light. The distance between each object and the probe was fixed at $1 \mathrm{~cm}$, with the angle of illumination and reflection fixed at $45^{\circ}$ to minimize glare. Irradiance was measured with a cosine corrected sensor and a D65 (normal daylight) light bulb as a reference. Spectra were calculated at 5-nm intervals from 300 to $700 \mathrm{~nm}$ with SpectraSuite software.

We used an eye model based on the spectral sensitivities and receptor noise of the four avian cone types ( $\mathrm{u}, \mathrm{s}, \mathrm{m}$, and 1 ). We quantified the appearance of leaves using the contrast comparison method, which follows simple color pattern measures related to photon capture (Vorobyev et al. 1998; Endler and Mielke 2005). A detailed explanation of the mathematical formulation model is given elsewhere (Osorio and Vorobyev 1996; Vorobyev et al. 1998), but they are sufficient to predict the discriminability of any two of spectra, provided that only receptor spectral sensitivities and noise can be estimated. The calculation provides photon capture values for each type of cone receptor in the bird's eye. The receptor spectral sensitivity values were obtained from Endler and Mielke (2005) for both the $U$ and $V$ avian cones. Since exact spectral discrimination data are not available for moa, we used the $V$ model on the basis of its closest living relative, the ostrich (Struthio camelus). We chose to use the ostrich because of its close phy- logenetic relation to moa and widespread evolutionary conservatism in avian color vision (Odeen and Hastad 2003; Turvey et al. 2005).

Color can be defined as a point in a perceptual space whose coordinate axes represent quantum catches of optical receptors (Poirson and Wandell 1990). Color perception is comprised of two components, chromatic (spectral distribution) and achromatic (brightness of all wavelengths) contrasts between an object and its visual background. For chromatic comparisons, we used Endler and Mielke's (2005) analytical technique. The outputs for each of the four retinal cones $(u$, $\mathrm{s}, \mathrm{m}$, and 1) were transformed into points in tetrahedron with a height of 1 , resulting in $x, y$, and $z$ Cartesian coordinates in three-dimensional space (Aitchison 2003). The chromatic contrast $(C)$ between any two samples (e.g., leaf a and background b) are then calculated as the Euclidean distance between the two points in tetrahedral color space:

$$
C=\sqrt{\left(x_{\mathrm{a}}-x_{\mathrm{b}}\right)^{2}+\left(y_{\mathrm{a}}-y_{\mathrm{b}}\right)^{2}+\left(z_{\mathrm{a}}-z_{\mathrm{b}}\right)^{2}} .
$$

Greater Euclidean distances between points indicate greater color contrasts and a more visually apparent object. Since the height of the tetrahedron is set to 1 , values range from 0 (indicating no contrast at all) to 1 (highest contrasting color).

We used a different analytical technique to make achromatic comparisons because the exact working nature of achromatic signals in birds is still poorly understood (Campenhausen and Kirschfeld 1998; Osorio et al. 1999; Hart 2001). Birds possess "double cones" that have broad spectral sensitivities that overlap with both long- and medium-wavelength-sensitive cones and are used in achromatic signal processing (non-color-based tasks; Hart et al. 2000; Jones and Osorio 2004; Cuthill 2006). Achromatic $(\Delta S)$ contrasts were calculated as

$$
\Delta S=\left|\frac{\Delta f_{\mathrm{i}}}{\omega_{\mathrm{D}}}\right|,
$$

where $\Delta f_{\mathrm{i}}$ is the difference in the stimulus of receptor mechanisms between signals (refer to Osorio and Vorobyev 1996; Vorobyev et al. 1998) and $\omega_{\mathrm{D}}$ is the value of double cones. Because $\omega_{\mathrm{D}}$ is the same for all targets, it does not affect relative achromatic contrasts. We used the only available data on double cone receptor sensitivity, which is based on red-billed Leiothrix (Leiothrix lutea), where $\omega_{\mathrm{D}}$ is valued at 0.05 . Discriminability of any two objects is described by the "distance" $(\Delta S)$ between them in units of "just noticeable differences" (JND). A JND value of 1 is at the threshold of discrimination. Increasing JND values indicate increasing ease of distinction, whereas values less than 1 JND are unlikely to be discriminated.

To test the hypothesis that Elaeocarpus hookerianus juveniles are cryptically colored from the perspective of birds against leaf litter backgrounds, we compared the chromatic and achromatic contrasts of juvenile and adult leaves against leaf litter using a general linear model. Euclidean distances in tetrahedral color space and JND values were used as dependent variables and life stage (adult vs. juvenile) was considered a fixed factor in separate analyses. Because multiple leaves were sampled from each plant, individual plants were also included in the model as a random factor to account for 
the independence problem associated with sampling multiple leaves from the same individual.

To test whether juvenile plants show greater morphological variability than adult plants, we quantified the size and shape of 10 leaves from each of 10 juvenile and 10 adult plants, leading to an overall sample size of 100 leaves from each life-history stage. We scanned each leaf electronically using a flatbed scanner and then used ImageJ software (Abramoff et al. 2004) to calculate total leaf area, circularity, length to width ratio, and the dissection index, which characterizes leaf lobbing (McLellan and Endler 1998). Next we used the technique described by Beaumont and Burns (2009) to test whether morphological variability is higher in juveniles than adults. We used multidimensional scaling (PROXSCAL) to transform these four variables into two dimensions, such that points situated close together in multivariate space represent morphologically similar leaves, while points that are widely separated represent morphologically divergent leaves. To test whether adult leaves were more variable morphologically than juvenile leaves, we conducted a $t$-test to compare the Euclidean distances from each leaf to the centroid of their respective ontogenetic grouping. All data were log transformed when necessary to improve normality, and all analyses were conducted in R (R Core Development Team 2008).

Quantitative comparisons between the morphology of juvenile leaves and leaf litter would provide a valuable additional test of the hypothesis that heteroblastic changes in the morphology of E. hookerianus has evolved to deter avian browsers. However, leaf litter is comprised of a variety of very different objects, including dead leaves, twigs, stones, and soil. Although the measurements used to quantify leaf morphology (length, width, area, circularity, and lobbing) can be made accurately on recently abscised leaves, much of the leaf litter is comprised of heavily decomposed leaves, which are often loosely stuck together in brittle mats. Many decomposed leaves are also contorted in three dimensions and have large open spaces where the lamina has rotted away from the midvein. These attributes of decomposing leaves render accurate, quantitative comparisons with healthy juvenile leaves intractable. Quantifying the length, width, area, and lobbing of twigs, stones, and soil in a way that can be compared quantitatively with live leaves is also impossible, rendering quantitative comparisons between juvenile leaves and leaf litter impossible.

\section{Results}

The average reflectance curve for Elaeocarpus hookerianus juvenile leaves was similar to the average reflectance curve for leaf litter (fig. 1). Juvenile leaves had significantly lower chromatic contrasts $(0.21 \pm 0.11)$ with leaf litter than the adult leaves $(0.53 \pm 0.12)$ on the basis of Euclidean distances in tetrahedral color space $(F=65.20, \mathrm{df}=1, P<0.001)$. Juvenile leaves also showed lower achromatic contrasts $(-4.50 \pm 22.08)$ compared with the adult leaves $(11.17 \pm 12.20)$ on the basis of JND values $(F=7.60, \mathrm{df}=1, P=0.01)$.

Juvenile leaves were more variable in size and shape than adult leaves (fig. 2). Like all multivariate procedures, multidimensional scaling seeks to reduce a large number of variables (four in our case) into two dimensions, which inevitably results in the loss of information. An inverse goodness-of-fit measure called "stress" can be used to determine the accuracy of the two dimensions in describing variability in the original four variables. In this instance, normalized raw stress

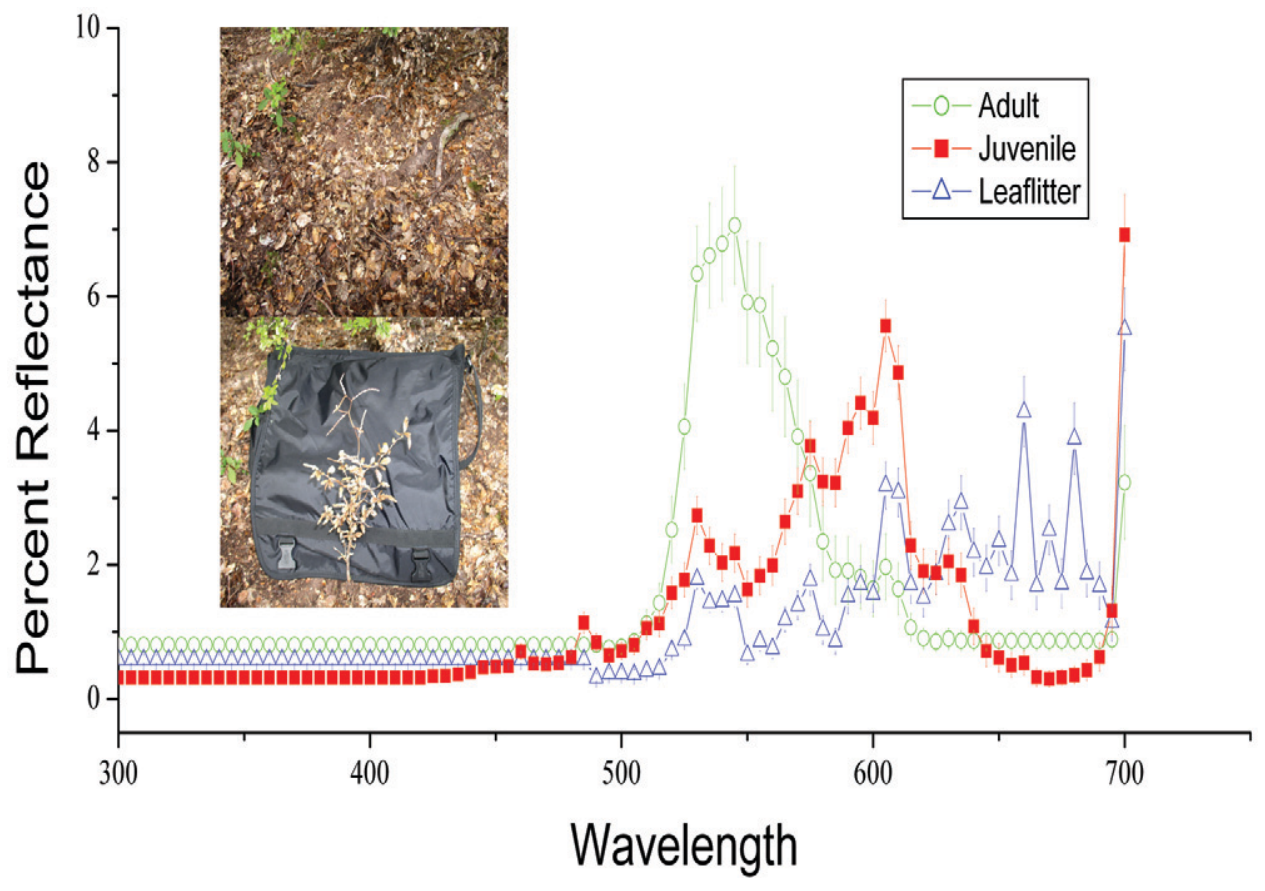

Fig. 1 Average reflectance curves (with standard error lines) for the adult and juvenile Elaeocarpus hookerianus and the leaf litter background. Inset shows two photographs of a single seedling taken from the same location after changes in its background. 


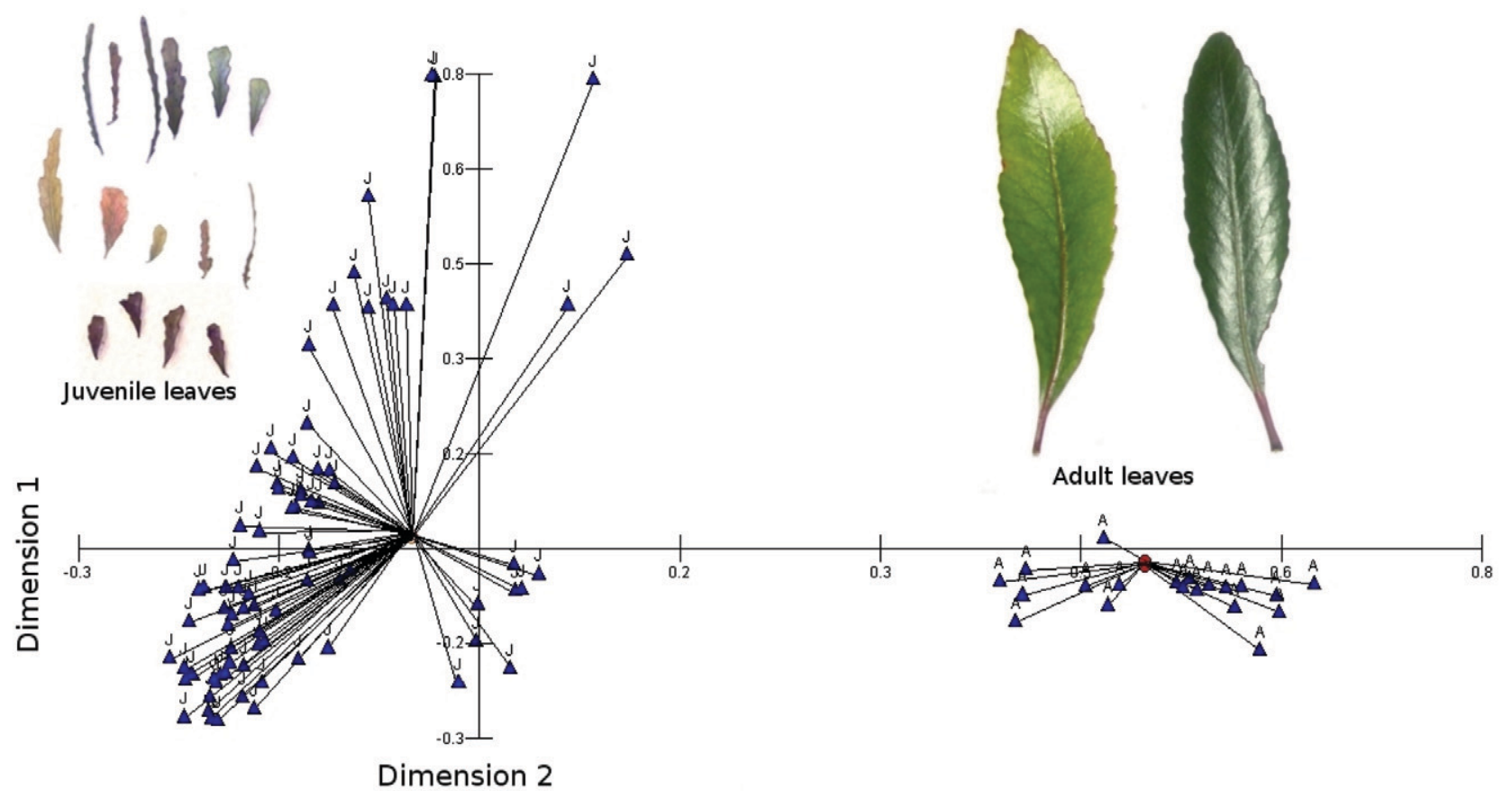

Fig. 2 Multidimensional scaling analyses $(A=$ adult leaves, $J=$ juvenile leaves). Lines are distances between each sample to their group centroid. Juvenile leaves (left inset) have a varied leaf shape pattern compared with the typical adult leaves (right inset).

was 0.1 , indicating that the two dimensions generated by the Q1 multidimensional scaling analysis provided an accurate representation of leaf size and shape (see Sturrock and Rocha 2000). Juvenile leaves exhibited greater variability in their multivariate distributions than adult leaves, which instead formed a tight cluster of points in multidimensional space. Euclidean distances between each leaf and the centroid for its ontogenetic group were higher in juvenile leaves than adult leaves $(t$-test $=-5.93, \mathrm{df}=198, P=0.01)$, indicating that juvenile leaves had higher leaf shape diversity.

\section{Discussion}

Results are consistent with the hypothesis that heteroblasty in Elaeocarpus hookerianus evolved as a defensive strategy to deter moa browsing. Juvenile leaves displayed low chromatic and achromatic contrasts against litter backgrounds, which likely made them difficult for moa to locate. Results also showed that juvenile leaves were highly variable in both size and shape. Given that leaf litter is composed of a variety of objects that are highly variable in size and shape, morphological variability may have contributed to the cryptic appearance of juvenile leaves. However, there are other plausible explanations for heteroblastic changes in morphology (see Cockayne 1912; McGlone and Webb 1981; Godley 1985; Kelly 1994; Gamage and Jesson 2007), so this explanation for our results remains speculative.

There are many putative examples of reduce visual apparency in the New Zealand flora (see Burns 2010). For example, Celmisia lyalli and Celmisia petrei appear to mimic structurally defended species of Aciphylla, and Parsonia capsularis leaves look strikingly similar to dead twigs to the human eye (Brown et al. 1991). However, until recently, quantitative tests for reduced visual apparency in the New Zealand flora were lacking. Fadzly et al. (2009) recently documented that Pseudopanax crassifolius seedlings are strikingly similar to the color of leaf litter to the avian eye, which they interpret as evidence for crypsis. However, as plants grow taller, they begin to produce long, rigid leaves with spinelike projections on their margins, which would have made them difficult for toothless browsers to swallow. Each lateral spine is also associated with a patch of brightly colored tissue, which appears to serve as an honest signal of defense (aposematism).

Similar to E. hookerianus, once $P$. crassifolius plants grow above $3 \mathrm{~m}$ in height, they begin to produce leaves that are typical in size and shape. The average spectral properties of adult leaves are also ordinary and are consistent with the reflectance properties of the primary pigments involved in photosynthesis (chlorophyll $a$ and $b$ ), which have peak absorbance values above and below the peak in reflectance at $545 \mathrm{~nm}$. However, there are several notable differences between species. First, E. hookerianus displays a morphological form of heteroblasty (i.e., divaricately branched juveniles) different from $P$. crassifolius, which is completely unbranched until it matures (Burns and Dawson 2009). Second, P. crassifolius goes through two very obvious morphological transitions during ontogeny (cryptic seedlings, aposematic saplings, and adults that are typical in appearance), while E. hookerianus goes through only a single transition (cryptic seedlings, typical adults; see also Day et al. 1995). Last, E. hookerianus displays exceptional variability in the size and shape of juvenile leaves, which is absent in P. crassifolius and may further enhance their similarity in appearance to leaf litter.

Klooster et al. (2009) provide another quantitative test for plant crypsis in another part of the world. Monotropsis odorata 
is a nonphotosynthetic plant native to eastern North America that acquires carbon resources from mycorrhizal fungi (i.e., mycoheterotrophic). In the case of M. odorata, their reproductive structures are covered in bracts that strongly resemble leaf litter, effectively camouflaging stem and floral tissues from herbivory in a somewhat similar way to E. hookerianus. However, in this instance, the authors experimentally removed the bracts and showed that they effectively deter herbivores. The authors also suggest that color-based defense might be particularly common in mycoheterotrophic plants, because they do not need to use photosynthetic pigments to meet their energetic needs.

Divaricate branching, high variability of leaf shapes, and low chromatic and achromatic contrasts with leaf litter may create an isodipole texture in which visual processing cannot discriminate textures that have the same power spectrum or whose statistics are identical (Julesz 1962; Caelli and Julesz $1978 a, 1978 b)$. In this way, E. hookerianus juveniles may have been difficult for browsing moa to distinguish. However, crypsis is unlikely to be a fully effective defensive strategy on its own, since many animals including birds can learn to locate highly cryptic prey items. For instance, poultry chicks can be trained to pick up odd from even isodipole textures, provided there is high enough chromatic and achromatic contrast (Osorio et al. 1999; Jones and Osorio 2004).

Although these results are consistent with the moabrowsing hypothesis, other causal factors cannot be ruled out. The unique architecture of juvenile E. hookerianus could be a physiological adaptation to environmental conditions. Day and Gould (1997) suggest that the unusual morphology of E. hookerianus juveniles could be a strategy to exploit spatial variation in environmental conditions. Divaricate branching may help plants "explore" new light environments both laterally and vertically, in addition to "exploiting" previously sequestered regions within their canopy (see also Day et al. 1997). Variable leaf shapes may also have a physiological explanation. Linear-lanceolate type leaves, although costly to produce, could provide greater energetic returns to the plant if they provide better light penetration into the interior of plants, facilitating greater gas and heat exchange in the shorter, wider, obovate type leaves below (see Horn 1971; Givnish 1986; Kelly 1994).

Because moa are now extinct, the effectiveness of leaf colors in deterring moa herbivory cannot be tested directly. However, future work could be conducted on extant ratites, such as emu, as a surrogate for moa. An experimental approach similar to that of Bond et al. (2004) could be employed by manipulating leaf and background colors to test whether ratites have difficulties locating juvenile leaves that match their backgrounds, as their eye physiology suggests. These and other quantitative tests of reduced visual apparency in plants will help to establish whether crypsis is a common strategy of plant defense.

\section{Literature Cited}

Abramoff MD, Magelhaes PJ, Ram SJ 2004 Image processing with ImageJ. Biophotonics Int 11:36-42.

Aitchison J 2003 The statistical analysis of compositional data. Blackburn, Caldwell, NJ.

Allan H 1961 Flora of New Zealand. Government Printer, Wellington.

Atsatt PR 1983 Mistletoe leaf shape: a host morphogen hypothesis. Pages 259-275 in M Calder, P Bernhardt, eds. The biology of mistletoes. Academic Press, Sydney.

Barlow BA, D Weins 1977 Host-parasite resemblance in Australian mistletoes: the case for cryptic mimicry. Evolution 31:69-84.

Beaumont S, KC Burns 2009 Vertical gradients in leaf trait diversity in a New Zealand forest. Trees Struct Funct 23:339-346.

Bond WJ, WG Lee, JM Craine 2004 Plant structural defences against browsing birds: a legacy of New Zealand's extinct moas. Oikos 104: 500-508.

Bond WJ, JA Silander 2007 Springs and wire plants: anachronistic defences against Madagascar's extinct elephant birds. Proc R Soc B 274:1985-1992.

Brown VK, JH Lawton, PJ Grubb 1991 Herbivory and the evolution of leaf size and shape. Philos Trans R Soc B 333:265-272.

Burns KC 2010 Is crypsis a common defensive strategy in plants? speculation on signal deception in the New Zealand flora. Plant Signal Behav 5:9-13.

Burns KC, J Dawson 2009 Heteroblasty on Chatham Island: a comparison with New Zealand and New Caledonia. N Z J Ecol 33:156-163.

Caelli T, B Julesz 1978a On perceptual analyzers underlying visual texture discrimination. I. Biol Cybern 28:167-175.

- $1978 b$ On perceptual analyzers underlying visual texture discrimination. II. Biol Cybern 29:201-214.
Campenhausen MV, K Kirschfeld 1998 Spectral sensitivity of the accessory optic system of the pigeon. J Comp Physiol A 183:1-6.

Canyon DV, CJ Hill 1997 Mistletoe host-resemblance: a study of herbivory, nitrogen and moisture in two Australian mistletoes and their host trees. Aust J Ecol 22:395-403.

Cockayne L 1912 Observations concerning evolution, derived from ecological studies in New Zealand. Trans N Z Inst 44:1-50.

Cuthill IC 2006 Color perception. Pages 3-40 in GE Hill, KJ McGraw, eds. Bird coloration. Harvard University Press, Cambridge, MA.

Day JS 1998 Light conditions and the evolution of heteroblasty (and the divaricate form) in New Zealand. N Z J Ecol 22:43-54.

Day JS, KS Gould 1997 Vegetative architecture of Elaeocarpus hookerianus: periodic growth patterns in divaricating juveniles. Ann Bot 79:607-616.

Day JS, KS Gould, PE Jameson 1997 Vegetative architecture of Eleaocarpus hookerianus: transition from juvenile to adult. Ann Bot 79:617-624.

- 1998 Adventitious root initiation, plasticity, and response to plant growth regulator treatments of seedling, juvenile, and adult Elaeocarpus hookerianus plants. N Z J Bot 36:477-484.

Day JS, PE Jameson, KS Gould 1995 Cytokinnis associated with metamorphic vegetative growth in Elaeocarpus hookerianus. Aust J Plant Physiol 22:67-73.

Ehrlich PR, PH Raven 1964 Butterflies and plants: a study in coevolution. Evolution 18:586-608.

Endler JA, PW Mielke 2005 Comparing entire colour patterns as birds see them. Biol J Linn Soc 86:405-431.

Everard B, BD Morley 1970 Wild flowers of the world. Ebury and Michael Joseph, London.

Fadzly N, J Cameron, HM Schaefer, KC Burns 2009 Ontogenetic 
colour changes in an insular tree species: signalling to extinct browsing birds? New Phytol 184:495-501.

Gamage HK, L Jesson 2007 Leaf heteroblasty is not an adaptation to shade: seedling anatomical and physiological responses to light. N Z J Ecol 31:245-254.

Givnish TJ 1986 Biomechanical constraints in crown geometry in forest herbs. Pages 525-583 in TJ Givnish, ed. On the economy of plant form and function. Cambridge University Press, Cambridge.

Godley EJ 1985 Paths to maturity. N Z J Bot 23:687-706.

Gould KS 1993 Leaf heteroblasty in Pseudopanax crassifolious: functional significance of leaf morphology and anatomy. Ann Bot 71:61-70.

Greenwood RM, IAE Atkinson 1977 Evolution of the divaricating plants in New Zealand in relation to moa browsing. Proc N Z Ecol Soc 24:21-33.

Grubb PJ 1992 A positive distrust in simplicity: lessons from plant defences and from competition among plants and among animals. J Ecol 80:585-610.

Hart NS 2001 The visual ecology of avian photoreceptors. Prog Retinal Eye Res 20:675-703.

Hart NS, JC Partridge, IC Cuthill, ATD Bennet 2000 Visual pigments, oil droplets, ocular media and cone photoreceptor distribution in two species of passerine bird: the blue tit (Parus caeruleus L.) and the blackbird (Turdus merula L.). J Comp Physiol 186:375-387.

Horn HS 1971 The adaptive geometry of trees. Princeton University Press, Princeton, NJ.

Howell CJ, D Kelly, MH Turnbull 2002 Moa ghosts exorcised? New Zealand's divaricate shrubs avoid photoinhibition. Funct Ecol 16: 232-240.

Jones CD, D Osorio 2004 Discrimination of oriented visual textures by poultry chicks. Vision Res 44:83-89.

Julesz B 1962 Visual pattern discrimination. IRE Trans Inf Theory 8: 84-92.

Kelly D 1994 Towards a numerical definition for divaricate (interlaced small-leaved) shrubs. N Z J Bot 32:509-518.

Klooster MR, D Clark, TA Culley 2009 Cryptic bracts facilitate herbivore avoidance in the mycoheterotrophic plant Monotropsis odorata (Ericaceae). Am J Bot 96:2197-2205.

Lev-Yadun S 2001 Aposematic (warning) coloration associated with thorns in higher plants. J Theor Biol 210:385-388.

2003 Why do some thorny plants resemble green zebras? J Theor Biol 224:483-489.

2006 Defensive functions of white coloration in coastal and dune plants. Isr J Plant Sci 54:317-325. 2009a Aposematic (warning) coloration in plants. Pages 167202 in F Baluska, ed. Plant-environment interactions from behavioural perspective. Vol II. Springer, Berlin.

- $2009 b$ Mullerian and Batesian mimicry rings of whitevariegated aposematic spiny and thorny plants: a hypothesis. Isr J Plant Sci 57:107-116.

McGlone MS, CJ Webb 1981 Selective forces influencing the evolution of divaricating plants. N Z J Ecol 4:20-28.

McLellan T, JA Endler 1998 The relative success of some methods for measuring and describing the shape of complex objects. Syst Biol 47:264-281.

Midgely JJ, M Botha, D Balfour 2001 Patterns of variation in thorn length, density, type and colour in African acacias. Afr J Range Forage Sci 18:59-61.

Nobel PS 1989 Shoot temperatures and thermal tolerances for succulent species of Hawthoria and Lithops. Plant Cell Environ 12:643-651.

Odeen A, O Hastad 2003 Complex distribution of avian colour vision systems revealed by sequencing the SWS1 opsin from total DNA. Mol Biol Ecol 20:855-861.

Osorio D, M Vorobyev 1996 Colour vision as an adaptation to frugivory in primates. Proc R Soc B 263:593-599.

Osorio D, M Vorobyev, CD Jones 1999 Colour vision of domestic chicks. J Exp Biol 202:2951-2959.

Poirson AB, BA Wandell 1990 The ellipsoidal representation of spectral sensitivity. Vision Res 30:647-652.

R Core Development Team 2008 R: a language and environment for statistical computing. R Foundation for Statistical Computing, Vienna.

Schaefer HM, G Ruxton 2009 Deception in plants: mimicry or perceptual exploitation? Trends Ecol Evol 24:676-685.

Stone BC 1979 Protective coloration of young leaves in certain Malaysian palms. Biotropica 11:126.

Sturrock K, J Rocha 2000 A multidimensional scaling stress evaluation table. Field Methods 12:49-60.

Turvey ST, OW Green, RN Holdaway 2005 Cortical growth marks reveal extended juvenile development in New Zealand moa. Nature 435:940-943.

Uy C, JA Endler 2004 Modification of the visual background increases the conspicuousness of golden-collared manakin displays. Behav Ecol 15:1003-1010.

Vorobyev M, D Osorio, ATD Bennet, NJ Marshall, IC Cuthill 1998 Tetrachromacy, oil droplets and bird plumage colours. J Comp Physiol 183:621-633.

Wiens D 1978 Mimicry in plants. Evol Biol 11:365-403. 


\section{References}

Abramoff MD, Magelhaes PJ, Ram SJ. 2004. Image processing with ImageJ.

Biophotonics International. 11: 36-42.

Aitchison J. 2003. The statistical analysis of compositional data. Caldwell, NJ: Blackburn Press.

Allan H. 1961. Flora of New Zealand. Government Printer, Wellington.

Andersson S, Pryke SR, Ornborg, J, Lawes MJ, Andersson M. 2002. Multiple receivers, multiple ornaments, and a trade-off between agonistic and epigamic signaling in a widowbird. The American Naturalist. 160: 683-691.

Archetti M. 2000. The origin of autumn colours by coevolution. Journal of Theoretical Biology 205: 625-630.

Archetti, M. 2009a. Classification of hypotheses on the evolution of autumn colours.Oikos. 118: $328-333$.

Archetti, M. 2009b. Evidence from the domestication of apple for the maintenance of autumn colours by coevolution. Proceedings of the Royal Society B- Biological Sciences. 276: 2575-2580.

Atsatt PR. 1983. Mistletoe leaf shape: a host morphogen hypothesis In The biology of mistletoes. Sydney (eds. Calder M, Bernhardt P,): Academic Press, 259-275.

Bach CE, Kelly D. 2004a. Effects of forest edges on herbivory in New Zealand mistletoe, Alepis flavida. New Zealand Journal of Ecology 28, 195-205. 
Bach CE, Kelly D. 2004b. Effects of forest edges, fruit display size, and fruit colour on bird seed dispersal in a New Zealand mistletoe, Alepis flavida. New Zealand Journal of Ecology 28, 93-103.

Backhaus W. 1991. Colour opponent coding in the visual system of the honeybee. Vision Research 31: 1381-1397.

Balkenius A, Kelber A. 2004. Colour constancy in diurnal and nocturnal hawkmoths. Journal of Experimental. Biology. 207: 3307-3316.

Barlow BA, Wiens D. 1977. Host-parasite resemblance in Australian mistletoes: the case for cryptic mimicry. Evolution. 31: 69-84.

Barlow C. 2000. The ghosts of evolution. Nonsensical fruits, missing partners, and other ecological anachronisms. New York, NY: Basic Books. 304 pp.

Beaumont S, Burns KC. 2009. Vertical gradients in leaf trait diversity in a New Zealand forest. Trees-Structure and Function. 23: 339-346.

Behmer ST, Belt CE, Shapiro MS. 2005. Variable rewards and discrimination ability in an insect herbivore: what and how does a hungry locust learn? Journal of Experimental Biology 208:3462-3473.

Bennet ATD, Thery M. 2007. Avian color vision and coloration: Multidisciplinary Evolutionary Biology. The American Naturalist. 169: 1-6

Bernays EC, Wrubel RP. 1985. Learning by grasshoppers: association of colour/light intensity with food. Physiological Entomology 10:359-369 
Boege K, Marquis RJ. 2005. Facing herbivory as you grow up: the ontogeny of resistance in plants. Trends in Ecology and Evolution. 20: 441-448.

Bond WJ, Lee WG, Craine JM. 2004. Plant structural defences against browsing birds: A legacy of New Zealand's extinct moas. Oikos. 104: 500-508.

Bond WJ, Silander JA. 2007. Springs and wire plants: anachronistic defences against Madagascar's extinct elephant birds. Proceedings of the Royal Society BBiological Sciences.274: 1985-1992.

Boulay R, Fedriani JM, Manzaned AJ, Cerda, X. 2005. Indirect effects of alternative food resources in an ant-plant interaction. Oecologia 144: 72-79.

Briscoe AD, Chittka L. 2001. The evolution of colour vision in insects. Annual Review of Entomology. 46: 471-510.

Brown CL, Sommer HE. 1992. Shoot growth and histogenesis of trees possessing diverse patterns of shoot development. American Journal of Botany. 79: 335-346.

Brown VK, Lawton JH, Grubb PJ. 1991. Herbivory and the evolution of leaf size and shape [and Discussion]. Philosophical Transactions: Biological Sciences. 333: 265-272.

Burns KC, Dalen, JL. 2002. Foliage colour contrasts and adaptive fruit colour variation in a bird-dispersed plant community. Oikos. 96: 463-469.

Burns KC, Cazetta E, Galetti M, Valido A, Schaefer HM. 2009a. Geographic patterns in fruit colour diversity: do leaves constrain the colour of fleshy fruits? Oecologia. 159: 337-343. 
Burns KC, Dawson JW. 2006. A morphological comparison of leaf heteroblasty between New Caledonia and New Zealand. New Zealand Journal of Botany. 44 : 387-396.

Burns KC, Dawson JW. 2009. Heteroblasty on Chatham Island: A comparison with New Zealand and New Caledonia. New Zealand Journal of Ecology. 33 (In press).

Burns KC, Lake B. 2009b. Fruit frugivore interactions in two southern hemisphere forests: allometry, phylogeny and body size. Oikos. 118: 1901-1907.

Burns KC. 2004. Scale and macroecological patterns in seed disperser mutualisms. Global Ecology \& Biogeography. 13: 289-293.

Burns KC. 2005b. Effects of bi-colored displays on avian fruit color preferences in a color polymorphic plant. Journal of the Torrey Botanical Society. 32: 505-509.

Burns KC. 2006a. A simple null model predicts fruit-frugivore interactions in a temperate rainforest. Oikos. 115: 427-432.

Burns KC. 2006b. Weta and the evolution of fleshy fruits in New Zealand. New Zealand Journal of Ecology. 30: 405-406.

Burns KC. 2008. When is it coevolution? A reply to Morgan-Richards et al. New Zealand Journal of Ecology. 32: 113-114.

Burns KC. 2010. Is crypsis a common defensive strategy in plants? Speculation on signal deception in the New Zealand flora. Plant Signalling and Behaviour 5:9-13.

Caelli T, Julesz B. 1978a. On perceptual analyzers underlying visual texture discrimination. Part I. Biological Cybernetics. 28: 167-175. 
Caelli T, Julesz B. 1978b. On perceptual analyzers underlying visual texture discrimination. Part II. Biological Cybernetics. 29: 201-214.

Caine NG, Osorio D, Mundy NI. 2009. A foraging advantage for dichromatic marmosets (Callithrix geoffroyi) at low light intensity. Biology Letters. 6: 36-38.

Campenhausen MV, Kirschfeld K. 1998. Spectral sensitivity of the accessory optic system of the pigeon. Journal of Comparative Physiology A-Sensory Neural and Behavioral. 183: 1-6.

Canyon DV, Hill CJ. 1997. Mistletoe host-resemblance: A study of herbivory, nitrogen and moisture in two Australian mistletoes and their host trees. Australian Journal of Ecology. 22: 395-403.

Cazetta E, Schaefer HM, \& Galetti M. 2007. Why are fruits colorful? The relative importance of achromatic and chromatic contrasts for detection by birds. Evolutionary Ecology. 1573-8477 (Online edition).

Chalker-Scott L. 1999. Environmental significance of anthocyanins in plant stress responses. Photochemistry and Photobiology 70: 1-9.

Chen J, Fleming TH, Zhang L, Wang H, Liu Y. 2004. Patterns of fruit traits in a tropical rainforest in Xishuangbanna, SW China. Acta Oecologica- International Journal of Ecology. 26: 157-164.

Chen L, Zhang S, Srinivasan V .2003. Global perception in small brains: Topological pattern recognition in honey bees. Proceedings of the National Academy of Sciences of the United States of America 100:6884-6889 
Chittka L .1992. The colour hexagon: a chromaticity diagram based on photoreceptor excitatons as a generalised representation of colour opponency. Journal of Comparative Physiology A 170:533-543

Chittka L, Döring TF. 2007. Are autumn foliage colors red signals to aphids? PLoS Biology 5(8): e187. doi:10.1371/journal.pbio.0050187

Chittka L, Wells H. 2004. Colour vision in bees: mechanisms, ecology and evolution. Complex worlds from simpler nervous systems. (ed. Prete FR.) MIT Press: 165-191

Clearwater MJ, Gould KS. 1994. Comparative leaf development of juvenile and adult Pseudopanax crassifolius. Canadian Journal of Botany. 72: 658-670.

Cockayne L. 1912. Observations concerning evolution, derived from ecological studies in New Zealand. Transactions of the New Zealand Institute. 44: 1-50

Coombe PE. 1981. Wavelength specific behaviour of the Whitefly Trialeurodes vaporariorum (Homoptera: Aleyrodidae). Journal of Comparative Physiology. 144: 83-90.

Cooper WE, Vitt LJ. 2002. Distribution, extent, and evolution of plant consumption by lizards. Journal of Zoology. 257.

Cuthill IC. 2006. Color Perception. In. Bird Coloration (Hill GE, McGraw KJ, eds), Cambridge MA: Harvard University Press.

Dawson JW. 1991. New Zealand Botany with a difference-The Chathams Island. Tuatara. 31: $23-40$. 
Day J, Jameson PE, Gould KS. 1995. Cytokinnis associated with metamorphic vegetative growth in Elaeocarpus hookerianus. Australian Journal of Plant Physiology 22: 67-73.

Day J, Gould KS, Jameson PE. 1997. Vegetative architechture of Eleaocarpus hookerianus. Transition from juvenile to adult. Annals of Botany. 79: 617-624.

Day J, Gould KS. 1997. Vegetative architecthture of Elaeocarpus hookerianus. Periodic growth patterns in divaricating juveniles. Annals of Botany. 79:607-616.

Day J. 1998. Light conditions and the evolution of heteroblasty (and the divaricate form) in New Zealand. New Zealand Journal of Ecology. 22: 43-54.

Day JS, Gould KS, Jameson PE. 1998. Adventitious root initiation, plasticity, and response to plant growth regulator treatments of seedling, juvenile, and adult Elaeocarpus hookerianus plants. New Zealand Journal of Botany. 36: 477-484.

Diamond JM. 1990. Biological effects of ghosts. Nature. 345: 769-770

Dominy, NJ, Lucas PW. 2001. Ecological importance of trichromatic vision to primates. Nature. 410: 363-366.

Duthie C, Gibbs G, Burns KC. 2006. Seed dispersal by weta. Science. 311, 1575.

Ehrlich PR, Raven PH. 1964. Butterflies and plants: A study in coevolution. Evolution. 18: 586-608.

Endler JA. 1978. A predator's view of an animal colour patterns. Evolutionary Biology. 11: 319-364. 
Endler JA. 1993. The color of light in forests and its implications. Ecological Monographs. 63: 1-27.

Endler JA, Mappes J. 2004. Predator mixes and the conspicuousness of aposematic signals. The American Naturalist. 163: 532-547.

Endler JA, Mielke PW. 2005. Comparing entire colour patterns as birds see them. Biological Journal of the Linnean Society. 86: 405-431.

Eskildsen LI, Olesen JM, Jones CG. 2004. Feeding response of the Aldabra giant tortoise (Geochelone gigantea) to island plants showing heterophylly. Journal of Biogeography. 31: 1785-1790.

Everard B, Morley BD. 1970. Wild flowers of the world. London: Ebury Press \& Michael Joseph

Fadzly N, Cameron J, Schaefer HM, Burns KC. 2009. Ontogenetic colour changes in an insular tree species: signalling to extinct browsing birds? New Phytologist. 184: 495501.

Field LH. 2001. The biology of wetas, king crickets and their Allies. New York: CABI Publishing.

Gamage HK, Jesson L. 2007. Leaf heteroblasty is not an adaptation to shade: seedling anatomical and physiological responses to light. New Zealand Journal of Ecology. 31:245-254.

Gautierhion A, Duplantier JM, Quris R, Feer F, Sourd C, Decoux JP, Dubost G, Emmons L, Erard C, Hecketsweiler P, Moungazi A, Roussilhon C, Thiollay JM. 
1985. Fruit characters as a basis of fruit choice and seed dispersal in a tropical forest vertebrate community. Oecologia. 65: 324-337.

Gibbs G. 2001. Habitats and biogeography of New Zealand's Deinacridine and Tusked weta species. In The biology of wetas, king crickets and their allies (ed. Field LH.). New York: CABI Publishing.

Gibbs G. 2006. Ghosts of Gondwana: Craig Potton Publishing.

Givnish TJ, Sytsma KJ, Smith JF, Hahn WJ. 1994. Thorn-like prickles and heterophylly in Cynae: Adaptations to extinct avian browsers on Hawaii? Proceedings of the National Academy of Sciences of the United States of America. 91: 2810-2814.

Givnish TJ. 1986. Biomechanical constraints in crown geometry in forest herbs. In On the economy of plant form and function (Givnish TJ, ed.). Cambridge: Cambridge University Press, 525-583.

Givnish TJ. 1990. Leaf Mottling: Relation to growth form and leaf phenology and possible role as camouflage. Functional Ecology. 4: 463-474.

Godley EJ. 1985. Paths to maturity. New Zealand Journal of Botany. 23: 687-706.

Gould KS. 1993. Leaf heteroblasty in Pseudopanax crassifolious: Functional significance of leaf morphology and anatomy. Annals of Botany. 71: 61-70.

Gorochov AV .2001. The higher classification, phylogeny and evolution of the superfamily Stenopelmatoidae. In The biology of wetas, king crickets and their allies (ed. Field LH). New York: CABI Publishing. 540 pp 
Gould KS, Kuhn DN, Lee DW, Oberbauer SF. 1995. Why leaves are sometimes red.

Nature 378: 241-242.

Grant JB. 2007. Ontogenetic colour change and the evolution of aposematism: a case study in panic moth caterpillars. Journal of Animal Ecology. 76: 439-447.

Greenwood RM, Atkinson IAE. 1977. Evolution of the divaricating plants in New Zealand in relation to Moa browsing. Proceedings of the New Zealand Ecological Society. 24: 21-33.

Greenwood RM. 1992. Some differences between plants of the Chatham Island and the New Zealand mainland. New Zealand Journal of Ecology. 16: 51-52.

Grubb PJ. 1992. A positive distrust in simplicity: lessons from plant defences and from competition among plants and animals. Journal of Ecology 80:585-610.

Hansen DM, Galetti M. 2009. The forgotten megafauna. Science. 324: 42-43.

Hanzawa FM, Beattie AJ, Culver DC. 1988. Directed Dispersal: Demographic Analysis of an Ant-Seed Mutualism. The American Naturalist. 131: 1-13.

Hart NS, Partridge JC, Cuthill IC, Bennet ATD. 2000. Visual pigments, oil droplets, ocular media and cone photoreceptor distribution in two species of passerine bird: the blue tit (Parus caeruleus L.) and the blackbird (Turdus merula L.). Journal of Comparative Physiology. 186: 375-387.

Hart NS. 2001. The visual ecology of avian photoreceptors. Progress in Retinal and Eye Research. 20: 675-703. 
Herrera CM .1989. Frugivory and seed dispersal by carnivorous mammals, and associated fruit characteristics, in undisturbed Mediterranean habitats. Oikos 55:250-262

Herrera CM. 1982. Seasonal variation in the quality of fruits and diffuse coevolution between plants and avian dispersers. Ecology. 63: 773-785.

Herrera CM. 1992. Interspecific variation in fruit shape: allometry, phylogeny, and adaptation to dispersal agents. Ecology. 73: 1832-1841.

Herrera CM. 2002. Seed dispersal by vertebrates. In Plant-Animal Interactions (ed. C. M. Herrera \& O. Pellmyr), pp. 185-208: Blackwell Science Ltd.

Hoch, WA, Zeldin EL, McCown BH. 2001. Physiological significance of anthocyanins during autumnal leaf senescence. Tree Physiology 21: 1-8.

Honkavaara J, Koivula M, Korpimaki E, Siitari H, Viitala DJ. 2002. Ultraviolet vision and foraging in terrestrial vertebrates. Oikos. 98:505-511

Horn HS. 1971. The adaptive geometry of trees. Princeton: Princeton University Press.

Howe HF, Smallwood J. 1982. Ecology of Seed Dispersal. Annual Review of Ecology and Systematics. 13: 201-228.

Howell CJ, Kelly D, Turnbull MH. 2002. Moa ghosts exorcised: New Zealand's divaricate shrubs avoid photoinhibition. Functional. Ecology. 16: 232-240.

Janson CH. 1983. Adaptation of fruit morphology to dispersal agents in a Neotropical Forest. Science. 219: 187-189.

Janzen DH. 1979. How many babies do fig pays for babies Biotropica 7: 48-50. 
Janzen DH. 1980. When is it Coevolution? Evolution. 34: 611-612.

Janzen DH. 1986. Chihuahuan desert nopaleras: Defaunated big mammal vegetation. Annual Review of Ecology and Systematics. 17: 595-636.

Janzen DH, Martin PS. 1982. Neotropical anachronisms: The fruits the gomphotheres ate. Science. 215: 19-27.

\section{Johnsen S, Kelber A, Warrant E, Sweeney AM, Widder EA, Lee RL, Hernandez-} Andres J. 2006. Crepuscular and nocturnal illumination and its effects on color perception by the nocturnal hawkmoth Deilephila elpenor. Journal of Experimental Biology. 209: 789-800.

Jones CD, Osorio D. 2004. Discrimination of oriented visual textures by poultry chicks. Vision Research. 44: 83-89.

Julesz B. 1962. Visual pattern discrimination. Information Theory, IRE Transaction. 8: 8492.

Kakegawa K, Hattori E, Koike K, Takeda K. 1991. Induction of anthocyanin synthesis and related enzyme activities in cell cultures of Centaurea cyanus by UV-light irradiation. Phytochemistry 30: 2271-2271.

Kapustjansky A, Chittka L, Spaethe J. 2010. Bees use three-dimensional information to improve target detection. Naturwissenschaften. 97: 229-233.

Kelber A. 1996. Colour learning in the hawk moth Macroglossum stellatarum. Journal of Experimental Biology 199: 1127-1131. 
Kelber A, Warrant E, Pfaff M, Wallen R, Theobald JC, Wcislo WT, Raguso RA .2005.

Light intensity limits foraging activity in nocturnal and crepuscular bees. Behavioural Ecology 17:63-72.

Kelber A., Roth LSV. 2006. Nocturnal colour vision - not as rare as we might think. 209: 781-788.

Kelly D. 1994. Towards a numerical definition for divaricate (interlaced small- leaved) shrubs. New Zealand Journal of Botany. 32: 509-518.

King P, Milicich L, Burns KC .2010. Body size determines rates of seed dispersal by giant king crickets. Population Ecology. DOI 10.1007/s10144-010-0222-9.

Kissling WD, Rahbek C, Bohning-Gaese K. 2007. Food plant diversity as broad- scale determinant of avian frugivore richness. Proceedings of the Royal Society BBiological Sciences. 274: 799-808.

Klaper R, Frankel S, Berenbaum MR. 1996. Anthocyanin content and UVB sensitivity in Brassica rapa. Phytochemistry 63: 811-813.

Klooster MR, Clark D, Culley TA. 2009. Cryptic bracts facillitate herbivore avoidance in the mychoheterotrophic plant Monotropsis odorata (Ericaceae). American Journal of Botany 96: 2197-2205.

Knight RS, Siegfried WR. 1983. Inter-relationships between type, size and color of fruits and dispersal in Southern African trees. Oecologia 56: 405-412.

Lee D, Gould K. 2009. Three birds with one stone: moas, heteroblasty and the New Zealand flora. New Phytologist. 184: 282-284. 
Lee D. 2007. Nature's palette. The science of plant color. Chicago, MI: University of Chicago Press.

Lee WD, Gould KS. 2002. Anthocyanins in leaves an other vegetative organs: an introduction . Advances in Botanical Research 37:1-16.

Lee WG, Bastow Wilson J., Johnson PN. 1988. Fruit colour in relation to the ecology and habit of Coprosma (Rubiaceae) species in New Zealand. Oikos.53: 325331.

Lee WG, Hodgkinson IJ, Johnson PN. 1990. A test for ultraviolet reflectance from fleshy fruits of New Zealand plant species. New Zealand Journal of Botany. 28: 21-24.

Lee WG, Weatherall IL, Wilson, JB. 1994. Fruit conspicuousness in some New Zealand Coprosma (Rubiaceae) species. Oikos. 69: 87-94.

\section{Leinert C, Bowyer S, Haikala LK, Hanner MS, Hauser MG, Levasseur-Regourd A-C,} Mann I, Mattila K, Reach WT, Schlosser W, et al. (1998) The 1997 reference of diffuse night sky brightness. Astronom Astrophys Supp Ser 127:S1-S99

Lev-Yadun S. 2001. Aposematic (warning) coloration associated with thorns in higher plants. Journal of Theoretical Biology. 210:385-388.

Lev-Yadun S, Gould KS. 2007. What do red and yellow autumn leaves signal? The Botanical Review 73: 279-289

Lev-Yadun S, Inbar M. 2002. Defensive ant, aphid and caterpillar mimicry in plants? Biological Journal of Linnaean Society. 77: 393-398. 
Lev-Yadun S, Ne'eman G. 2006. Color changes in old aposematic thorns, spines, and prickles. Israel Journal of Plant Sciences. 54: 327-333.

Lev-Yadun S. 2003. Why do some thorny plants resemble green zebras? Journal of Theoretical Biology. 224: 483-489.

Lev-Yadun S. 2009a. Aposematic (warning) coloration in plants. In: Plant-environment interactions from behavioural perspective, (Baluska F, eds.) Vol II. Berlin, Germany: Springer-Verlag, 167-202.

Lev-Yadun S. 2009b. Mullerian and Batesian mimicry rings of white-variegated aposematic spiny and thorny plants: a hypothesis. Israel Journal of Plant Sciences. (In press)

Lewis RD, York A .2001. Circadian rhythms in Tree Wetas, Hemideina thoracica. In The biology of wetas, king crickets and their allies (ed. Field LH). New York: CABI Publishing, 540 pp.

Lomascolo SB, Schaefer HM. 2010. Signal convergence in fruits: a result of selection by frugivores? Journal of Evolutionary Biology 23: 614-624.

Lomáscolo SB, Speranza P, Kimball RT. 2008. Correlated evolution of fig size and color supports the Dispersal Syndromes hypothesis. Oecologia 156: 783-796

Lord JM, Markey AS, Marshall J. 2002. Have frugivores influenced the evolution of fruit traits in New Zealand. In Seed Dispersal and Frugivory: Ecology, Evolution and Conservation (ed. D. J. Levey, W. R. Silva \& M. Galetti), pp. 511. United Kingdom: CAB International. 
Lord JM, Marshall J. 2001. Correlations between growth form, habitat, and fruit colour in the New Zealand flora, with reference to frugivory by lizards. New Zealand Journal of Botany. 39: 567-576.

Lubbock J .1881. Observations on ants, bees, and wasps. IX. Color of flowers as an attraction to bees: Experiments and considerations thereon. Journal of Linnean Society of London 16: 110-112

Lunau K, Maier EJ. 1995. Innate colour preferences of flower visitors. Journal of Comparative Physiology A 177: 1-19

Mantel N. 1967. Assumption-free estimators using u statistics and a relationship to Jacknife Method. Biometrics. 23: 567-571.

Marquez AL, Real R, Vargas JM. 2004. Dependence of broad-scale geographical variation in fleshy-fruited plant species richness on disperser bird species richness. Global Ecology and Biogeography. 13: 295-304.

Marrero P, Padilla DP, Valdes F, Nogales M .2007. Comparison of three chemical tests to assess seed viability: the seed dispersal system of the Macaronesian endemic plant Rubia fruticosa (Rubiaceae) as an example. Chemoecology 17:47-50

McGlone MS, Webb CJ. 1981. Selective forces influencing the evolution of divaricating plants. New Zealand Journal of Ecology. 4: 20-28.

McLellan T, Endler JA. 1998. The relative success of some methods for measuring and describing the shape of complex objects. Systematic Biology. 47: 264-281. 
Menzel R. 1979. Spectral sensitivity and colour vision in invertebrates In (Autrum, H. ed). Handbook of sensory physiology, Vol VII/6A. Springer, Berlin Heidelberg New York. 503-580 pp.

Midgely JJ, Botha M, Balfour D. 2001. Patterns of variation in thorn length, density, type and colour in African acacias. African Journal of Range and Forage Science. 18: 5961.

Midgley JJ. 2004. Why are spines of African Acacia species white? African Journal of Range and Forage Science 21: 211-212.

Mitchell AD, Wagstaff SJ. 1997. Phylogenetic relationships of Pseudopanax species (Araliaceae) inferred from parsimony analysis of rDNA sequence data and morphology. Plants Systematics and Evolution. 208: 121-138.

Morgan-Richards M, Trewick SA, Dunavan S. 2008. When is it coevolution? The case of ground weta and fleshy fruits in New Zealand. New Zealand Journal of Ecology. 32: 108-112.

Neill SO, Gould KS, Kilmartin PA, Mitchell KA, Markham KR. 2002. Antioxidant activities of red versus green leaves in Elatostema rugosum. Plant Cell and Environment. 25: 537-549.

Nobel PS. 1989. Shoot temperatures and thermal tolerances for succulent species of Hawthoria and Lithops. Plant, Cell, and Environment. 12: 643-651.

Ödeen A, Håstad O. 2003. Complex distribution of avian color vision systems revealed by sequencing the SWS1 Opsin from total DNA. Molecular Biology and Ecology. 20: 855-861. 
Olesen JM, Valido A. 2003. Lizards as pollinators and seed dispersers: an island phenomenon. Trends in Ecology and Evolution. 18: 177-181.

Osorio D, Vorobyev M. 1996. Colour vision as an adaptation to frugivory in primates. Proceedings of the Royal Society Biological Sciences. 263: 593-599.

Osorio D, Vorobyev M. 2005. Photoreceptor Spectral Sensivities in Terrestrial Animals: Adaptations for Luminance and Color Vision. Proceedings of the Royal Society of London Biology. 271.

Osorio D, Vorobyev M, Jones CD. 1999. Colour vision of domestic chicks. Journal of Experimental Biology. 202: 2951-2959.

Osorio D, Vorobyev M. 2008. A review of the evolution of animal colour vision and visual communication signals. Vision Research. 48: 2042-2051.

Pizo MA. 2002. The seed dispersers and fruit syndromes of Myrtaceae in the Brazilian Atlantic Forest. Seed dispersal and frugivory: ecology, evolution and conservation (D.J. Levey, W.R. Silva, M. Galetti eds.), pp. 129-144. CAB International, Wallingford.

Pohl F, Watolla T, Lunau K. 2008. Anther-mimicking floral guides exploit a conflict between innate preference and learning in bumblebee (Bombus terrestris). Behaviour Ecology and Sociology. 63: 295-302.

Poirson AB, Wandell BA. 1990. The ellipsoidal representation of spectral sensitivity. Vision Research. 30: 647-652. 
Price PW. 2002. Species interactions and the evolution of biodiversity. In Seed Dispersal and Frugivory:Ecology, Evolution and Conservation (ed. D. J. Levey, W. R. Silva \& M. Galetti), pp. 511. United Kingdom: CAB International.

R Development Core Team. 2010 R: A Language and Environment for Statistical Computing. Vienna, Austria. http:// www.R-project.org.

Raine N, Chittka L. 2007. The adaptive significance of sensory bias in a foraging context: floral colour preferences in bumblebee (Bombus terrestris).PloSOne 2(6):e556. Doi:10.1371/journal.pone 0000556.

Raine NE, Chittka L. 2005. Colour preferences n relation to the foraging performance and fitness of the bumblebee Bombus terrestris. Uludag Bee Journal 5(4): 145-150

Roth LSV, Kelber A. 2004. Nocturnal colour vision in geckos. Proceedings of the Royal Society of London B-Biology 271(S): 485-487.

Rowe C, Guilford T. 2000. Aposematism: to be red or dead. Trends in Ecology \& Evolution. 15: 261-262.

Sallabanks R, Courtney SP .1992. Frugivory, seed predation and insect-vertebrate interactions. Annual Review Entomology 37:377-400

Sanger JE. 1971. Quantitative investigations of leaf pigments from their inception in buds through autumn colouration to decomposition in falling leaves.Ecology. 52: 10751089 
Sanitjan S, Chen J. 2009. Habitat and fig characteristics influence the bird assemblage and network properties of fig trees from Xishuangbanna, South- West China. Journal of Tropical Ecology. 25: 161-170.

Sargent S. 1995. Seed fate in a tropical mistletoe: The Importance of host twig size. Functional Ecology. 9: 197-204.

Schaefer HM, Levey DJ Schaefer V, Avery ML. 2006. The role of chromatic and achromatic signals for fruit detection by birds. Behavioral Ecology. 17: 784-789.

Schaefer HM, Schaefer V, Levey DJ. 2004a. How plant-animal interactions signal new insights in communication. Trends in Ecology \& Evolution. 19.

Schaefer HM, Schaefer V, Vorobyev M. 2007. Are fruit colors adapted to consumer vision and birds equally efficient in detecting colorful signals? The American Naturalist. 169: $169-169$.

Schaefer HM, Schmidt V, Bairlein F. 2003a. Discrimination abilities for nutrients:which difference matters for choosy birds and why? Animal Behaviour. 65: 531-541.

Schaefer HM, Schmidt V, Winkler H. 2003b. Testing the defence trade-off hypothesis: how contents of nutrients and secondary compounds affect fruit removal. Oikos. $102: 318-328$

Schaefer HM, Schmidt V. 2004b. Detectability and content as opposing signal characteristics in fruits. Proceedings of the Royal Society of London Biology.271: 370-373. 
Schaefer HM, Ruxton G. 2009. Deception in plants: mimicry or perceptual exploitation?

Trends in Ecology and Evolution 24: 676-685.

Schmidt V, Schaefer HM, Winkler H. 2004. Conspicuousness, not colour as foraging cue in plant-animal signalling. Oikos 106: 551-557.

Skorupski P, Chittka L. 2009. Is colour cognitive? Optics \& Laser Technology. DOI 10.1016/j.optlastec.2008.12.015.

Smallwood PD. 2001. An Intergrative Approach to the Study of Plant-Animal Interactions. American Zoologist. 41: 807-809.

Somanathan H, Borges RM, Warrant EJ, Kelber A .2008a. Visual ecology of Indian carpenter bees I: Light intensities and flight activity. Journal of Comparative Physiology A 194(1): 97-107

Somanathan H, Borges RM, Warrant EJ, Kelber A .2008b. Nocturnal bees learn landmark colours in starlight. Current Biology 18(21): 996-997

Somanathan H, Kelber A, Borges RM, Wallen R, Warrant EJ .2009a. Visual ecology of Indian carpenter bees II: adaptations of eyes and ocelli to nocturnal and diurnal lifestyles. Journal of Comparative Physiology A 195(6): 571-583

Somanathan H, Warrant EJ, Borges RM, Wallen R, Kelber A (2009b). Resolution and sensitivity of the eyes of the Asian honeybees Apis florea, Apis cerana and Apis dorsata. Journal of Experimental Biology 212(15): 2448-2453

Stiles EW.1982. Fruit flags: two hypotheses. American Naturalist 120: 200-509. 
Stiles FG. 1981. Geographical aspects of birdflower coevolution, with particular reference to Central America. Annals of the Missouri Botanical Gardens 68: 323-351.

Stone BC. 1979. Protective coloration of young leaves in certain Malaysian palms. Biotropica. 11: 126.

Stuart-Fox DM, Moussali A, Johnston GR. Owens IPF. 2004. Evolution of colour variation in dragon lizards: quantitative tests of the role of crypsis and local adaptation. Evolution 58: 1549-1559.

Sturrock K, Rocha J. 2000. A multidimensional scaling stress evaluation table. Field Methods. 12: 49-60.

Takahasi A, Takeda K, Ohnishi T. 1991. Light-induced anthocyanin reduces the extent of damage to DNA in UV-Irradiated Centaurea cyanus cells in culture. Plant and cell Physiology 32: 541-547.

Thompson JN. 2005. The Geographic Mosaic of Coevolution. Chicago: The University of Chicago Press.

Torrice M. 2009. New Zealand tree stuck in a time warp. ScienceNow magazine. http://news.sciencemag.org/sciencenow/2009/07/24-01.html.

Trewick SA, Paterson AM, Campbell HJ. 2007. Hello New Zealand. Journal of Biogeography. 34: 1-6.

Trewick SA. 2000. Molecular evidence for dispersal rather than vicariance as the origin of flightless insect species on the Chathams Island, New Zealand. Journal of Biogeography. 27: 1189-1200. 
Turvey ST, Green OW, Holdaway RN. 2005. Cortical growth marks reveal extended juvenile development in New Zealand moa. Nature. 435: 940-943.

Uy C, Endler JA. 2004. Modification of the visual background increases the conspicuousness of golden-collared manakin displays. Behavioral Ecology.15: 10031010.

van der Pijl L. 1972. Principles of dispersal in higher plants. New York: Springer.

Varela FJ, Palacios AG, Goldsmith TH. 1993. Colour vision of birds In Vision, brain and behaviour in birds. (eds. Ziegler and Bischof) Cambridge MA, MIT Press.

Vishnevskaya TM, Shura-Bura TM .1990. Spectral sensitivity of photoreceptors and spectral inputs to the neurons of the first optic ganglion in the locust (Locusta migratoria). In Sensory systems and communications in arthropods, (ed. Popov AV) Basel, Birkhäuser Verlag, 106-111 pp

\section{Voigt FA, Bleher B, Fietz J, Ganzhorn JU, Schwab D, Böhning-Gaese K. 2004. A} comparison of morphological and chemical fruit traits between two sites with different frugivore assemblages. Oecologia 141: 94-104.

Vorobyev M, Osorio D. 1998. Receptor noise as a determinant of colour thresholds. Proceedings of the Royal Society B-Biological Sciences. 265: 351-358.

Vorobyev M, Osorio D, Bennet ATD, Marshall NJ, Cuthill IC. 1998b. Tetrachromacy, oil droplets and bird plumage colours. Journal of Comparative Physiology A. 183: 621-633. 
Warrant E, Kelber A, Gislen A, Greiner B, Ribi W, Wcislo WT .2004. Nocturnal vision and landmark orientation in a tropical Halictid Bee. Current Biology 14:1309-1318

Warrant E, Porombka T, Kirchner WH .1996. Neural image enhancement allows honeybees to see at night. Proceedings of the Royal Society B-Biological Sciences. $263: 1521-1526$

Waser NM, Chittka L, Price MV, Williams NM, Ollerton, J. 1996. Generalization in pollination systems, and why it matters. Ecology 77: 1043-1060.

Wasserman GS, Kong KL. 1982. Wavelength-discrimination behaviour in the grasshopper Phlaeoba. Vision Research. 22: 757-765

Watson DH. 2004. Mistletoe: A unique constituent of canopies world wide. In Forest Canopies (eds. M. D. Lowman \& H. B. Rinker). London, UK: Elsevier Academic Press.

Wehner R .1971. The generalization of directional visual stimuli in the honeybee, Apis mellifera. Journal of Insect Physiology 17:1579-1591

Wenny DG, Levey DJ. 1998. Directed seed dispersal by Bellbirds in a tropical cloud forest. Proceedings of the National Academy of Sciences of the United States of America. 95: 6204-6207.

Wheelwright NT, Janson CH. 1985. Colors of fruit displays of bird-dispersed plants in two tropical forests. The American Naturalist. 126: 777-799.

Whitaker AH. 1987. The roles of lizards in New Zealand plant reproductive strategies. New Zealand Journal of Botany. 25: 315-328. 
White PS. 1988. Prickle distribution in Aralia spinosa (Araliaceae). American Journal of Botany.75: 282-285.

Whitney KD, Rudgers JA. 2009. Constraints on plant signals and rewards to multiple mutualists? Plant Signaling and Behaviour. 4: 1-4.

Whitney KD, Lister CE. 2004. Fruit colour polymorphism in Acacia ligulata: seed and seedling performance, clinal patterns, and chemical variation. Evolutionary Ecology. 18: $165-186$

Whitney KD. 2005. Linking frugivores to the dynamics of a fruit colour polymorphism. American Journal of Botany 92: 859-867.

Wiens D. 1978. Mimicry in plants. Evolutionary Biology 11: 365-403.

Willmer PG, Stone GN . 2004. Behavioral, ecological and physiological determinants of the activity patterns of bees In Advances in the study of behaviour (eds. Slater PJB, Roper TJ, Rosenblatt JS, Brockmann HJ, Snowdon CT, Naguib M) 34:347-466

Willson MF, Whelan CJ. 1989. Ultraviolet reflectance of fruits of vertebratedispersed plants. Oikos. 55: 790-809.

Willson MF, Graff DA, Whelan CJ. 1990. Colour preferences of frugivorous birds in relation to the colours of fleshy fruits. The Condor. 92: 545-555.

Willson MF, Irvine AK, Walsh NG. 1989a. Vertebrate dispersal syndromes in some Australia and New Zealand plant communities, with geographic comparisons. Biotropica. 21: 133-147. 
Willson MF, Thompson JN. 1982. Phenology and ecology of colour in bird dispersed fruits, or why some fruits are red when they are 'green'. Canadian Journal of Botany. 60: 701-713

Willson MF, Whelan CJ. 1990. The evolution of fruit colour in fleshy-fruited plants. The American Naturalist. 136: 790-809.

Wilson A .2008. Insect frugivore interactions: the potential for beneficial and neutral effects on host plants. PhD. Dissertation. Queensland School of Technology. 115 pp.

Withgott J. 2000. Taking a Bird's-Eye View...in the UV. Bioscience. 50: 854-859.

Wood JR, Rawlence NJ, Rogers GM, Austin JJ, Worthy TH, Cooper A. 2008.

Coprolite deposits reveal the diet and ecology of the extinct New Zealand megaherbivore moa (Aves, Dinornithiformes). Quaternary Science Reviews. 27: 25932602

Worthy TH, Holdaway RN. 2002. The lost world of the moa: prehistoric life of New Zealand. Christchurch: Canterbury University Press in association with Indiana University Press. 212-229.

Wotton DM. 2002. Effectiveness of the common gecko (Hoplodactylus maculatus) as a seed disperser on Mana Island, New Zealand. New Zealand Journal of Botany. 40: $639-647$.

Zamora, R. 2000. Functional equivalence in plant-animal interactions: ecological and evolutionary consequences. Oikos. 88: 442-447. 
Zufall F, Schmitt M, Menzel R. 1988. Spectral and polarized light sensitivity of photoreceptors in the compound eye of the cricket (Gryllus bimaculatus). Journal of Comparative Physiology A. 164: 597-608 